\title{
Analysis of the role of Cox20 during the early steps of Cox2 biogenesis
}

\author{
Doctoral Thesis \\ In partial fulfillment of the requirements for the degree \\ "Doctor rerum naturalium (Dr. rer. nat)" \\ in the Molecular Medicine Study Program \\ at the Georg-August University Göttingen
}

submitted by

Isotta Lorenzi

born in Bologna, Italy

Göttingen, January 2016 
First member of the thesis committee (supervisor and first referee):

Prof. Dr. Peter Rehling

Institute of Cellular Biochemistry

Georg-August University, Göttingen, Germany

Second member of the thesis committee (second referee):

Prof. Dr. Ralph Kehlenbach

Institute of Molecular Biology

Georg-August University, Göttingen, Germany

Third member of the thesis committee:

Prof. Dr. Mikael Simons

Max Planck Institute for Experimental Medicine

Göttingen, Germany

Date of Disputation: 18 March 2016 


\section{AFFIDAVIT:}

Here I declare that my doctoral thesis entitled "Analysis of the role of Cox20 during the early steps of Cox2 biogenesis" has been written independently with no other sources and aids than quoted.

Isotta Lorenzi

Göttingen, January 2016

Parts of this thesis are published:

Lorenzi, I., Oeljeklaus, S., Ronsör, C., Bareth, B., Warscheid, B., Rehling, P., and Dennerlein, S. (2016). The ribosome-associated Mba1 escorts Cox2 from insertion machinery to maturing assembly intermediates. Molecular and Cellular Biology (in press). 
to my parents 


\section{TABLE OF CONTENTS}

LIST OF FIGURES viii

LIST OF TABLES $\ldots x$

LIST OF ABBREVIATIONS ......................................................................

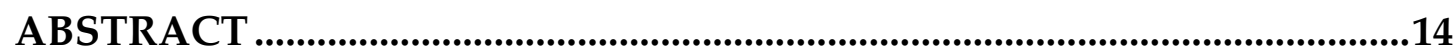

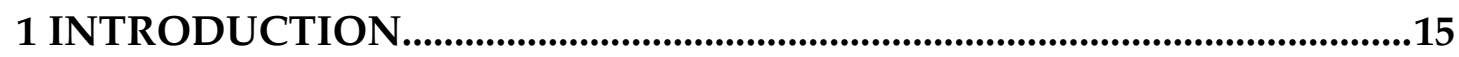

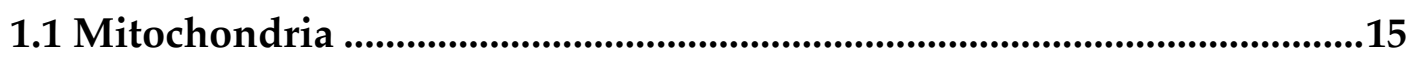

1.2 The oxidative phosphorylation system ..................................................16

1.3 Biogenesis of the respiratory chain .....................................................18

1.3.1 Mitochondrial protein import machineries: TOM and TIM23

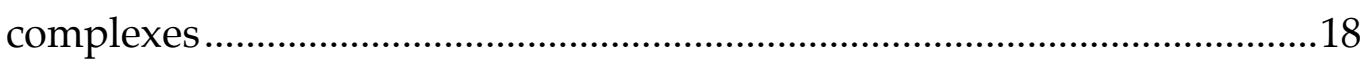

1.3.2 Mitochondrial protein export...........................................................20

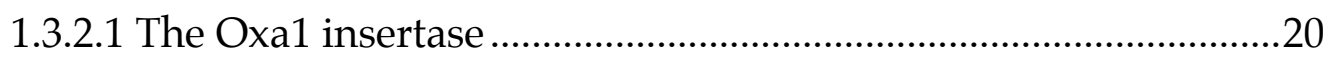

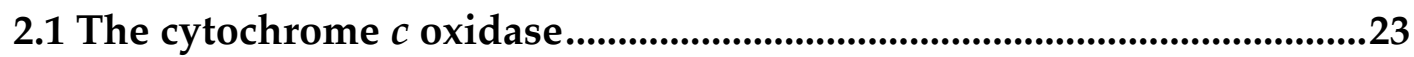

2.1.1 Structural details and functions .........................................................23

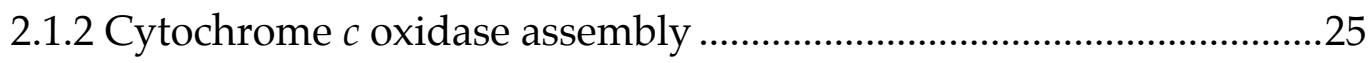

2.2 Biogenesis of Cox2 .............................................................................................28

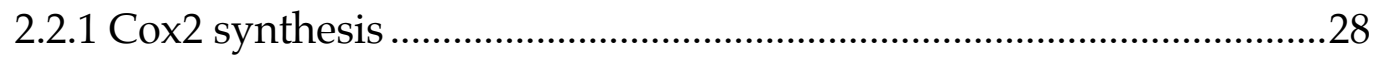

2.2.2 Cox2 N-terminal processing...............................................................29

2.2.3 Cox2 C-terminal translocation ..............................................................

2.2.4 Maturation of the copper prosthetic group of Cox 2 .........................32

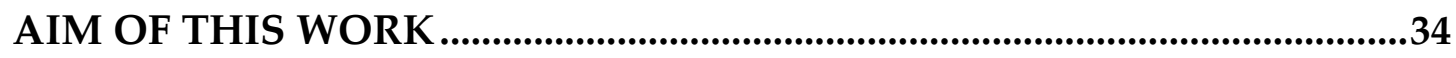

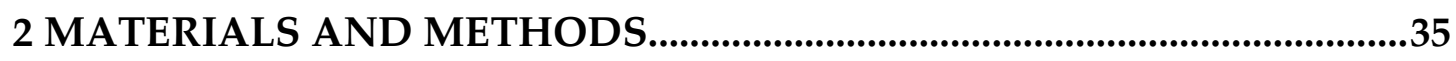

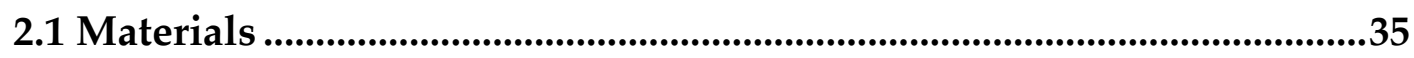

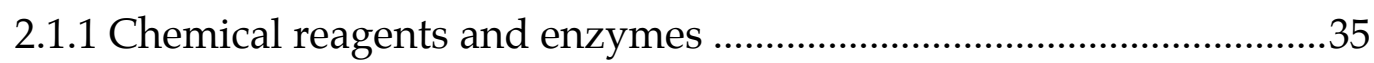

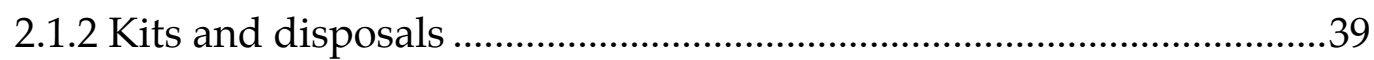

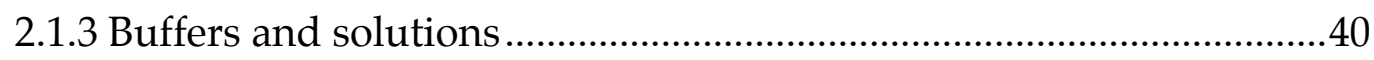

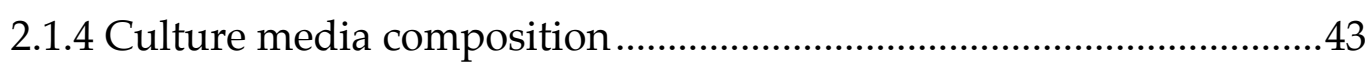

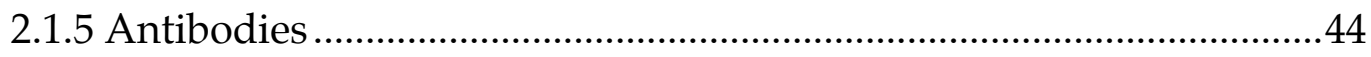

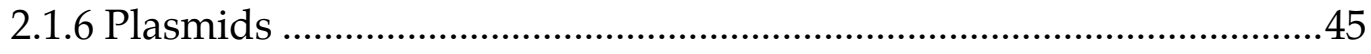

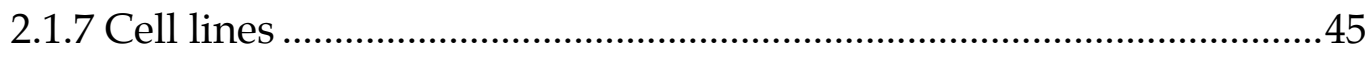




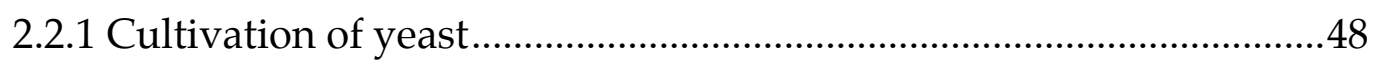

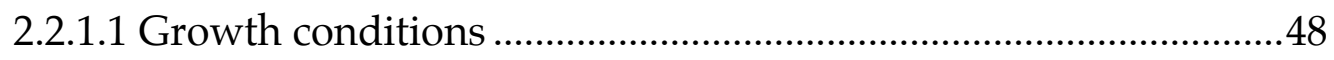

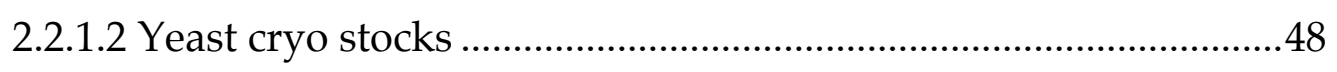

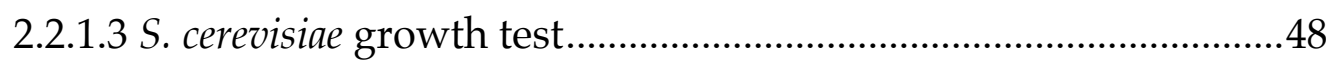

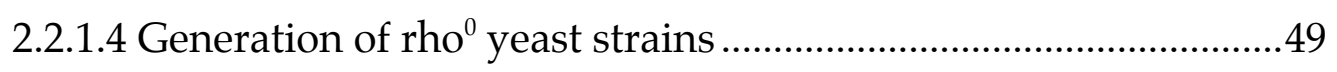

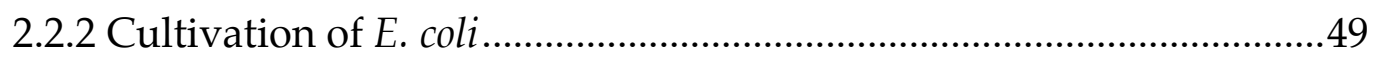

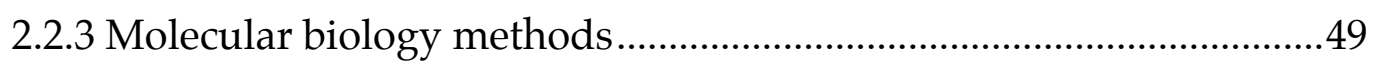

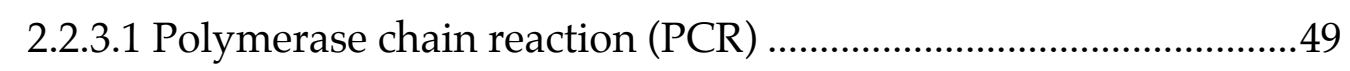

2.2.3.2 DNA isolation from E. coli ..........................................................50

2.2.3.3 Isolation of yeast genomic DNA ...................................................50

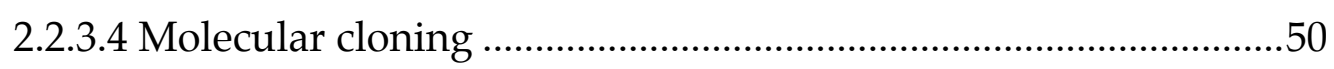

2.2.3.5 DNA electrophoresis and sequencing .........................................50

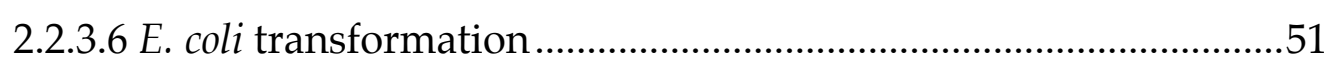

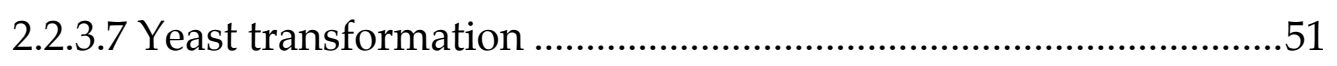

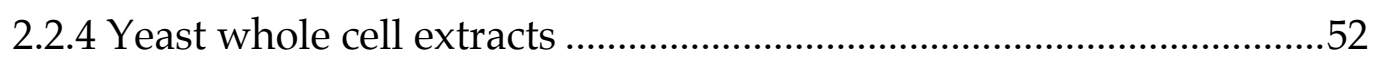

2.2.5 Isolation of yeast mitochondria ….....................................................52

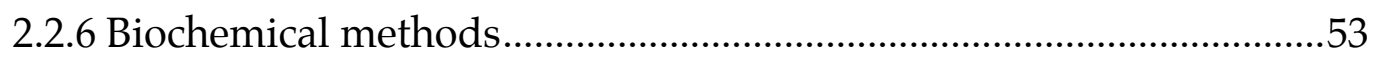

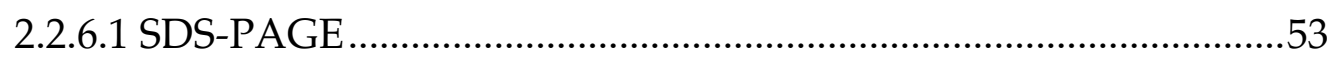

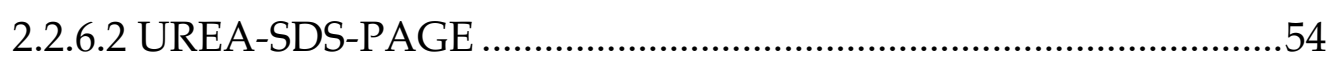

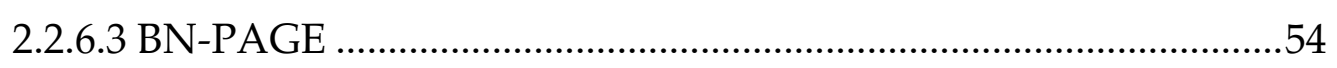

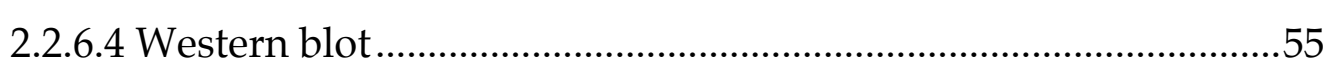

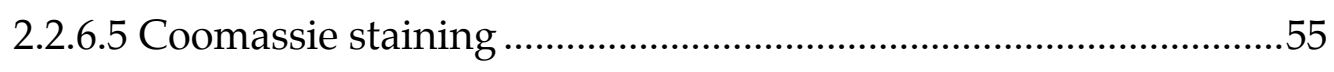

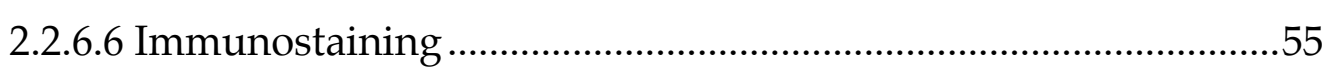

2.2.6.7 Determination of protein concentration ......................................56

2.2.6.8 Steady state analysis of protein levels.........................................56

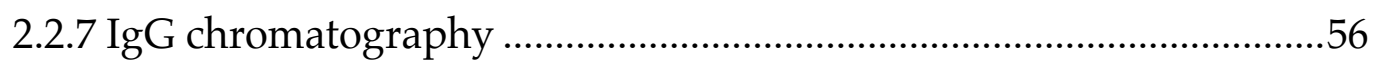

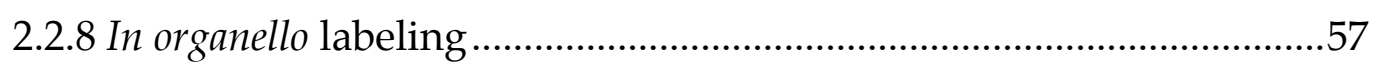

2.2.9 Stable isotope labeling of amino acids in cell culture (SILAC) .........58

2.2.10 Mass spectrometry of SILAC labeled protein complexes .................58

2.2.10.1 Mass spectrometry data analysis ..............................................59

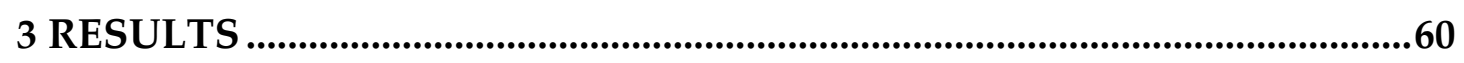

3.1 Functional analysis of Cox20 .................................................................60

3.1.1 Growth and respiratory ability of the Cox $20^{\text {ProtA }}$ strain.....................61

3.1.2 Analysis of mitochondrial translation products.................................62 
3.1.3 Protein steady state analysis of the Cox $20^{\text {ProtA }}$ and cox $20 \Delta$ strains....63

3.2 Biochemical analysis of Cox20-containing complexes ...........................66

3.2.1 Endogenous Cox20 forms multiple complexes .................................66

3.2.2 Cox20 interactome analysis by quantitative mass spectrometry ......69

3.2.3 BN-PAGE analysis of isolated SILAC labeled Cox20 complexes .....72

3.3 The role of Mba1 in Cox2 synthesis and assembly ...............................76

3.3.1 Cox20 interacts with mitochondrial ribosomes and Mba1 ................76

3.3.2 Mba1 binds newly synthesized Cox2 in the absence of Cox20 .........78

3.3.3 Mba1 and Cox20 interact during the early stages of Cox2 assembly

3.4 Characterization of the Cox20-Mba1 complex.......................................83

3.4.1 Cox20 and Mba1 association is mitochondrial translation dependent

3.4.2 Formation of the Cox20-Mba1 complex is Cox2 dependent.

3.4.3 Cox20 associates with the ribosome in an Mba1 independent manner

3.4.4 Cox2 assembly defects results in a reduction of the Mba1-ribosome interaction

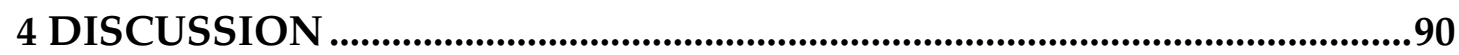

4.1 Identification of novel Cox20 complexes ................................................90

4.2 The involvement of Mba1 in the early steps of Cox2 assembly ..........93

4.3 Interaction between the ribosome and the Cox2 insertion machinery is highly dynamic.............................................................................................95

4.4 Potential role of Cox20 in copper insertion ............................................98

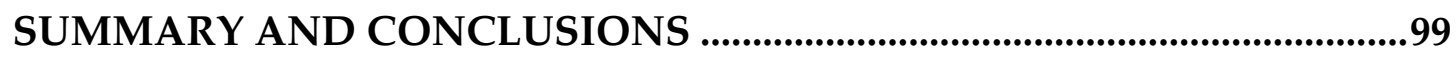

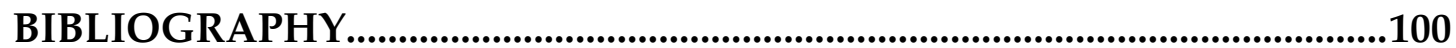

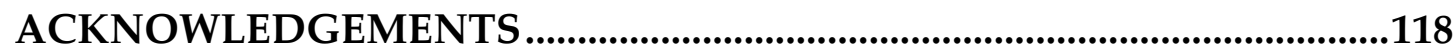




\section{LIST OF FIGURES}

Figure 1.1 Oxidative phosphorylation system. 16

Figure 1.2 Schematic representation of respiratory chain supercomplexes....

Figure 1.3 Biogenesis of the respiratory chain. .19

Figure 1.4 Crystal structure of the monomeric bovine cytochrome $c$ oxidase 23

Figure 1.5 Cytochrome $c$ oxidase maturation in S. cerevisiae......................26

Figure 1.6 Schematic representation of Cox1 translational regulation........27

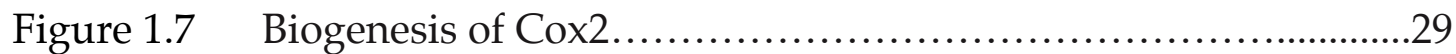

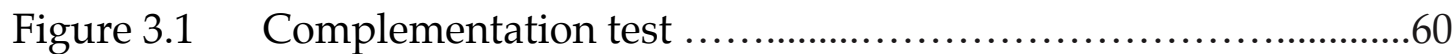

Figure 3.2 Growth analysis of C-terminally tagged Cox20.........................61

Figure 3.3 Labeling of mitochondria-encoded proteins in the Cox $20^{\text {ProtA }}$ strain...... .62

Figure 3.4 Analysis of protein steady state levels .63

Figure 3.5 OXPHOS complex analysis .65

Figure 3.6 Second dimension analysis of Cox20 complexes. . .66

Figure 3.7 Isolation of Cox20 complexes...... .68

Figure 3.8 Quantitative mass spectrometric analysis of Cox $20^{\text {ProtA }}$ purified complexes after SILAC labeling.....

Figure 3.9 Confirmation of putative Cox20 and Cox18 interaction partners

Figure 3.10 SILAC analysis of Cox20 protein complexes separated by BNPAGE.

Figure 3.11 Isolation of protein complexes from the Cox $20^{\text {ProtA }}, \mathrm{Mba}^{\text {ProtA }}$ and

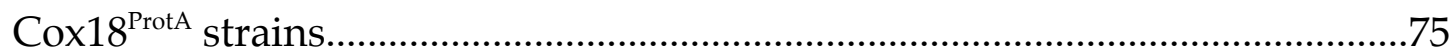

Figure 3.12 The Cox20 $0^{100 \mathrm{kDa}}$ complex contains Mba1.....................................76

Figure 3.13 Cox20 association with the mitochondrial ribosome...................77

Figure 3.14 Mba1 is needed for the association of Cox20 with pre-Cox2.....78

Figure 3.15 The Cox18-pre-Cox2 interaction requires Mba1..........................79

Figure 3.16 Mba1 associates with Cox2 in the absence of Cox20...................80

Figure 3.17 Comparison of $\mathrm{Mba}^{\text {ProtA }}$ and $\mathrm{Cox} 18^{\text {ProtA }}$ isolation for ribosome association. 
Figure 3.18 Interaction of Cox20 with Mba1 is mitochondrial DNAdependent.

Figure 3.19 Affinity purification from the indicated strains treated with Chloramphenicol. 84

Figure 3.20 Cox2 is required for Cox20-Mba1 interaction................................85

Figure 3.21 Protein complex purification via IgG chromatography...............86

Figure 3.22 Isolation of Mba1 ${ }^{\text {ProtA }}$ in wild-type and mutants background via IgG chromatography . .88

Figure 3.23 Cox20 ${ }^{\text {ProtA }}$ isolations in mutants of the Cox2 assembly line.........89

Figure 4.1 Mba1 forms a complex with Cox20 and associates with Cox2 assembly intermediates. . .97 


\section{LIST OF TABLES}

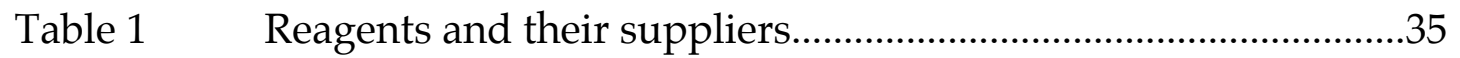

Table $2 \quad$ Kits and disposals used in this study.............................................39

Table 3 Composition of buffers and solutions..........................................40

Table 4 Composition of culture media used in this study........................43

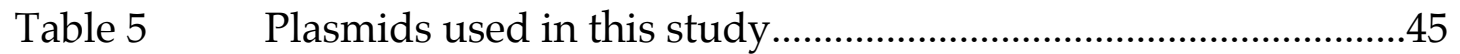

Table $6 \quad$ Yeast strains used in this study...................................................46 


\section{LIST OF ABBREVIATIONS}

\begin{tabular}{|c|c|}
\hline $\mathrm{ADP}$ & Adenosine diphosphate \\
\hline APS & Ammonium persulfate \\
\hline ATP & Adenosine triphosphate \\
\hline $\mathrm{BN}$ & Blue Native \\
\hline BSA & Bovine serum albumin \\
\hline${ }^{\circ} \mathrm{C}$ & Degree Celsius \\
\hline $\mathrm{COA}$ & Cytochrome $c$ oxidase assembly intermediate \\
\hline CoQ & Ubiquinone \\
\hline COX & Cytochrome $c$ oxidase \\
\hline CSM & Complete supplement mixture \\
\hline DDM & n-Dodecyl-b-D-maltoside \\
\hline DMSO & Dimethyl sulfoxide \\
\hline DNA & Deoxyribonucleic acid \\
\hline DTT & 1,4-dithiothreitol \\
\hline EDTA & Ethylene diamine tetraacetic acid \\
\hline $\mathrm{FADH}_{2}$ & Flavin adenine dinucleotide \\
\hline $\mathrm{g}$ & Gram \\
\hline GTP & Guanosine triphosphate \\
\hline h & Hour \\
\hline $\mathrm{HCl}$ & Hydrochloric acid \\
\hline HEPES & 4-(2-hydroxyethyl)-1-piperazineethanesulfonic acid \\
\hline HRP & Horseradish peroxidase \\
\hline $\operatorname{IgG}$ & Immunoglobulin G \\
\hline $\mathrm{IM}$ & Inner mitochondrial membrane \\
\hline IMS & Intermembrane space \\
\hline $\mathrm{kDa}$ & Kilodalton \\
\hline 1 & Liter \\
\hline LB & Lysogeny broth \\
\hline $\mathrm{LiAc}$ & Lithium acetate \\
\hline LC & Liquid Chromatography \\
\hline M & Mol per liter \\
\hline $\mathrm{mA}$ & Milliampere \\
\hline $\mathrm{mg}$ & Milligram \\
\hline
\end{tabular}




\begin{tabular}{|c|c|}
\hline $\min$ & Minute \\
\hline $\mathrm{ml}$ & Milliliter \\
\hline $\mathrm{mM}$ & Millimol per liter \\
\hline MOPS & Morpholinopropanesulfonic acid \\
\hline $\mathrm{MPP}$ & Matrix processing peptidase \\
\hline MS & Mass spectrometry \\
\hline mRNA & Messenger ribonucleic acid \\
\hline $\mathrm{NADH}$ & Nicotinamide adenine dinucleotide \\
\hline $\mathrm{nm}$ & Nanometer \\
\hline OD & Optical density \\
\hline $\mathrm{OM}$ & Outer mitochondrial membrane \\
\hline ORF & Open reading frame \\
\hline OXPHOS & Oxidative phosphorylation system \\
\hline PAGE & Polyacrylamide gel electrophoresis \\
\hline PAM & Presequence translocase associated motor \\
\hline PAP & Peroxidase anti-peroxidase antibody \\
\hline PBS & Phosphate buffered saline \\
\hline PCR & Polymerase chain reaction \\
\hline PEG & Polyethylene glycol \\
\hline PK & Proteinase K \\
\hline PMSF & Phenylmethanesulfonylfluoride \\
\hline ProtA & Protein A \\
\hline PVDF & Polyvinylidene fluoride \\
\hline RNA & Ribonucleic acid \\
\hline $\mathrm{rpm}$ & Revolutions per minute \\
\hline SDS & Sodium dodecyl sulfate \\
\hline sec & Second \\
\hline SILAC & Stable isotope labeling of amino acids in cell culture \\
\hline TBS & Tris buffered saline \\
\hline TBST & Tris buffered saline with Tween-20 \\
\hline TCA & Trichloroacetic acid \\
\hline TEMED & Tetramethylethylenediamine \\
\hline $\mathrm{TEV}$ & Tobacco etch virus \\
\hline TIM23 & Presequence translocase of the inner membrane \\
\hline $\mathrm{TM}$ & Transmembrane span \\
\hline
\end{tabular}




$\begin{array}{ll}\text { TOM } & \text { Translocase of the outer membrane } \\ \text { TX-100 } & \text { Triton X-100 } \\ \text { UTR } & \text { Untranslated region } \\ \text { V } & \text { Volt } \\ \text { WT } & \text { Wild-type } \\ \text { YNB } & \text { Yeast nitrogen base without amino acids } \\ \text { YPAD } & \text { YPD with adenine } \\ \text { YPD } & \text { Yeast extract, peptone, glucose } \\ \text { YPG } & \text { Yeast extract, peptone, glycerol } \\ \text { YPGal } & \text { Yeast extract, peptone, galactose } \\ \Delta \psi & \text { Membrane potential across the inner membrane } \\ \mu l & \text { Microliter } \\ \mu g & \text { Microgram } \\ \% & \text { Percent }\end{array}$




\begin{abstract}
The catalytic core of the cytochrome $c$ oxidase (complex IV), the terminal enzyme of the mitochondrial respiratory chain, comprises three mitochondria-encoded subunits Cox1, Cox2 and Cox3 that are highly conserved among species. Cytochrome $c$ oxidase maturation is a coordinated process requiring specialized assembly factors that assist in the sequential formation of sub-complexes, also termed assembly intermediates.

In recent decades, fruitful research of complex IV biogenesis, in the yeast $S$. cerevisiae, has revealed that Cox2 is inserted into the inner mitochondrial membrane via a co-translational mechanism. This is facilitated by the mitochondrial ribosome binding protein Mba1 and the Oxa1 insertase. Following insertion, various assembly factors, such as Cox20, are required for the maturation of Cox2. However, the mechanism by which insertion and assembly are coordinated is not well understood.

The Cox20 protein is a ubiquitous Cox2-chaperone, involved in Cox2 Nterminal processing. In human, Cox2 is expressed without N-terminal peptide, suggesting an additional role of Cox20 beyond its processing function. In fact, a patient mutation in the Cox20 human homolog leads to impaired cytochrome $c$ oxidase assembly.

Results presented in this thesis elucidate the molecular role of Cox20 in the early steps of Cox 2 biogenesis. For this purpose, a mass spectrometry analysis using a SILAC approach was undertaken to identify novel Cox20 interacting partners. Analysis of the composition of Cox20-containing complexes revealed proteins involved in Cox2 translation, membrane insertion and metallation.

For the first time, the identified interaction with the mitochondrial ribosome provides a new link of Cox20 function to Cox2 synthesis. Furthermore, functional analysis of the novel Cox20-Mba1 complex suggested a novel role of Mba1 with regard to Cox 2 maturation. The presented data propose a new shuttling mechanism of newly translated Cox2 from the ribosome and the insertion machinery to maturing mitochondrial assembly intermediates.
\end{abstract}




\section{INTRODUCTION}

\subsection{Mitochondria}

The structure and the functions of the cell strictly depend on cellular membranes, which not only separate the inside environment of the cell, but also define the interior sub-compartments of eukaryotic cells, including the nucleus and cytoplasmic organelles. Specialized environments provide an evolutionary advantage by compartmentalizing different cellular activities, which can take place depending on cellular demand in an optimized manner (Clapham, 2007). Within the cell, mitochondria are dynamic organelles and exist as a network that undergoes constant fission and fusion to satisfy cellular demand (Liesa et al., 2009). The mitochondrial ultrastructure is reminiscent of the endosymbiotic event between a $\alpha$-proteo-bacterium with a so far unidentified host. As a consequence, the inner and outer mitochondrial membranes correspond to the plasma membranes of the endosymbiont and the host, respectively. Mitochondrial membranes segregate two further compartments, the inner membrane space (IMS) and the matrix (Lithgow and Schneider, 2010).

Mitochondria are well known for their central role in ATP generation through the oxidative phosphorylation system (Castresana et al., 1994), but they additionally fulfill important metabolic functions within the eukaryotic cell. They are involved in the generation of iron-sulfur clusters (Lill et al., 2012), ion homeostasis, e.g. calcium signaling, lipid metabolism (Voss et al., 2012) and in catabolic pathways, like amino acid metabolism, the urea cycle and $\beta$ oxidation of fatty acids. Moreover, these organelles have essential roles also in apoptosis (Oberst et al., 2008; Campello and Scorrano, 2010). Since mitochondria are involved in a variety of processes, mitochondrial dysfunction has been implicated in several human disorders (DiMauro and Schon, 2008). 


\subsection{The oxidative phosphorylation system}

In higher eukaryotes, one of the crucial functions of mitochondria is the production of energy through the oxidative phosphorylation system (OXPHOS).

The citric acid cycle takes place in the mitochondrial matrix and generates reducing equivalents, $\mathrm{NADH}$ and $\mathrm{FADH}_{2}$, which transfer electrons to the respiratory chain in the inner mitochondrial membrane. These electrons are required for the reduction of molecular oxygen to water by cytochrome $c$ oxidase (complex IV). The energy generated by the transfer of electrons is used to translocate protons across the membrane from the matrix to the IMS (membrane potential, $\Delta \Psi$ ). The final complex of the oxidative phosphorylation system, the $\mathrm{F}_{1} \mathrm{~F}_{\mathrm{o}}$-ATPsynthase, employs this electro-chemical gradient (proton-motive force) to synthesize ATP (Mitchell and Moyle, 1968).

The mitochondrial respiratory chain comprises of four electron-transporting multi-subunit complexes: the NADH-ubiquinone oxidoreductase (complex I), succinate dehydrogenase (complex II), the ubiquinol-cytochrome $c$ reductase or cytochrome $b c_{1}$ (complex III) and the cytochrome $c$ oxidase (complex IV). These four complexes, together with the $\mathrm{F}_{1} \mathrm{~F}_{\mathrm{o}}$-ATPsynthase (complex V), constitute the oxidative phosphorylation system (FIG 1.1) (Castresana et al., 1994).

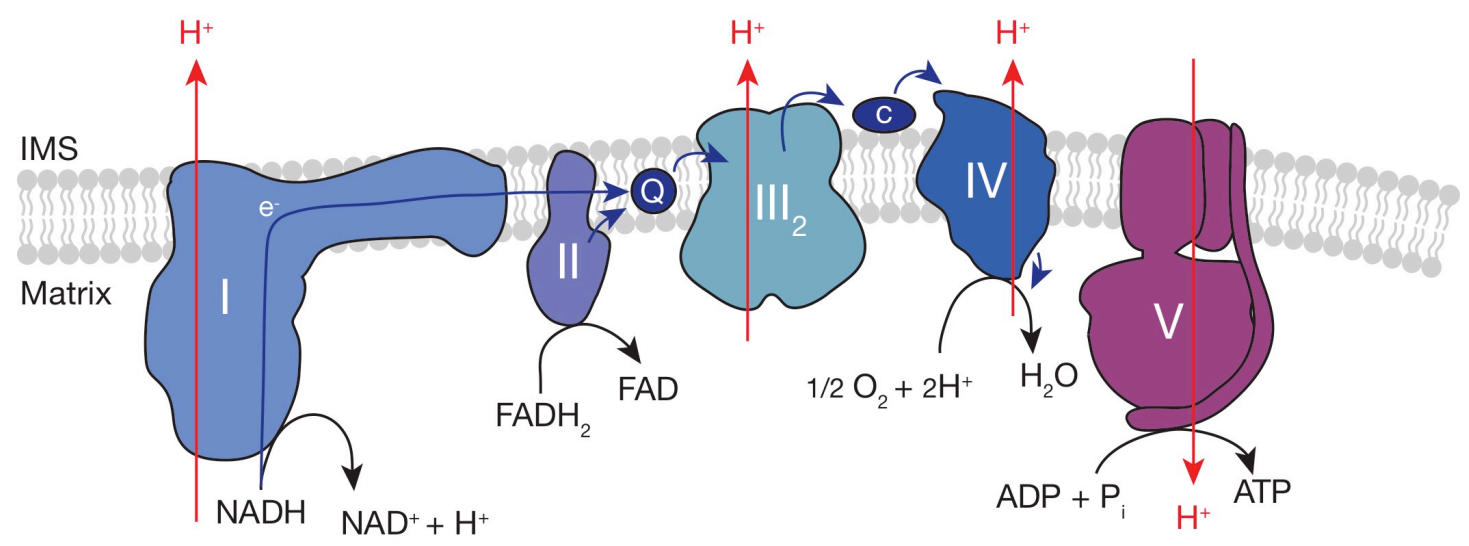

FIG 1.1 Oxidative phosphorylation system.

The respiratory chain complexes (I-IV) are shown together with the $F_{1} F_{0}$ ATPsynthase $(\mathrm{V})$. Electrons $\left(\mathrm{e}^{-}\right)$and their carrier ubiquinone $(\mathrm{Q})$ and cytochrome $c$ (C) are displayed. Red arrows indicate the proton flux across the membrane and the chemical reactions taking place at the respective complexes are displayed in black. IMS indicates inner mitochondrial membrane space. 
Electron transfer between the complexes is mediated via electron carriers. Ubiquinone (also known as CoQ) is located in the inner membrane and shuttles electrons from complex I and II to complex III, whereas Cytochrome $c$, located in the IMS, transfers electrons from complex III to IV. This electron transfer engages various non-protein co-factors, iron-sulfur clusters and copper-centers.

Interestingly, the respiratory complexes form oligomers, also named supercomplexes or respirasomes (Schägger and Pfeiffer, 2000). It has been suggested that the reason for this oligomerization is to optimize electron transfer between the complexes (Zick et al., 2009). In mammals, the complex III dimer $\left(\mathrm{III}_{2}\right)$ can associate with complex I and IV into I/ $\mathrm{III}_{2}$ or $\mathrm{I} / \mathrm{III}_{2} / \mathrm{IV}_{\mathrm{n}}$ (FIG 1.2 A). The yeast Saccharomyces cerevisiae, in which assembly of the supercomplexes have been extensively studied, does not contain complex I and instead consists of three NADH dehydrogenases; Ndi1 which faces the matrix side and Nde1 and Nde2, both of which face the IMS. Therefore, complex $\mathrm{III}_{2}$ can associate with one or two copies of complex IV, $\mathrm{III}_{2} / \mathrm{IV}$ or $\mathrm{III}_{2} / \mathrm{IV}_{2}$ (FIG $1.2 \mathrm{~B}$ ). In addition to supercomplexes of the respiratory chain, complex $\mathrm{V}$ can dimerize $\left(\mathrm{V}_{2}\right)$ into a structure with a fixed angle and this is involved in the definition of mitochondrial ultrastructure (Zick et al., 2009).

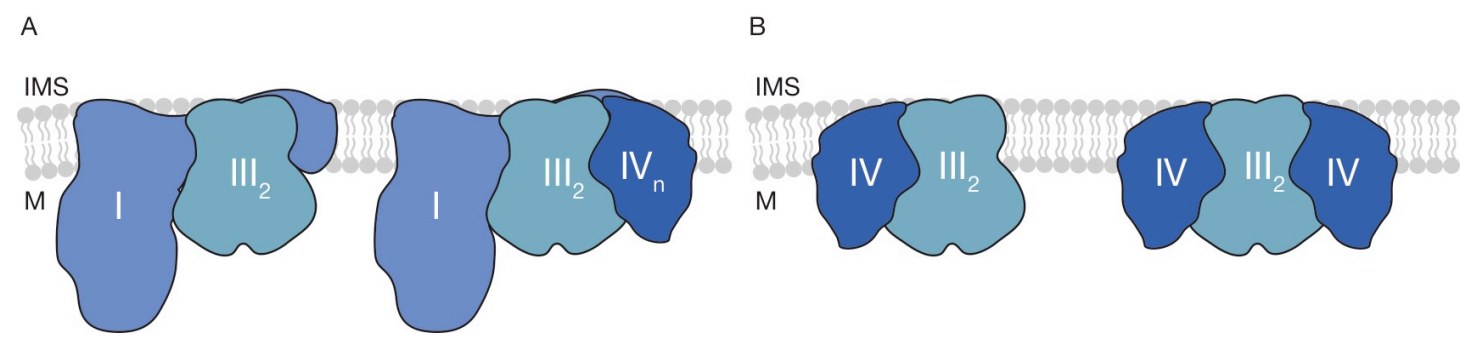

FIG 1.2 Schematic representation of respiratory chain supercomplexes.

Models of respiratory chain respirasomes in mammals (A) and yeast Saccharomyces cerevisiae (B). IMS indicates inner mitochondrial membrane space and $M$ indicates matrix. 


\subsection{Biogenesis of the respiratory chain}

Mitochondria originated from the endosymbiontic event of an $\alpha$-proteobacterial ancestor with an undefined host. Consequently, during evolution most of the mitochondrial genetic information was transferred to the nuclear genome (Daley et al., 2002). Although core subunits of the OXPHOS machinery are still encoded by the mitochondrial genome, $99 \%$ of mitochondrial proteins are nuclear-encoded and have to be imported from the cytosol across the organelle membranes. This engages specialized protein translocases (FIG 1.3).

Since this work is directed towards the biogenesis of the Cox2 subunit of the cytochrome $c$ oxidase, the following sections will focus on the translocation machineries that are involved in the biogenesis of the oxidative phosphorylation system.

\subsubsection{Mitochondrial protein import machineries: TOM and TIM23 complexes}

Most of the mitochondrial nuclear-encoded proteins are transported across the outer membrane by the TOM complex (Endo and Yamano, 2010).

Subsequent, protein targeting to mitochondrial compartments is achieved due to a variety of sorting signals encoded in the precursor proteins (preproteins) sequence. One of such signals, termed presequence, is an N-terminal cleavable, positively charged, amphipathic $\alpha$-helix (Heijne et al., 1986).

Presequence-containing proteins are inserted into the inner membrane or targeted into the matrix by the TIM23 complex (Becker et al., 2012; Dudek et al., 2013). In addition to the presequence some proteins have a downstream hydrophobic sorting signal, which leads to import arrest and lateral release of the import substrates (lateral sorting) into the inner mitochondrial membrane (Van der Laan et al., 2006; Bohnert et al., 2010).

Translocation of preproteins into the matrix requires the membrane potential and is an ATP-dependent process driven by the presequence translocaseassociated import motor, PAM (Van der Laan., 2010). 
After the import, the N-terminal presequence is processed via the MPP (mitochondrial processing peptidase) in the matrix and the mature protein is then released (Luciano and Geli, 1996; Vögtle et al., 2009).

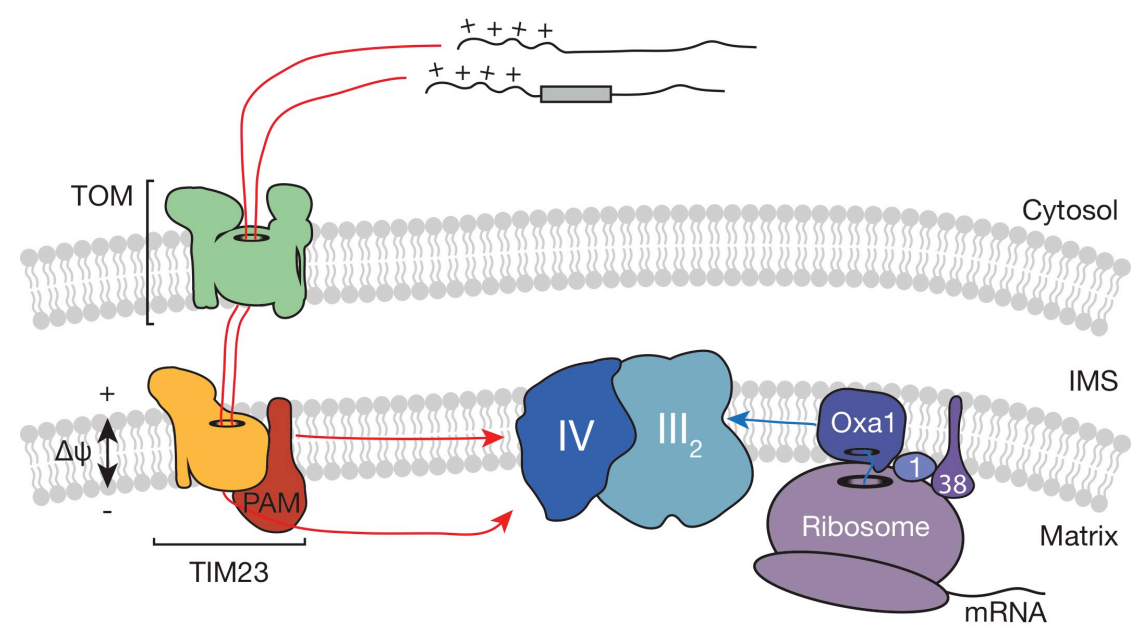

FIG 1.3 Biogenesis of the respiratory chain.

Nuclear-encoded precursor proteins are imported from the cytosol (red arrow) through the TOM complex (TOM, green). Translocation into or across the inner mitochondrial membrane is mediated by the TIM23 complex (TIM23, yellow) and the presequence translocase associated import motor (PAM). Mitochondria-encoded proteins are co-translationally inserted into the inner mitochondrial membrane (blue arrow) by Oxa1 and associated proteins, Mba1 (1) and Mdm38 (38). The exemplification of the respiratory chain is shown as $\mathrm{IV} / \mathrm{III}_{2}$ supercomplexes. See text for further details. IMS indicates inner membrane space; $\Delta \Psi$ indicates the membrane potential. 


\subsubsection{Mitochondrial protein export}

A limited numbers of proteins are encoded by the mitochondrial DNA. These are mainly part of the respiratory chain complexes together with the $F_{1} F_{o}-$ ATPsynthase. In the yeast $S$. cerevisiae, eight proteins are synthesized in the mitochondrial matrix: subunits of complex IV (Cox1, Cox2 and Cox3), cytochrome $b(\mathrm{Cob})$, subunits of complex V (Atp6, Atp8 and Atp9) and the ribosomal protein Var1. All these proteins, except for Var1, are transmembrane proteins and need to be co-translationally inserted into the membrane (Jia et al., 2003). Indeed, the mitochondrial ribosomes are attached to the matrix side of the inner mitochondrial membrane. Cryo-electron tomography studies of the yeast mitochondrial ribosomes have shown that their membrane association is mediated by the inner membrane mitochondrial ribosome receptor Mba1 (MRPL45 in human), which binds to the large subunit of the ribosome, next to the ribosome exit tunnel. In addition, the ribosome is tethered to the membrane by the mitochondrial rRNA, 96-ES1 (Pfeffer et al., 2015). In general, the yeast mitochondrial ribosome displays a higher protein to nucleic acid ratio compared to the bacterial ribosome (Graack and Wittmann-Liebold, 1998). In addition, compared with the bacterial counterpart, structural studies on the yeast mitochondrial large subunit revealed a new exit tunnel location and the unique proteins, Mrp144 and Mrpl50, which are implicated in forming the membrane-facing specific protuberance (Amunts et al., 2014). Collectively these results suggest that the ribosome exit tunnel, like the whole ribosome, has been modified to support organelle-specific mechanisms, possibly to allow the co-translational assembly of oxidative phosphorylation complexes.

\subsubsection{The Oxa1 insertase}

The insertion of proteins from the mitochondrial matrix into the inner membrane is mediated by the highly conserved translocase Oxa1 (Oxidase assembly mutant 1). Bacteria and chloroplasts contain proteins, termed YidC and Alb3 respectively, which are considered members of the "YidC/Alb3/Oxa1" family. Only the structure of YidC has been solved and 
the members of this family have five transmembrane domains and share a conserved topology (Bonnefoy et al., 2009; Ravaud et al., 2008). Recent electrophysiology studies have provided the first experimental evidence that Oxa1 forms a hydrophilic pore that is regulated in a membrane potential dependent manner (Krüger et al., 2012). Oxa1 couples membrane insertion and mitochondrial translation, but the precise mechanism remains unclear (FIG 1.3). It is known that Oxa1 interacts directly with the mitochondrial ribosomes via a long positively charged C-terminal domain exposed to the matrix (Jia et al., 2003). Chemical crosslinking data has revealed Oxa1 to be in proximity to the large ribosomal proteins, Mrpl20 and Mrpl40, located next to the ribosome exit tunnel (Jia et al., 2009). In addition to the export of mitochondria-encoded proteins into the inner membrane, Oxa1 also inserts nuclear-encoded mitochondrial proteins, including Mdl1 and Oxa1 itself (Hell et al., 1998). Presumably, membrane proteins that do not sort laterally by the TIM23 complex are subjected to this mechanism (Bohnert et al., 2010; Herrmann et al., 1997). These and other studies highlight the important function of Oxa1-ribosome complexes for biogenesis of the respiratory chain (Kaur and Stuart, 2011).

To ensure an optimal insertion process, two additional proteins, Mba1 and Mdm38, are likely to co-operate with Oxa1. Mba1 (Muti-copy Bypass of AFG3 mutant 1 ) is peripherally associated to the inner mitochondrial membrane, facing the matrix. It was originally identified in a high-copy suppressor screen of a null mutant of $A F G 3$, required for mitochondrial quality control (Rep and Grivell, 1996). Structural studies indicate that Mba1 is located next to the ribosome exit tunnel (see section 1.3.2), implying its involvement in the alignment of the insertion machinery with the ribosome exit tunnel. Furthermore, crosslinking experiments localize Mba1 next to the ribosomal proteins Mrp14 and Mrpl22, suggesting the simultaneous binding of Oxa1 and Mba1 to the mitochondrial ribosome (Gruschke et al., 2010). Deletion of Mba1 leads to a weak respiration phenotype, but concomitant deletion of Mba1 and the Oxa1 C-terminal domain causes synthetic growth and membrane insertion defects. This suggests that these two proteins may have overlapping functions and that Mba1 can operate independently of Oxa1 (Keil et al., 2012; Ott et al., 2006). 
Nevertheless, Mba1 and Oxa1 do not co-fractionate upon gel filtration indicating that Mba1 does not belong to the Oxa1-containing complex (Preuss et al., 2001). Despite these findings, a clear molecular function of this protein is still missing.

The second protein, Mdm38 (mitochondrial distribution and morphology mutant 38) is the homolog of the human LETM1 protein (Piao et al., 2009). The absence of Mdm38 led to the discovery of a function in the biogenesis of the respiratory chain resulting from a selective defect in translocation of Cob (cytochrome $b$ of complex III) and Atp6 (Frazier et al., 2006).

Mdm38, just like Mba1, binds to the mitochondrial ribosome. Moreover, double deletions of both proteins reveals a specific role in the regulation of mitochondrial translation of COX1 and CYTB mRNA (Bauerschmitt et al., 2010). 


\subsection{The cytochrome $c$ oxidase}

\subsubsection{Structural details and functions}

The cytochrome $c$ oxidase (complex IV), the last enzyme of the mitochondrial electron transport chain, is a multimeric structure formed by proteins of dual genetic origin. Complex IV consists of 11 subunits in the yeast $S$. cerevisiae and 13 subunits in human. The three core subunits, Cox1, Cox2 and Cox3 are mitochondria-encoded and highly conserved among respiring organisms (Castresana et al., 1994).

Complex IV catalyzes the reduction of molecular oxygen to water, together with the pumping of protons across the inner mitochondrial membrane. This reaction requires co-factors that are deeply hidden inside the structure. The $X-$ ray crystallographic structure of the dimeric bovine cytochrome $c$ oxidase (Tsukihara et al., 1995; 1996) reveals co-factors inserted into the Cox1 and Cox2 proteins (FIG 1.4).
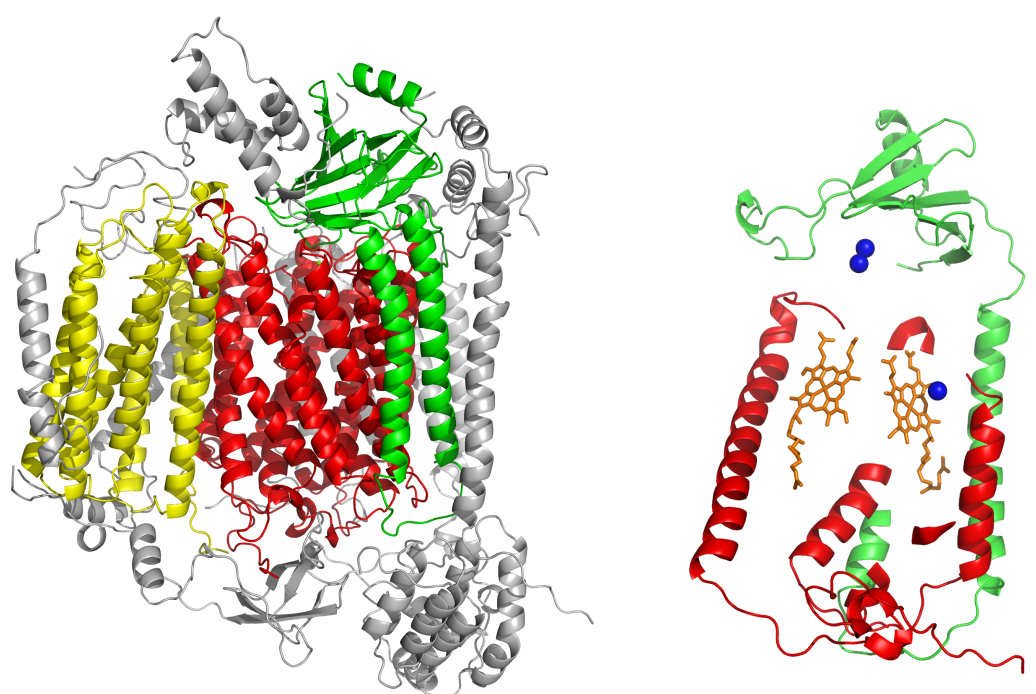

FIG 1.4 Crystal structure of the monomeric bovine cytochrome $c$ oxidase.

Cartoon representation of the mitochondria-encoded subunits Cox1 (red), Cox2 (green) and Cox3 (yellow) in complex with the nuclear-encoded subunits displayed in gray (Tsukihara et al., 1996). Side view, the matrix side is at the bottom and the inner membrane space is at the top. On the right hand side is shown a side view of the cofactors, the copper ions are shown in blue, while the heme centers are in orange. The PDB entry 1OCC was analyzed with the PyMOL software. 
Cox 1 is the central subunit of the enzyme and contains 12 transmembrane helical spans and two redox centers; heme $a$, as well as the binuclear center formed by $\mathrm{Cu}_{\mathrm{B}}$ and heme $a_{3}$, which are essential for the catalytic activity of the complex.

Additionally, Cox1 is also involved in proton pumping and in fact contains two proton translocation channels, the D- and K-channels respectively (Gennis et al., 1998).

Among the mitochondria-encoded subunits, Cox2 is the least hydrophobic. It spans the membrane twice with the $\mathrm{N}$ and $\mathrm{C}$ termini facing the IMS. The $\mathrm{Cu}_{\mathrm{A}}$ site is positioned within the intermembrane space domain of Cox2, which forms the entry site for electrons in the cytochrome $c$ oxidase. Electrons then pass through this site to heme $a$ and subsequently to the binuclear center in Cox1, where they are required for the reduction of molecular oxygen to water. The third subunit, Cox3, completes the catalytic core. In contrast to Cox1 and Cox2, Cox3 does not contain prosthetic groups and its function remains enigmatic. However, studies performed on the bacterial homolog of Cox3 (subunit III) have suggested that Cox3 could play a role in the stability and assembly of Cox 1 and Cox 2 and assist in the efficiency of proton pumping (Hosler, 2004).

Several nuclear-encoded proteins (Cox4, Cox5a, Cox5b, Cox6, Cox7, Cox8, Cox9, Cox12, Cox13, Rcf1 and Rcf2 in yeast) are associated with the hydrophobic core of cytochrome $c$ oxidase. These subunits are absent in bacteria and are not well conserved among different eukaryotic species. The function of these accessory subunits is not yet clear, but it is believed that they may be predominantly involved in the assembly, stabilization and regulation of the complex (Galati et al., 2009, Soto et al., 2012). For example, Cox5 isoforms are differentially expressed depending on the availability of oxygen and these isoforms have been found to modulate cytochrome $c$ oxidase activity (Allen et al., 1995). 


\subsubsection{Cytochrome $c$ oxidase assembly}

The cytochrome $c$ oxidase assembly process has been the subject of intense studies over the last three decades. Due to the dual genetic origin of its components, complex IV biogenesis is a highly coordinated pathway that is thought to take place through the transient and sequential formation of subcomplexes, also called assembly-intermediates (Mick et al., 2011).

Different approaches, like mutant screens, pulse chase radiolabelling experiments, BN-PAGE analysis in combination with co-isolation experiments, have all led to the idea that assembly is a linear process and initiates with the core subunits. Cox 1 and Cox 2 follow independent assembly pathways but whether these pathways merge before or after co-factor insertion is not clear (Williams et al., 2004).

The assembly of the enzyme complex continues by addition of other nuclear subunits FIG 1.5. This is thought to begin with the association of Cox5 and Cox6 with Cox1, before the other mitochondria-encoded subunits (Cox2 and Cox3) and Cox4 associate to the complex (Horan et al., 2005; Stiburek et al., 2005; Tiranti et al., 2000). Subsequently, the chaperone Pet100 facilitates the incorporation of the Cox7-Cox8-Cox9 complex into the oxidase (Church et al., 2005). The assembly of Cox12, Rcf1 and Cox13 ends the formation of the complex (Massa et al., 2008).

Given the complexity of the process, it is not surprising that the assembly of the mature enzyme involves a large number of non-structural accessory proteins, termed assembly factors. Their functions are required for all the steps of the assembly pathway and some are conserved from yeast to man. Although the roles of many of these factors remains enigmatic, some have been assigned to defined processes like co-factor insertion or the regulation of translation. 


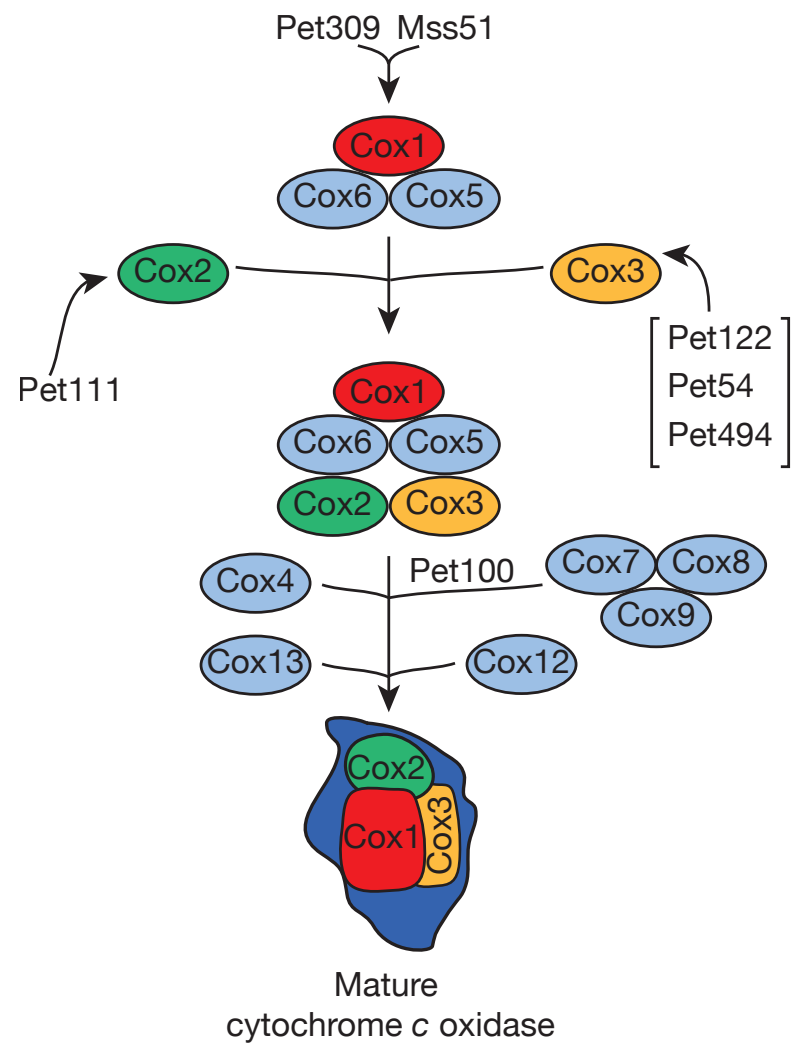

FIG 1.5 Cytochrome $c$ oxidase maturation in S. cerevisiae.

The mitochondria-encoded subunits (Cox 1 in red, Cox2 in green and Cox3 in yellow) assemble with the nuclear-encoded subunits (light blue) in a linear manner. Formation of the mature enzyme requires dedicated translational regulators (Mss51, Pet54, Pet111, Pet122, Pet309 and Pet494) and chaperones (Pet100).

The assembly of mitochondria-encoded proteins is tightly linked to their translation and Cox1 has been one of the most characterized examples (FIG 1.6). Pet309 and Mss51 are required to activate Cox1 synthesis by binding to the 5'-UTR of COX1 mRNA (Perez-Martinez et al., 2003). During Cox1 translation, Mss51 is further able to dynamically interact with newly synthesized Cox1 and the early assembly factors, Coa3 and Cox14 (Barrientos et al., 2004; Fontanesi et al., 2011; Mick et al., 2010; Perez-Martinez et al., 2009). The association of the ancillary factor Coa1 with the Cox1-Mss51-Cox14-Coa3 complex then converts Mss51 into an inactive form, which prevents it from activating translation and at the same time promotes recruitment of the later assembly factor, Shy1 (Mick et al., 2007). The addition of other nuclearencoded structural subunits leads to the release of Mss51, with its sequential reactivation and initiation of further rounds of COX1 translation. 
Similar to Cox1, Cox2 biogenesis also requires dedicated translation regulators and assembly factors that coordinate the early steps of its biogenesis.

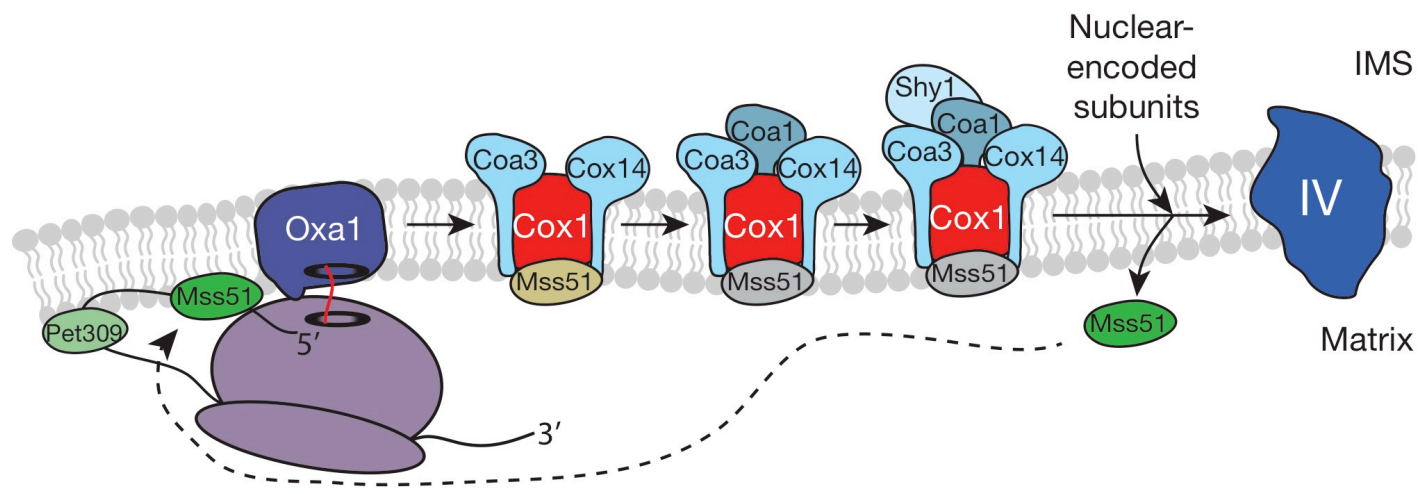

FIG 1.6 Schematic representation of Cox1 translational regulation.

Cox1 co-translational insertion into the inner mitochondrial membrane requires Oxa1 and the specific translational activators Pet309 and Mss51 (green). Newly synthesized Cox1 associates with the early assembly factors Coa3 and Cox14 that trigger the binding of Mss51, which is still able to initiate further rounds of translation (yellow). The recruitment of Coa1 to the complex converts Mss51 in an inactive state, unable to activate translation (grey). After Shy1 has joined the complex, other nuclear subunits associate and Mss51 is released (green), allowing additional round of Cox1 translation. IMS indicates inner membrane space. 


\subsection{Biogenesis of Cox2}

\subsubsection{Cox2 synthesis}

Cox2, like Cox1 and Cox3, it is co-translationally inserted into the IMM resulting in two transmembrane spans, with both the $\mathrm{N}$ and $\mathrm{C}$ termini facing the IMS. The translocation of these membrane spans occurs in two steps. First, the N-terminus and the first transmembrane span are inserted and then, in the second step, the C-terminal tail is translocated (Ott et al., 2010).

In yeast, Cox2 expression is regulated by the action of Pet111, a membrane bound COX2 mRNA-specific translational activator. Experiments using chimeric genes demonstrate that Pet111 acts specifically at the 5'-UTR of COX2 to promote translation of downstream coding sequences (Mulero and Fox, 1993). Moreover, its interaction with the 5'-UTR of COX2 seems to play an important role for localizing Cox2 synthesis to the inner membrane (Sanchirico et al., 1998). On a different level of regulation, it has been shown that the first six codons comprising the Cox2 leader peptide appear to positively regulate translation of COX2 mRNA. In contrast, downstream codons (14-91) show an inhibitory effect on translation in the absence of this positive element (Bonnefoy et al., 2001). It has been hypothesized that interplay among regulatory elements during the translation of COX2 mRNA could play a role in coupling regulated synthesis of the nascent polypeptide with its insertion (Williams et al., 2003).

In fungi and plants, Cox 2 is expressed with a short $\mathrm{N}$-terminal leader peptide (pre-Cox2), which is then processed to form the mature protein. The yeast Cox2 amino terminal extension does not contain any of the usual features of the signal sequence required for protein export in the bacterial and eukaryotic systems. However, protease protection experiments reveal that the pre-Cox2 leader peptide promotes membrane association, but not translocation (He and Fox, 1997a).

Cox2 is synthesized on mitochondrial ribosomes and is co-translationally inserted into the inner mitochondrial membrane via the Oxa1 insertase and Mba1 (FIG 1.7; Ott et al., 2010). Experiments with post-translational imported proteins demonstrate that the export of the $\mathrm{N}$-terminal tail and the first transmembrane domain of Cox2 is mediated via Oxa1 (Hell et al., 1998). Complementation of the yeast Oxa1 null mutation with the human homolog, 
OXA1L, show that although there is no cleavable N-terminus in mammalian Cox2 (see section 2.2.4), OXA1L functionally replaces the yeast protein, indicating that both proteins play a similar role (Bonnefoy et al., 1994).

The export of the Cox 2 is further mediated by the mitochondrial ribosome binding protein Mba1 (Preuss et al., 2001). Mba1 has been implicated in the co-translational membrane insertion of newly synthesized mitochondrial products and especially in the efficient insertion of the N-terminus of Cox2. However, Mba1 is not required for translocation of the C-terminal domain of Cox2 (Preuss et al., 2001).

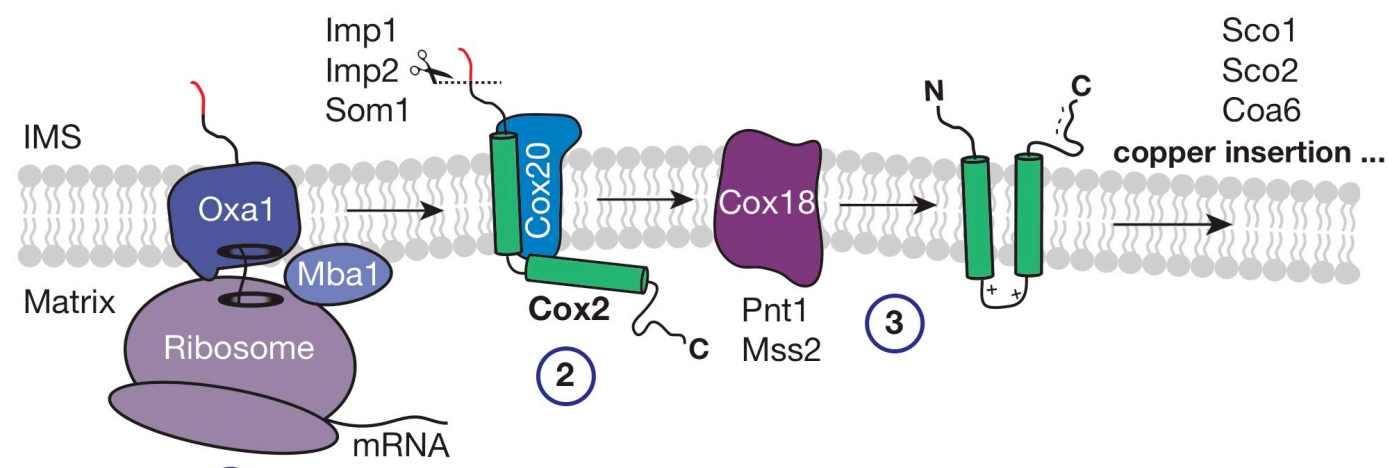

(1)

FIG 1.7 Biogenesis of Cox2.

The scheme represents the multiple steps and proteins involved in co-translational membrane insertion (1), N-tail-processing (2), C-tail translocation (3) maturation of Cox2 (see explanation in the text). IMS indicates the inner membrane space.

\subsubsection{Cox2 N-terminal processing}

Following export into the inner membrane space, the Cox2 N-terminal tail is processed by the IMP protease complex (FIG 1.7; Elliot et al., 2012). The IMP peptidase is formed by three subunits; Imp1, Imp2 and Som1. The first two carry the catalytic activity but recognize distinct substrates even though both belong to the same protease family (Nunnari et al., 1993; Luo et al., 2006). Unprocessed Cox 2 is among the Imp1 substrates, together with cyt $b_{2}$, the NADH-cytochrome (cyt) $b_{5}$ reductase and the FAD-dependent glycerol-3- 
phosphate (G-3-P) dehydrogenase. The cytochrome $c_{1}$ is the only known substrate of Imp2. Som1, the third component of this complex, together with Imp2, is required for Imp1 stability (Jan et al., 2000). On the baseis of sequence similarity, the Imp2 human homolog IMMP2L has been identified. Due to the lack of experimental evidence, it remains uncertain if the function of the yeast Imp2 protein is conserved in mammals (Petek et al., 2001). However, it is unlikely that the role of IMMP2L is involved Cox2 biogenesis, since human COX2 lacks any cleavable presequence.

The processing of Cox2 depends on its specific chaperone, Cox20 (Elliott et al., 2012; Hell et al., 2000). The Cox20 protein is essential for respiration, in fact the deletion mutant is unable to growth on non-fermentable media.

The recently identified human homolog (COX20) shares the same topology with the yeast protein, consisting of two transmembrane domains with the Nand C-terminus facing the IMS and short hydrophilic loop sitting in the matrix (FIG 1.7; Hell et al., 2000). A patient presenting with muscle hypotonia and ataxia was found to have a mutation in the matrix domain of COX20 which led to impaired cytochrome $c$ oxidase assembly (Szklarczyk et al., 2013). The proposed role of the human COX20 in the biogenesis of complex IV is sustained by its association with newly synthesized COX2 (Bourens et al., 2014).

The chaperone-like function of yeast Cox20 has been suggested based on the finding that the majority of Cox 2 accumulates with Cox20 in imp1 and cox 4 mutants, which prevent Cox2 from associating with other subunits of the cytochrome $c$ oxidase. Consistent with this hypothesis, cells lacking Cox20, as well i-AAA protease components (Yme1, Mgr1 and Mgr3), display increased levels of pre-Cox2 and mature Cox2. These findings support the chaperone role of Cox20 in protecting unassembled Cox2 from degradation by the iAAA protease complex during the maturation process downstream of membrane insertion (Elliott et al., 2012; Graef et al., 2007). The observed interaction of Cox20 with unprocessed Cox 2 in the absence of Imp1 suggests that this Cox20-Cox2 association may occur prior to, and/or independent of Cox2 processing.

In addition, studies in the oxa1 mutant indicate that the Cox20-Cox2 interaction occurs after pre-Cox2 is inserted into the inner membrane (Hell et al., 2000). Protease protection experiments show that Cox20 is required for 
processing of the N-terminus of Cox 2 and also for the efficient export of the Cox2 C-tail. In fact, Cox20 interacts with the Cox2 C-terminal translocase Cox18, but only when Cox 2 is present. This possibly indicates the involvement of Cox20 in handing over unassembled Cox2 to Cox18 (Elliott et al., 2012). Consistent with this, cox18 deletion leads to the accumulation of processed Cox2, sustaining the notion that association between Cox20 and Cox2 happens before the action of Cox18. However, the Cox20 function in the C-tail export of Cox2 is independent of its role in the Cox2 N-tail processing (Elliott et al., 2012; Saracco and Fox, 2002).

\subsubsection{Cox2 C-terminal translocation}

The export of the large hydrophilic Cox2 C-tail domain was shown to depend on signals contained in the C-tail itself and on the inner mitochondrial membrane potential (Herrmann et al., 1995). This is in contrast to the insertion of the N-tail which occurs independently of membrane potential (He and Fox, $1997 b)$. Therefore, although both processes require Oxa1 they engage distinct mechanisms.

Downstream of Oxa1, along the Cox2 assembly line, the Cox18 protein has been proposed to have a specific role in translocation of the Cox2 C-tail domain (FIG 1.7; Saracco and Fox, 2002). Indeed, yeast strains lacking Cox18 accumulate Cox 2 in an $\mathrm{N}_{\text {out }}-\mathrm{C}_{\text {in }}$ topology, where "out" indicates mitochondrial inner membrane space and "in" indicates mitochondrial matrix (Saracco and Fox, 2002). In addition, human Cox18 shares sequence similarity with the yeast homolog, suggesting a conserved function among species (Sacconi et al., 2005).

Interestingly, the Cox18 homolog in N. crassa, (termed Oxa2) resembles some Oxa1 family members (Bonnefoy et al., 2009) but lacks the long hydrophilic Cterminal domain, which is responsible for ribosome binding. Both Cox18 and Oxa1 contain five transmembrane domains with a $\mathrm{N}_{\text {out }}-\mathrm{C}_{\text {in }}$ orientation across the inner mitochondrial membrane. However, while Oxa1 mutants display defects in the biogenesis of the respiratory chain, Cox18 mutants exhibit specific cytochrome $c$ oxidase defects (Funes et al., 2004; Souza, 2000). Indeed, OXA1 overexpression is not able to suppress the respiratory deficiency of the 
cox18 $\Delta$ strain, suggesting that both components fulfill different functions. However, Oxa1 does support, to a limited extent, the C-terminal export of Cox2, but not its assembly into cytochrome $c$ oxidase. This finding indicates that Cox18, in addition to being involved in Cox2 C-tail translocation, also appears to promote Cox2 assembly (Fiumera et al., 2009). Nevertheless, a direct interaction between Cox 2 and Cox18 remains to be determined. Cox18 has been shown to physically and genetically interact with Mss2 and Pnt1, indicating that they belong to the same translocon complex (Saracco and Fox, 2002), however, the detailed mechanism of the Cox2 C-tail export is still not clear.

Yeast mutants lacking the Mss2 and Pnt1 proteins also accumulate a fraction of Cox2 in an $\mathrm{N}_{\text {out }}-\mathrm{C}_{\text {in }}$ topology (He and Fox, 1999; Ludewig and Staben, 1994). Pnt1 and Mss2 are peripherally associated to the inner mitochondrial membrane. A C-terminal truncated version of Cox2 failed to associate with Mss2, supporting the idea that Mss2 binds to the C-tail of wild-type Cox2 in the matrix and promotes its export (Broadley et al., 2001).

Interestingly, missense mutations in the copper binding amino acids in the Cterminal domain of Cox 2 do not prevent its export, indicating that formation of the copper site is not essential for C-tail translocation (Fiumera et al., 2007).

\subsubsection{Maturation of the copper prosthetic group of Cox2}

The $\mathrm{Cu}_{\mathrm{A}}$ site in Cox2 is composed of a CxExCGx ${ }_{2} \mathrm{Hx}_{2} \mathrm{M}$ motif and contains two copper ions. It has been suggested that the copper shuttle, Cox17, donates the copper ions to Sco1, which is then responsible for the formation of the $\mathrm{Cu}_{\mathrm{A}}$ center (Horng et al., 2004). Cox17 has two homologs, Cox23 and Cox19 which, like Cox17, have been shown to bind copper and display dual localization both in the cytoplasm and in the mitochondrial IMS (Barros et al., 2004; Nobrega et al., 2002). Overexpression of COX17, together with the addition of exogenous copper can compensate for the absence of Cox23, indicating that this protein might act upstream of Cox17 (Barros et al., 2004). In the copper delivery pathway, factors downstream of Cox17 are members of the Sco family. Both Sco1 and Sco2 present an N-tail inner membrane anchor with a large C-tail domain in the IMS (Glerum et al., 1996). In vitro experiments show 
that Sco1 is able to bind copper donated from Cox17 (Nittis, 2001), although proof of a physical interaction between Sco1 and Cox17 is still missing. In addition to the role of Sco1 in copper insertion, it has been suggested that it could be involved in the reduction of the cysteine in the Cox $2 \mathrm{Cu}_{\mathrm{A}}$ site, facilitating copper incorporation (Williams et al., 2005). SCO2 overexpression partially rescues sco 1 point mutant phenotype indicating that these proteins have overlapping functions (Banci et al., 2011; Glerum et al., 1996). However, the precise function of Sco2 remains unknown.

Similar to yeast, human mitochondria possess two Sco proteins, termed SCO1 and SCO2 (Petruzzella et al., 1998). Both are homologs of the yeast Sco1 protein and are essential for cytochrome $c$ oxidase assembly. Gene mutations result in severe tissue-specific mitochondrial disorders (Leary et al., 2013; Papadopoulou et al., 1999; Valnot et al., 2000). Human SCO1 and SCO2 have been shown to perform cooperative functions in copper delivery. In addition, size exclusion chromatography experiments indicate that these proteins function as homodimers (Leary et al., 2004). Therefore, these findings converge with the proposed model in which COX17 transfers copper to SCO2, which metalizes COX2 in a reaction facilitated by SCO1 (Leary et al., 2009). While both Sco proteins are necessary for copper transfer to COX2, SCO2 is also involved in COX2 biogenesis, since $\mathrm{SCO} 2$ depletion in cultured cells leads to a decreased level of newly synthesized COX2 (Leary et al., 2009). Additional studies show that SCO1 and $\mathrm{SCO} 2$ also play a role in the maintenance of cellular copper homeostasis (Leary et al., 2007).

Recently, new cytochrome $c$ oxidase assembly factors, COA6 and COX20 have been linked to copper metabolism. COA6 has been suggested to promote $\mathrm{SCO} 2$ function, while COX20 acts as a chaperone, presenting newly synthesized COX2 to the copper-chaperones SCO1 and SCO2 (Bourens et al., 2014; Pacheu-Grau et al., 2015). After the insertion of copper, COX2 and COX1 assembly lines merge and the biogenesis of cytochrome $c$ oxidase continues with the addition of other subunits. 


\section{AIM OF THIS WORK}

Like the gears inside a clock, the biogenesis of membrane protein complexes, such as the cytochrome $c$ oxidase, is a highly coordinated process. Single components need to be synthesized both within the cytosol and mitochondria, transported and inserted into the membrane, along with other components, in a proper topology, to form a mature enzyme. Defects that hamper cytochrome $c$ oxidase function result in severe human disorders. The catalytic activity of complex IV resides within the core subunits Cox1 and Cox2. In the yeast, S. cerevisiae, fruitful research has, in recent decades, revealed several components implicated in Cox 2 maturation. However, the mechanism by which insertion and maturation machineries co-operate with each other is not well understood. The Cox20 protein, with a proposed chaperone function, is a ubiquitous assembly factor for Cox2, involved in the early steps of its maturation. Previous findings have revealed an involvement of Cox20 in Cox $2 \mathrm{~N}$-terminal processing, however the function of this protein is not limited to organisms that express Cox2 versions with a cleavable leader peptide. Indeed, a patient mutation in the Cox20 human homolog leads to muscle hypotonia and impaired cytochrome $c$ oxidase assembly. Therefore, the aim of this study is to dissect the molecular role of Cox20 in the insertion and in the early step of Cox2 maturation. Specifically, to exploit the chaperone-like function of Cox20 throughout the early stages of Cox2 maturation to identify additional interacting factors required at these steps. For this purpose, a proteomics approach was undertaken to identify novel Cox20 interacting partners. The discovery of components of the insertion machinery led to additional biochemical analyses for a better understanding of the molecular link between the insertion and assembly process. 


\section{MATERIALS AND METHODS}

\subsection{Materials}

\subsubsection{Chemical reagents and enzymes}

TABLE 1: Reagents and their suppliers.

\begin{tabular}{|c|c|}
\hline Chemical & Supplier \\
\hline$\left[{ }^{35} \mathrm{~S}\right]$-L-methionine & Hartmann Analytic \\
\hline 2-mercaptoethanol ( $\beta$-mercaptoethanol) & Sigma-Aldrich \\
\hline 6-aminocaproic acid & Sigma-Aldrich \\
\hline Acetic acid & Roth \\
\hline Acetone & AppliChem or Merk \\
\hline $\begin{array}{l}\text { Acrylamide/bisacrylamide (37.5:1) solution } \\
\text { (Rotiphorese }{ }^{\circledR} \text { Gel 30) }\end{array}$ & Roth \\
\hline Acrylamide, $4 \mathrm{x}$ crystallized & Roth \\
\hline AcTEV protease & Invitrogen \\
\hline Adenine hemisulfate salt & Sigma-Aldrich \\
\hline ADP (adenosine-5'-diphosphate) & Sigma-Aldrich \\
\hline Agarose NEEO ultra-quality & Roth \\
\hline Ammonium acetate $\left(\mathrm{NH}_{4} \mathrm{Ac}\right)$ & Merck \\
\hline Ammonium persulfate & Roth \\
\hline Ampicillin & AppliChem \\
\hline Antimycin A & Sigma-Aldrich \\
\hline ATP (adenosine-5'-triphosphate) & Roche \\
\hline Bacto $^{\mathrm{TM}}$ Agar & $\mathrm{BD}$ \\
\hline Bacto $^{\mathrm{TM}}$ Peptone & $\mathrm{BD}$ \\
\hline Bacto $^{\mathrm{TM}}$ Tryptone & $\mathrm{BD}$ \\
\hline Bacto Yeast Extract & BD \\
\hline N, N'-Methylene bisacrylamide & Roth \\
\hline Bis-Tris & AppliChem \\
\hline Bovine serum albumin (BSA) fatty acid free & Sigma-Aldrich \\
\hline
\end{tabular}




\begin{tabular}{|c|c|}
\hline Bromophenol Blue & Merck \\
\hline Calcium chloride $\left(\mathrm{CaCl}_{2}\right)$ dehydrate & Roth \\
\hline Chloramphenicol & Roth \\
\hline cOmplete, EDTA-free protease inhibitor tablet & Roche \\
\hline Coomassie Brilliant Blue G-250 & Serva \\
\hline Coomassie Brilliant Blue R-250 & Serva \\
\hline Creatine kinase & Roche \\
\hline Creatine phosphate & Roche \\
\hline $\begin{array}{l}\text { CSM-HIS / CSM-TRP / CSM-URA } \\
\text { (Dropout mixes) }\end{array}$ & MP Biomedicals \\
\hline Cyanogen bromide activated Sepharose $4 \mathrm{~B}$ & GE Healthcare \\
\hline Diaminobenzidine (DAB) & Sigma-Aldrich \\
\hline DDM (n-Dodecyl-b-D-maltoside) & Sigma-Aldrich \\
\hline Digitonin & Calbiochem \\
\hline DMSO (dimethylsulfoxide) & AppliChem \\
\hline DNase I & Roche \\
\hline DTT (1,4-dithiothreitol) & Roth \\
\hline ECL Western Blotting detection reagent & GE-Healthcare \\
\hline EDTA (ethylene diamine tetraacetic acid) & Roth \\
\hline Ethanol & Roth \\
\hline Ethidium bromide $0.07 \%$ & AppliChem \\
\hline Galactose, D (+) & Roth \\
\hline Geneticin 418 Sulfate (G418) & PAA \\
\hline GeneRuler DNA Ladder Mix & Fermentas \\
\hline Glucose, D (+) & Roth \\
\hline Glycerol & Sigma-Aldrich \\
\hline Glycine & Roth \\
\hline $\begin{array}{l}\text { HEPES (4-(2-hydroxyethyl)-1- } \\
\text { piperazineethanesulfonic acid) }\end{array}$ & Roth \\
\hline Herring sperm DNA & Promega \\
\hline KOD Hot Start DNA Polymerase & Novagen \\
\hline HMW calibration Kit & GE-Healthcare \\
\hline
\end{tabular}




\begin{tabular}{|c|c|}
\hline $\begin{array}{l}\text { L-Arginine: } 2 \mathrm{HCl} \\
(\mathrm{U}-13 \mathrm{C} 6,99 \% ; \mathrm{U}-15 \mathrm{~N} 4,99 \%)\end{array}$ & $\begin{array}{l}\text { Cambridge Isotope } \\
\text { Laboratories }\end{array}$ \\
\hline L-Histidine & Serva \\
\hline Hydrochloric acid $(\mathrm{HCl}) 37 \%$ & Roth \\
\hline Hydrogen peroxide solution & Sigma-Aldrich \\
\hline IgG from bovine serum & Bio-Rad \\
\hline IgG from human serum & Sigma-Aldrich \\
\hline Imidazole & Merck \\
\hline IPTG (Isopropyl $\beta$-D-1-thiogalactopyranoside) & Roth \\
\hline L-Leucine & Serva \\
\hline Lithium acetate (LiAc) & AppliChem \\
\hline L-Lysine & Serva \\
\hline $\begin{array}{l}\text { L-Lysine: 2HCl } \\
\text { (U-13C6, 99\%; U-15N2, 99\%) }\end{array}$ & $\begin{array}{l}\text { Cambridge Isotope } \\
\text { Laboratories }\end{array}$ \\
\hline Lysozyme from chicken egg white & Sigma-Aldrich \\
\hline Mannitol, D (+) & Roth \\
\hline Magnesium chloride $\left(\mathrm{MgCl}_{2}\right)$ heptahydrate & Merck \\
\hline Magnesium sulfate $\left(\mathrm{MgSO}_{4}\right)$ heptahydrate & Roth \\
\hline Manganese (II) chloride $\left(\mathrm{MnCl}_{2}\right)$ tetrahydrate & Roth \\
\hline Methanol & Roth \\
\hline L-Methionine & Roth \\
\hline Milk powder & Grano Vita \\
\hline MOPS (morpholinopropanesulfonic acid) & Sigma-Aldrich \\
\hline NADH (nicotinamide adenine dinucleotide) & Roche \\
\hline Ni-NTA agarose & Qiagen \\
\hline Oligomycine & Sigma-Aldrich \\
\hline Oligonucleotides & Metabion \\
\hline OrangeG & Sigma-Aldrich \\
\hline Oxaloacetic acid & Sigma-Aldrich \\
\hline PEG-4000 (polyethylene glycol 4000) & Merck \\
\hline PMSF (phenylmethanesulfonyluoride) & Roth \\
\hline Potassium acetate (KAc) & Merck \\
\hline
\end{tabular}




\begin{tabular}{|c|c|}
\hline Potassium chloride $(\mathrm{KCl})$ & Roth \\
\hline Potassium cyanide $(\mathrm{KCN})$ & Sigma-Aldrich \\
\hline Potassium dihydrogen phosphate $\left(\mathrm{KH}_{2} \mathrm{PO}_{4}\right)$ & Merck \\
\hline di-Potassium hydrogen phosphate $\left(\mathrm{K}_{2} \mathrm{HPO}_{4}\right)$ & Roth \\
\hline Potassium hydroxid (KOH) & Roth \\
\hline Proteinase K & Roche \\
\hline Protein-A Sepharose & GE-Healthcare \\
\hline Roti-Quant $^{\circledR}$ reagent & Roth \\
\hline Rubidium chloride $(\mathrm{RbCl})$ & Roth \\
\hline Saccharose & Roth \\
\hline SDS (sodium dodecyl sulfate) & Serva \\
\hline SDS marker broad range & Biorad \\
\hline Sodium chloride $(\mathrm{NaCl})$ & Roth \\
\hline Sodium hydroxide $(\mathrm{NaOH})$ & Roth \\
\hline Sodium bicarbonate $\left(\mathrm{Na}_{2} \mathrm{CO}_{3}\right)$ & Sigma-Aldrich \\
\hline Sodium hydrogen carbonate $\left(\mathrm{NaHCO}_{3}\right)$ & Merck \\
\hline di-Sodium hydrogen phosphate $\left(\mathrm{Na}_{2} \mathrm{HPO}_{4}\right)$ & AppliChem \\
\hline Sorbitol & Roth \\
\hline Sulfuric acid $\left(\mathrm{H}_{2} \mathrm{SO}_{4}\right)$ & Merck \\
\hline TCA (trichloroacetic acid) & Merck \\
\hline TEMED (tetramethylethylenediamine) & Roth \\
\hline Tricine & Roth \\
\hline Tris (tris(hydroxymethyl)aminomethane) & Roth \\
\hline Triton X-100 & Sigma-Aldrich \\
\hline L-Tryptophan & AppliChem \\
\hline Tween-20 & Roth \\
\hline Uracil & Sigma-Aldrich \\
\hline USB $®$ Taq DNA Polymerase & Affymetrix \\
\hline $\begin{array}{l}\text { Unstained SDS PAGE Protein Marker (6.5 -200 } \\
\mathrm{kDa})\end{array}$ & Serva \\
\hline Urea & Roth \\
\hline
\end{tabular}


Valinomycine

Sigma-Aldrich

Yeast nitrogen base without amino acids (YNB)

$\mathrm{BD}$

Zymolyase 20T

Nacalai Tesque

\subsubsection{Kits and disposals}

TABLE 2: Kits and disposals used in this study.

\begin{tabular}{|c|c|}
\hline Product & Supplier \\
\hline $\begin{array}{l}\text { Amicon® Ultra-4 centrifugal filter unit } \\
\text { 10K MWCO }\end{array}$ & Millipore \\
\hline Blotting paper & Heinemann Labortechnik \\
\hline $\begin{array}{l}\text { CELLSTAR }{ }^{\circledR} \text { Centrifuge Tubes } 15 \text { ml, } 50 \\
\text { ml }\end{array}$ & Greiner Bio-One \\
\hline Fast Digest restriction enzymes & Fermentas \\
\hline GeneRuler DNA Ladder Mix & Fermentas \\
\hline $\begin{array}{l}\text { High Pure PCR Template Preparation } \\
\text { Kit }\end{array}$ & Roche \\
\hline $\begin{array}{l}\text { Immobilon-P Transfer membrane } \\
\text { (PVDF) }\end{array}$ & Millipore \\
\hline MEDIX X-ray films & FOMA BOHEMIA \\
\hline Microtube $1.5 \mathrm{ml}$ and $2.0 \mathrm{ml}$ & Sarstedt \\
\hline Minisart syringe filters & Sartorius AG \\
\hline Pipette tips $10 \mu \mathrm{l}, 200 \mu \mathrm{l}$, and $1 \mathrm{ml}$ & Sarstedt \\
\hline Rapid DNA Ligation Kit & Thermo Scientific \\
\hline Resourse $\mathrm{S}$ column $5 \mathrm{ml}$ & GE Healthcare \\
\hline Spin columns Mobicol "classic" & MoBiTec \\
\hline $\begin{array}{l}\text { Wizard }{ }^{\circledR} \text { Plus SV Gel and PCR DNA } \\
\text { Purification System }\end{array}$ & Promega \\
\hline
\end{tabular}


Wizard® Plus SV Minipreps DNA

Purification System

Promega

\subsubsection{Buffers and solutions}

TABLE 3: Composition of buffers and solutions.

\begin{tabular}{|c|c|}
\hline Buffer/Solution & Composition \\
\hline Acetate buffer & $0.5 \mathrm{M} \mathrm{NH}_{4} \mathrm{Ac} /$ acetic acid pH 3.5 \\
\hline $\begin{array}{l}\text { Amino acids solution } \\
\text { without methionine } \\
\text { (AA-Met) }\end{array}$ & $\begin{array}{l}\text { 1mM alanine, arginine, asparagine, } \\
\text { aspartate, cysteine, glutamate, } \\
\text { glutamine, glycine, histidine, } \\
\text { isoleucine, leucine, lysine, } \\
\text { phenylalanine, proline, serine, } \\
\text { threonine, tryptophan, tyrosine, valine } \\
\text { in } \mathrm{H}_{2} \mathrm{O}\end{array}$ \\
\hline Agarose gel solution & $1 \%$ agarose, TAE buffer \\
\hline Blocking solution & $5 \%-10 \%$ milk powder in TBST \\
\hline Blotting buffer & $\begin{array}{l}25 \text { mM Tris, } 192 \text { mM glycine, } \\
10 \% \text { methanol }\end{array}$ \\
\hline BN acrylamide & $48 \%$ acrylamide, $1.5 \%$ bis-acrylamide \\
\hline BN anode buffer & $50 \mathrm{mM}$ Bis-Tris / $\mathrm{HCl}$ pH 7.0 \\
\hline BN clear cathode buffer & $50 \mathrm{mM}$ tricine, $15 \mathrm{mM}$ Bis-Tris \\
\hline BN blue cathode buffer & $\begin{array}{l}50 \mathrm{mM} \text { tricine, } 15 \mathrm{mM} \text { Bis-Tris, } 0.2 \% \\
\text { Coomassie Brilliant Blue G-250 }\end{array}$ \\
\hline BN gel buffer (3X) & $\begin{array}{l}200 \text { mM 6-aminocaproic acid, } \\
150 \text { mM Bis-Tris } / \mathrm{HCl} \text { pH } 7.0\end{array}$ \\
\hline BN loading buffer (10X) & $\begin{array}{l}\text { 5\% Coomassie Brilliant Blue G-250, } \\
500 \mathrm{mM} \text { 6-aminocaproic acid, } \\
100 \mathrm{mM} \text { Bis-Tris/ HCl pH } 7.0\end{array}$ \\
\hline BN solubilization buffer & $\begin{array}{l}20 \mathrm{mM} \text { Tris } / \mathrm{HCl}, 60 \mathrm{mM} \mathrm{NaCl} \text {, } \\
10 \% \text { glycerol, } 1 \mathrm{mM} \text { EDTA, } 1 \mathrm{mM} \text { PMSF } \\
\text { with } 1 \% \text { digitonin or } 0.6 \% \mathrm{DDM}\end{array}$ \\
\hline
\end{tabular}




\begin{tabular}{|c|c|}
\hline Carrier DNA & $\begin{array}{l}\text { Herring sperm DNA }(10 \mathrm{mg} / \mathrm{ml}) \text { in } \\
\mathrm{H}_{2} \mathrm{O}\end{array}$ \\
\hline $\begin{array}{l}\text { Coomassie destaining } \\
\text { solution }\end{array}$ & $40 \%$ ethanol, $10 \%$ acetic acid \\
\hline Coomassie staining solution & $\begin{array}{l}0.25 \% \text { Coomassie Brilliant Blue R-250, } \\
40 \% \text { ethanol, } 10 \% \text { acetic acid }\end{array}$ \\
\hline Digitonin stock solution & $5 \%$ digitonin in $\mathrm{H}_{2} \mathrm{O}$ \\
\hline DNA loading dye & $10 \%$ saccharose, $0.25 \%$ OrangeG \\
\hline DTT buffer & $\begin{array}{l}10 \mathrm{mM} \text { DTT, } 100 \mathrm{mM} \text { Tris } / \mathrm{H}_{2} \mathrm{SO}_{4} \mathrm{pH} \\
9.4\end{array}$ \\
\hline Homogenization buffer & $\begin{array}{l}0.6 \mathrm{M} \text { sorbitol, } 1 \mathrm{mM} \text { EDTA, } 0.2 \% \text { fatty } \\
\text { acid free BSA, } 1 \mathrm{mM} \text { PMSF, } 10 \mathrm{mM} \\
\text { Tris } / \mathrm{HCl} \mathrm{pH} 7.4\end{array}$ \\
\hline PMSF stock & $0.2 \mathrm{M}$ PMSF in ethanol \\
\hline $\begin{array}{l}\text { Potassium phosphate }(\mathrm{KPi}) \\
\text { buffer }\end{array}$ & $80.2 \% \mathrm{~K}_{2} \mathrm{HPO}_{4}, 19.8 \% \mathrm{KH}_{2} \mathrm{PO}_{4}$ \\
\hline Resolving gel (SDS PAGE) & $\begin{array}{l}\text { 10- } 16 \% \text { acrylamide (Rotiphorese }{ }^{\circledR} \text { Gel } \\
\text { 30), } 0.05 \% \text { TEMED, } 0.1 \% \text { APS, } 0.1 \% \\
\text { SDS, } 386 \text { mM Tris } / \mathrm{HCl} \text { pH } 8.8\end{array}$ \\
\hline Resolving gel (Urea PAGE) & $\begin{array}{l}\text { 17.5\% acrylamide, } \\
0.23 \% \text { bis-acrylamide, } \\
5.4 \mathrm{M} \text { urea, } 8 \mathrm{mM} \mathrm{NaCl}, 0.09 \% \text { SDS, } \\
0.1 \% \text { APS, } 0.05 \% \text { TEMED, } \\
684 \mathrm{mM} \text { Tris } / \mathrm{HCl} \mathrm{pH} 8.8\end{array}$ \\
\hline SDS loading buffer & $\begin{array}{l}10 \% \text { glycerol, } 2 \% \text { SDS, } 0.01 \% \\
\text { bromophenole blue, } 1 \% \beta- \\
\text { mercaptoethanol, } \\
60 \mathrm{mM} \text { Tris } / \mathrm{HCl} \text { pH } 6.8\end{array}$ \\
\hline SDS running buffer & $25 \mathrm{mM}$ Tris, $192 \mathrm{mM}$ glycine, $0.1 \%$ SDS \\
\hline SEM buffer & $\begin{array}{l}250 \mathrm{mM} \text { saccharose, } 1 \mathrm{mM} \text { EDTA, } \\
10 \mathrm{mM} \text { MOPS/KOH } \mathrm{pH} 7.2\end{array}$ \\
\hline Stacking gel (SDS PAGE) & $\begin{array}{l}4 \% \text { arylamide, } 0.1 \% \text { SDS, } 0.1 \% \text { APS, } \\
0.05 \% \text { TEMED, } 80 \mathrm{mM} \text { Tris } / \mathrm{HCl} \mathrm{pH} \\
6.8\end{array}$ \\
\hline Stacking gel (Urea PAGE) & $\begin{array}{l}5.4 \% \text { arylamide, } 0.07 \% \text { bis-acrylamide, } \\
0.12 \% \text { SDS, } 3.33 \mathrm{M} \text { urea, } 0.1 \% \text { APS, } \\
0.05 \% \text { TEMED, } 109 \mathrm{mM} \text { Tris } / \mathrm{HCl} \mathrm{pH} \\
6.8\end{array}$ \\
\hline $\begin{array}{l}\text { Solubilization buffer } \\
\text { (mitochondria) }\end{array}$ & $\begin{array}{l}150 \mathrm{mM} \mathrm{NaCl}, 10 \% \text { glycerol, } 1 \mathrm{mM} \\
\mathrm{EDTA}, 1 \mathrm{mM} \text { PMSF, } 50 \mathrm{mM} \text { Tris/HCl } \\
\text { pH } 7.4 \text { with } 1 \% \text { digitonin or } 0.6 \% \text { DDM }\end{array}$ \\
\hline
\end{tabular}




\begin{tabular}{|c|c|}
\hline TAE buffer & $\begin{array}{l}2 \text { mM EDTA, } 40 \mathrm{mM} \text { Tris / acetic acid } \\
\text { pH } 8.0\end{array}$ \\
\hline TBS (Tris-Buffered Saline) & $150 \mathrm{mM} \mathrm{NaCl}, 50 \mathrm{mM}$ Tris $/ \mathrm{HCl} \mathrm{pH} 7.5$ \\
\hline TBST (TBS and Tween-20) & $\begin{array}{l}150 \mathrm{mM} \mathrm{NaCl}, 0.05 \% \text { Tween-20, } \\
50 \mathrm{mM} \text { Tris/ } \mathrm{HCl} \mathrm{pH} 7.5\end{array}$ \\
\hline TCA solution & $100 \%$ TCA in water \\
\hline TE buffer & $1 \mathrm{mM}$ EDTA, $10 \mathrm{mM}$ Tris $/ \mathrm{HCl} \mathrm{pH} 8.0$ \\
\hline TfB1 buffer & $\begin{array}{l}30 \mathrm{mM} \mathrm{KAc} 100 \mathrm{mM} \mathrm{RbCl}, 10 \mathrm{mM} \\
\mathrm{CaCl}_{2}, 50 \mathrm{mM} \mathrm{MnCl}{ }_{2 \prime} \\
15 \% \text { glycerol / acetic acid pH } 5.8\end{array}$ \\
\hline TfB2 buffer & $\begin{array}{l}10 \mathrm{mM} \mathrm{RbCl}, 75 \mathrm{mM} \mathrm{CaCl}_{2} \\
15 \% \text { glycerol, } \\
10 \mathrm{mM} \text { MOPS/KOH pH } 6.5\end{array}$ \\
\hline Translation buffer (1.5x) & $\begin{array}{l}900 \mathrm{mM} \text { sorbitol, } 225 \mathrm{mM} \mathrm{KCl}, 22.5 \\
\mathrm{mM} \mathrm{KPi} \mathrm{pH} 7.4,30 \mathrm{mM} \text { Tris } \mathrm{pH} 7.5,4.5 \\
\mathrm{mg} / \mathrm{ml} \text { fatty acid free BSA, } 6 \mathrm{mM} \\
\text { adenosine triphosphate, } 0.75 \mathrm{mM} \\
\text { guanosine triphosphate, } 9 \mathrm{mM} \\
\text { 2-ketoglutarate, } 12 \mathrm{mM} \text { creatine } \\
\text { phosphate, } 0.15 \mathrm{mM} \text { amino acid } \\
\text { mixture without methionine (AA-Met), } \\
19 \mathrm{mM} \mathrm{MgSO} \mathrm{Mg}_{4} \\
0.0075 \mathrm{mg} / \mathrm{ml}^{\text {cycloheximide }}\end{array}$ \\
\hline Urea PAGE acrylamide & $\begin{array}{l}60 \% \text { acrylamide, } 0.8 \% \text { bis-acrylamide } \\
\text { in } \mathrm{H}_{2} \mathrm{O}\end{array}$ \\
\hline Urea PAGE running buffer & $50 \mathrm{mM}$ Tris, $192 \mathrm{mM}$ glycine, $0.1 \%$ SDS \\
\hline $\begin{array}{l}\text { Washing buffer } \\
\text { (mitochondria) }\end{array}$ & $\begin{array}{l}150 \mathrm{mM} \mathrm{NaCl}, 10 \% \text { glycerol, } 1 \mathrm{mM} \\
\text { EDTA, } 1 \mathrm{mM} \text { PMSF, } 50 \mathrm{mM} \text { Tris } / \mathrm{HCl} \\
\text { pH } 7.4 \text { with } 0.3 \% \text { digitonin or } 0.6 \% \\
\text { DDM }\end{array}$ \\
\hline Yeast cell lysis solution & $255 \mathrm{mM} \mathrm{NaOH}, 1 \% \beta$-mercaptoethanol \\
\hline $\begin{array}{l}\text { Yeast cracking buffer for } \\
\text { DNA extraction }\end{array}$ & $0.2 \mathrm{M} \mathrm{LiAc}, 1 \%$ SDS \\
\hline $\begin{array}{l}\text { Yeast transformation } \\
\text { solution }\end{array}$ & $\begin{array}{l}0.1 \mathrm{M} \text { LiAc, } 40 \% \text { PEG-4000 in water, } \\
\text { filter sterilized }\end{array}$ \\
\hline Zymolyase buffer & 1.2 M sorbitol, $20 \mathrm{mM} \mathrm{KPi} \mathrm{buffer}$ \\
\hline
\end{tabular}




\subsubsection{Culture media composition}

All media were either autoclaved or filter-sterilized. Solid media plates were prepared by adding $2.5 \%$ agar before autoclaving.

TABLE 4: Composition of culture media used in this study.

\begin{tabular}{|c|c|}
\hline Medium & Composition \\
\hline LB & $0.5 \%$ yeast extract, $1 \%$ tryptone, $1 \% \mathrm{NaCl}$ \\
\hline LB cryo storage medium & $\begin{array}{l}0.5 \% \text { yeast extract, } 1 \% \text { tryptone, } 1 \% \\
\mathrm{NaCl}, 15 \% \text { glycerol }\end{array}$ \\
\hline SILAC & $\begin{array}{l}0.67 \% \text { YNB (yeast nitrogen base), 20mg/1 } \\
\text { histidine, } \\
\text { 20mg/1 tryptophane, } 20 \mathrm{mg} / 1 \text { adenine, } \\
20 \mathrm{mg} / 1 \text { methionine, } 20 \mathrm{mg} / 1 \text { uracil, } \\
30 \mathrm{mg} / 1 \text { isoleucine, } \\
30 \mathrm{mg} / 1 \text { tyrosine, } 50 \mathrm{mg} / 1 \text { phenylalanine, } \\
100 \mathrm{mg} / \mathrm{ml} \text { leucine, } 150 \mathrm{mg} / 1 \text { valine, } \\
200 \mathrm{mg} / 1 \text { threonine, } 200 \mathrm{mg} / 1 \text { proline, } \\
\text { 20mg/1 (heavy or light, respectively) } \\
\text { lysine, 20mg/1 (heavy or light, } \\
\text { respectively) arginine }\end{array}$ \\
\hline $\begin{array}{l}\text { Synthetic drop-out } \\
\text { medium }\end{array}$ & $\begin{array}{l}0.67 \% \text { YNB, } 0.07 \% \text { single dropout } \\
\text { mixture (CSM) }\end{array}$ \\
\hline $\begin{array}{l}\text { Synthetic complete } \\
\text { medium }\end{array}$ & $\begin{array}{l}0.67 \% \text { yeast nitrogen base without } \\
\text { aminoacids (YNB), } 0.2 \% \text { adenine } \\
\text { hemisulfate, } 0.2 \% \text { L-histidine, } 0.3 \% \text { L- } \\
\text { leucine, } 0.3 \% \text { L-lysine, } 0.2 \% \text { L- } \\
\text { methionine, } 0.2 \% \text { L-tryptophan, } 0.2 \% \\
\text { uracil, filter sterilized }\end{array}$ \\
\hline YP medium & $1 \%$ yeast extract, $2 \%$ peptone \\
\hline YPAD $(2 x)$ & $\begin{array}{l}2 \% \text { yeast extract, } 4 \% \text { peptone, } 4 \% \\
\text { glucose, } 0.008 \% \text { adenine hemisulfate }\end{array}$ \\
\hline YPD cryo storage medium & $\begin{array}{l}1 \% \text { yeast extract, } 2 \% \text { peptone, } 2 \% \\
\text { glucose, } 0.3 \% \text { adenine hemisulfate, } 15 \% \\
\text { glycerol. }\end{array}$ \\
\hline YPD & $\begin{array}{l}1 \% \text { yeast extract, } 2 \% \text { peptone, } 2 \% \\
\text { glucose }\end{array}$ \\
\hline YPGal & $\begin{array}{l}1 \% \text { yeast extract, } 2 \% \text { peptone, } 2 \% \\
\text { galactose }\end{array}$ \\
\hline
\end{tabular}




\begin{tabular}{|l|l|}
\hline YPG & $\begin{array}{l}1 \% \text { yeast extract, } 2 \% \text { peptone, 3\% } \\
\text { glycerol } \mathrm{pH} 5.6\end{array}$ \\
\hline
\end{tabular}

\subsubsection{Antibodies}

Primary polyclonal antibodies were raised in rabbit by injecting synthetic peptides, or purified proteins, into rabbits. Secondary antibody goat antirabbit coupled to horseradish-peroxidase (HRP) (Dianova) was used at a 1:5000 dilution in 5\% blocking solution. Peroxidase Anti-Peroxidase Soluble Complex antibody (Sigma-Aldrich) was used for detection of Protein A-tag. 


\subsubsection{Plasmids}

Plasmids generated in this study are listed in table 5 and were propagated in Escherichia coli (E. coli) XL1-Blue cells (Stratagene).

TABLE 5: Plasmids used in this study.

\begin{tabular}{|l|l|l|l||}
\hline Plasmid & Backbone & Insert & Source \\
\hline p415MET25 & - & - & Mumberg et \\
& & al., 1994 \\
p415MET25-COX20 & p415MET25 & Cox20 & This study \\
p415MET25-YDR230W & p415MET25 & Ydr230W & This study \\
\hline
\end{tabular}

\subsubsection{Cell lines}

The E. coli strain XL1-blue (Stratagene) was used for molecular cloning. The yeast strains used in this study are listed in the table 6 . They are derivatives of YPH499 (Sikorski and Hieter, 1989), with the exception of the imp1 $\Delta$ strain that derives from the BY4741 strain (Brachmann et al., 1998). Tagged versions of COX20, MBA1 and COX18 were generated by homologous recombination using PCR-derived cassettes from the plasmid pYM10 (Janke et al., 2004). Deletions strains were created by introduction of HIS3MX6, klTRP1, natNT2 and kanMX4 cassettes. In the double deletion strain cox20 $y d r 230 W \Delta$ the two overlapping reading frames were both deleted with the HIS3MX6 cassette. 


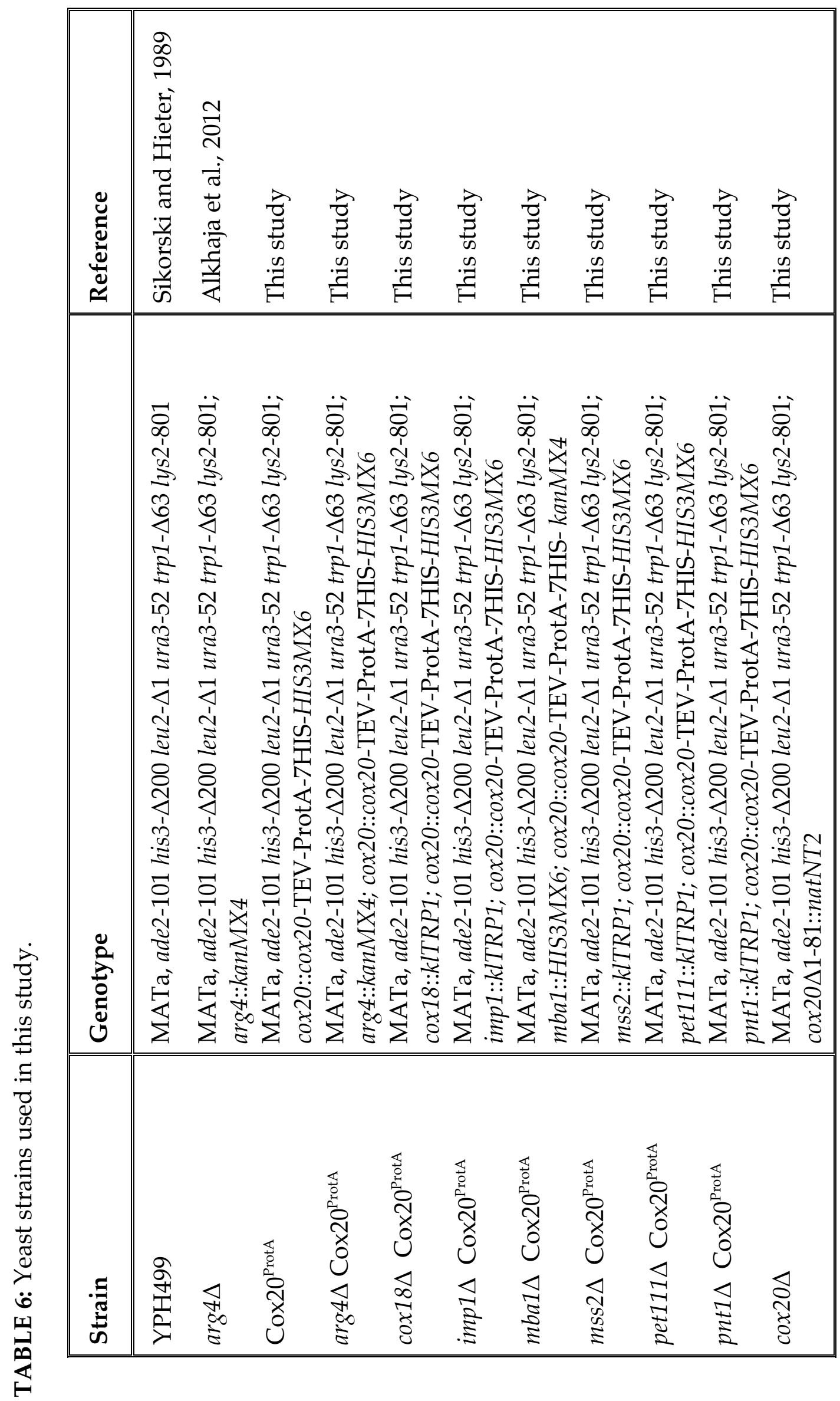




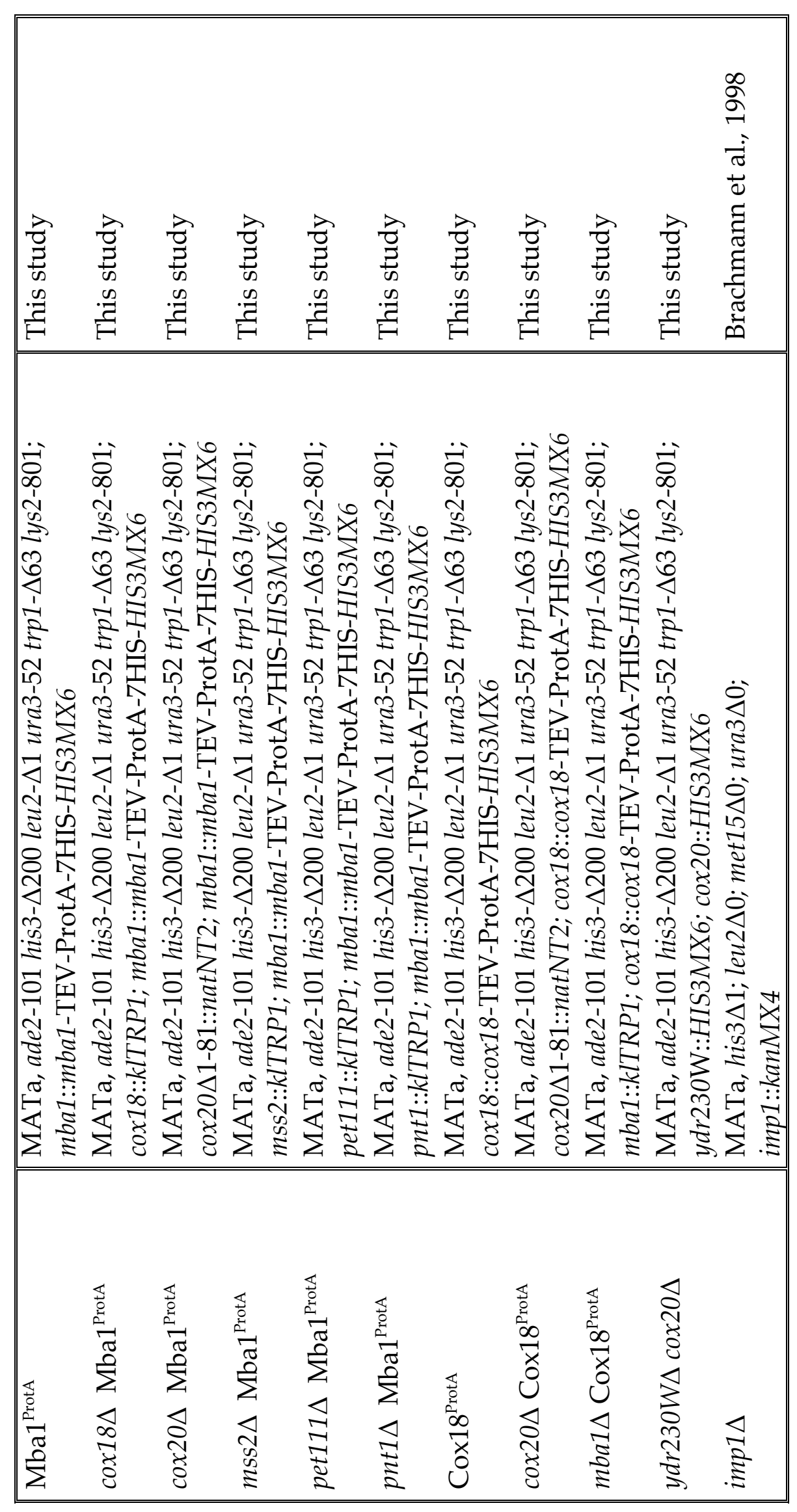




\subsection{Methods}

\subsubsection{Cultivation of yeast}

\subsubsection{Growth conditions}

The yeast strains used in this study are listed in Table 6. In general, yeast $S$. cerevisiae were grown in rich YP medium at $30^{\circ} \mathrm{C}$ with shaking (160-220 rpm), according to standards procedures (Curran and Bugeja, 2006). Yeast cells were grown on fermentable media (YPD or YPGal) or non-fermentable media (YPG). Synthetic medium lacking the appropriate amino acid was used to select and propagate strains. Cells containing a plasmid carrying a geneticin resistant marker were grown on solid YP media with $0.2 \mathrm{~g} / \mathrm{L}$ geneticin.

Yeast cells were plated onto appropriate solid media from cryo stocks and grown for 2-3 days at $30{ }^{\circ} \mathrm{C}$. Liquid cultures were inoculated with biomass from liquid pre-cultures (1:10 or 1:20) or plates. Cell density was monitored by measuring optical density at $600 \mathrm{~nm}\left(\mathrm{OD}_{600}\right.$ of $1 \sim 1 \times 10^{7}$ cells $\left./ \mathrm{ml}\right)$. For mitochondrial translation inhibition treatment, yeast cells were grown until mid-log phase and incubated for three hours with $6 \mathrm{mM}$ chloramphenicol prior to mitochondrial isolation (Mick et al., 2010).

\subsubsection{Yeast cryo stocks}

Yeast cryo stocks were prepared by re-suspending biomass from solid media in $1 \mathrm{ml}$ of YPD cryo storage medium (table 4 ) and stored at $-80^{\circ} \mathrm{C}$.

\subsubsection{S. cerevisiae growth test}

Yeast growth test was performed by adjusting fresh cultures to an $\mathrm{OD}_{600}$ of 0.3 . Afterwards, serial 10 -fold dilutions of yeast cells were prepared (0.3 to $0.0003 \mathrm{OD}_{600}$ ) and same amount of each dilution was spotted on solid media. Plates were incubated for 2-5 days at different temperatures. Images were acquired with a Perfection V750 Pro Scanner for documentation. 


\subsubsection{Generation of rho $^{0}$ yeast strains}

Cells were kept growing in YPD medium with $25 \mu \mathrm{g} / \mathrm{ml}$ ethidium bromide (EtBr) and diluted in fresh YPD containing EtBr every day. After 3 days, cells were streaked onto solid medium without $\mathrm{EtBr}$ and single colonies were harvested. Absence of mitochondrial-encoded proteins was assessed by Western blotting.

\subsubsection{Cultivation of $E$. coli}

E. coli, XL1-Blue, were grown at $37{ }^{\circ} \mathrm{C}$ in LB medium with agitation at 220 rpm, according to standard protocols (Sambrook and Russel, 2001). For solid media plates, $1.5 \%$ agar was added to LB medium prior to sterilization.

To select for cells containing a plasmid carrying an $A m p^{R}$ marker, $0.1 \mathrm{~g} / 1$ ampicillin was added to LB medium. Liquid cultures of $E$. coli were inoculated with biomass from a pre-culture (1:100 or 1:1000) or solid media plates. Cell growth was monitored by measuring optical density at $600 \mathrm{~nm}$ $\left(\mathrm{OD}_{600}\right.$ of $1 \sim 8 \times 10^{8}$ cells $\left./ \mathrm{ml}\right)$. For long-term storage cryo stocks, $800 \mu \mathrm{l}$ of culture was mixed with $200 \mu \mathrm{l}$ of glycerol $80 \%$ and frozen at $-80{ }^{\circ} \mathrm{C}$.

\subsubsection{Molecular biology methods}

\subsubsection{Polymerase chain reaction (PCR)}

DNA fragments for yeast transformation and cloning purposes were amplified by PCR using the KOD hot start polymerase (Novagen). Amplification conditions were adjusted according to manufacturer's specifications and melting temperatures of the primer pairs. PCR products were analyzed by agarose gel electrophoresis. 


\subsubsection{DNA isolation from $E$. coli}

Wizard ${ }^{\circledR}$ Plus SV Minipreps DNA purification System (Promega) was used to purified plasmids from E. coli. Plasmids were then stored in water at $-20^{\circ} \mathrm{C}$.

\subsubsection{Isolation of yeast genomic DNA}

Genomic DNA was isolated from $1 \mathrm{ml}$ of yeast culture grown until $\mathrm{OD}_{600} 1$. The cell pellet was re-suspended in $1 \mathrm{ml}$ of solution A $(50 \mathrm{mM}$ Tris $/ \mathrm{HCl} \mathrm{pH}$ 7.4, $10 \mathrm{mM}$ EDTA, $0.3 \% \quad \beta$-mercaptoethanol, $0.5 \mathrm{mg} / \mathrm{ml}$ zymolyase) and incubated for $1 \mathrm{~h}$ at $30{ }^{\circ} \mathrm{C}$. Genomic DNA isolation was performed with High Pure PCR Template Preparation Kit and stored in water at $-20^{\circ} \mathrm{C}$.

\subsubsection{Molecular cloning}

Molecular cloning was performed according to published protocols (Sambrook and Russel, 2001). DNA fragments and plasmids were digested with the Fast Digest restriction enzymes (Fermentas) according to manufacturer's specifications. Insert and digested plasmid were ligated with the DNA Ligation Kit (Thermo Scientific) for 1 hour at $22{ }^{\circ} \mathrm{C}$. Constructs were then analyzed by restriction and sequencing.

\subsubsection{DNA electrophoresis and sequencing}

DNA fragments were visualized by agarose gel electrophoresis. 1\% agarose gels were prepared in TAE buffer containing EtBr. DNA samples were mixed with the loading dye ( $4 \%$ saccharose, $0.1 \%$ Orange $\mathrm{G}$ ) and electrophoresis run was performed in TAE buffer at $120 \mathrm{~V}$ in Mini-Sub® Cell GT system.

GeneRuler DNA Ladder mix (Fermentas) was used as a marker of molecular weight. DNA was visualized using an UVsolo TS transilluminator. 
Purity and concentration of the nucleic acids were measured with the NanoVue spectrometer (GE Healthcare) at 260/280 nm. For DNA purification Wizard ${ }^{\circledR}$ SV Gel and PCR Clean-Up System kits were used.

Sequencing of DNA was performed by Seqlab (Göttingen) and sequences data were analyzed with Geneious Pro 5.3.6.

\subsubsection{E. coli transformation}

Competent E. coli cells were prepared with the RbCl method (Hanahan, 1983). Overnight pre-culture was diluted in 1:100 and grown until $\mathrm{OD}_{600}$ 0.6. Cells were cooled down on ice for $15 \mathrm{~min}$ and harvested. Cell pellet was resuspended first in cold TfB1buffer $(100 \mathrm{ml} / \mathrm{g})$ and then in cold TfB2 buffer (20 $\mathrm{ml} / \mathrm{g}$ ). Aliquots of competent cells were frozen in liquid nitrogen and then stored at $-80^{\circ} \mathrm{C}$.

$100 \mu \mathrm{l}$ of chemically competent cells were thawed on ice and incubated with plasmid DNA for $15 \mathrm{~min}$ on ice. Heat shock of the reaction was performed for $1 \mathrm{~min}$ at $42{ }^{\circ} \mathrm{C}$ and subsequently cells were cooled down on ice for $2 \mathrm{~min} .1 \mathrm{ml}$ of LB media was added to the reaction and the culture was grown for $1 \mathrm{~h}$ at 37 ${ }^{\circ} \mathrm{C}$ shacking. Afterwards, transformed cells were harvested by centrifugation at $1000 \mathrm{rpm}$ and plated onto LB agar plates with antibiotic for selection. Plates were incubated at $37^{\circ} \mathrm{C}$ over night until single colonies were visible.

\subsubsection{Yeast transformation}

Competent yeast cells were prepared with the lithium-acetate method as described by Gietz and Schiestl, 2007. Cells were grown overnight in YPAD $(2 x)$. On the next day they were diluted to $\mathrm{OD}_{600} 0.2$ and grown until $\mathrm{OD}_{600}$ 0.8-1.5. Cells were harvested and incubated in transformation buffer $(0.1 \mathrm{M}$ LiAc, $0.1 \mathrm{M}$ EDTA, $5 \mathrm{mM}$ Tris $/ \mathrm{HCl} \mathrm{pH}$ 8) for $30 \mathrm{~min}$ at $30{ }^{\circ} \mathrm{C}$ with mild agitation. For this purpose $1 / 5$ of the original culture volume of the transformation buffer was used. Subsequently, yeast cells were re-suspended 
in transformation buffer, $1 / 50$ of the original culture volume, and aliquoted to $100 \mu l$ per reaction.

Cells now competent were directly used for transformation procedure. To each reaction, $1 \mu \mathrm{g}$ of carrier DNA (denatured herring sperm DNA) was added together with the target DNA (200 ng plasmid DNA or $1 \mu \mathrm{g}$ purified PCR product) at $30{ }^{\circ} \mathrm{C}$ for $30 \mathrm{~min}$ with agitation at $700 \mathrm{rpm}$. After addition of $600 \mu \mathrm{l}$ of yeast transformation solution (table 3 ), the reaction was incubated for one hour at $30{ }^{\circ} \mathrm{C}$ shacking at $1400 \mathrm{rpm}$. Heat shock was performed at 42 ${ }^{\circ} \mathrm{C}$ for $15 \mathrm{~min}$. Cells were harvested, re-suspended in water and plated onto appropriate plates and left at $30{ }^{\circ} \mathrm{C}$ for 3 days. Single colonies were picked and transfered to fresh plates for additional selection. Integration of exogenous DNA was confirmed by Western blotting of whole cell extract and colony PCR.

\subsubsection{Yeast whole cell extracts}

Whole cell extracts were prepared as described by Yaffe and Schatz, 1984. A cell pellet corresponding to $\mathrm{OD}_{600} 3$ was re-suspended in yeast lysis solution. The reaction was incubated for $10 \mathrm{~min}$ on ice and then $15 \%$ of TCA was added to the mixture. After additional $10 \mathrm{~min}$ on ice, precipitated material was pelleted by centrifugation ( $2 \mathrm{~min}$ at $14000 \mathrm{rpm}$ ) and the pellet was re-suspend in SDS sample buffer. The $\mathrm{pH}$ of the reaction was titrated with $1 \mathrm{M}$ Tris $(\mathrm{pH}$ 11.5) up to neutralization, prior to SDS-PAGE analysis.

\subsubsection{Isolation of yeast mitochondria}

Mitochondria from yeast cells were prepared according to published protocols (Meisinger et al., 2006). To endorse respiratory growth and mitochondrial proliferation, cells were grown in non-fermentable medium containing 3\% glycerol with the exception of respiratory deficient strains that were grown in fermentable medium with $2 \%$ glucose or galactose. Yeast cells were grown to $\mathrm{OD}_{600} 2$ at $30{ }^{\circ} \mathrm{C}$. After a first wash with water, cell pellet was 
re-suspended in $2 \mathrm{ml} / \mathrm{g}$ wet cell weight of DTT buffer and incubated under mild agitation $(90 \mathrm{rpm})$ for $30 \mathrm{~min}$ at $30{ }^{\circ} \mathrm{C}$. Following DTT treatment, cells were pelleted (4000 rpm, $10 \mathrm{~min}$ at $18{ }^{\circ} \mathrm{C}$ ), washed once with zymolyase buffer and re-suspended in $7 \mathrm{ml} / \mathrm{g}$ wet cell weight of zymolyase buffer containing $4 \mathrm{mg}$ zymolyase/g wet cell weight.

Zymolyase ${ }^{\circledR}$-20T enzyme digests the cells wall and converts cells to spheroplasts. After zymolyase treatment (90 rpm, $60 \mathrm{~min}$ at $30{ }^{\circ} \mathrm{C}$ ), spheroplasts were pelleted $\left(3000 \mathrm{rpm}, 10 \mathrm{~min}\right.$ at $\left.18{ }^{\circ} \mathrm{C}\right)$, washed once with zymolyase buffer and re-suspended in $7 \mathrm{ml} / \mathrm{g}$ wet cell weight of cold homogenization buffer. After homogenization with a Potter $\mathrm{S}$ homogenizer (20 strokes, at $700 \mathrm{rpm}$ at $4{ }^{\circ} \mathrm{C}$ ), cell debris, unopened cells and nuclei were removed by differential centrifugation at $3000 \mathrm{rpm}, 10 \mathrm{~min}$ at $4{ }^{\circ} \mathrm{C}$, followed by the second step at $4000 \mathrm{rpm}, 10 \mathrm{~min}$ at $4{ }^{\circ} \mathrm{C}$. Mitochondria (crude membrane fraction) were pelleted at $12000 \mathrm{rpm}, 15 \mathrm{~min}$ at $4{ }^{\circ} \mathrm{C}$. Obtained mitochondrial pellet was washed once and finally re-suspended in SEM buffer at a concentration of $10 \mathrm{mg} / \mathrm{ml}$. Mitochondria were aliquoted and snap-frozen in liquid nitrogen and stored at $-80^{\circ} \mathrm{C}$.

\subsubsection{Biochemical methods}

\subsubsection{SDS-PAGE}

SDS-PAGE, originally developed by Laemmli (1970), was performed to separate proteins under denaturing conditions according to their molecular weight (Chakavarti and Chakavarti, 2008).

$30 \%$ Acrylamide/ $0.8 \%$ bisacrylamide $(37.5: 1)$ was used as a stock to prepare gels. Gel systems used in this study comprised of $4 \%$ acrylamide for stacking gel and $15-17 \%$ acrylamide for resolving gel, depending on the size of the proteins of interest. Prior to gel loading, samples were mixed with SDSloading buffer. Electrophoresis run was performed in custom-made gel chambers or Mini-PROTEAN Tetra cell at $30 \mathrm{~mA}, 230 \mathrm{~V}$ per gel. As standard of molecular weight SDS-PAGE Protein Marker (Serva) was used. 


\subsubsection{UREA-SDS-PAGE}

To increase separation in the molecular range below $10 \mathrm{kDa}$, SDS-PAGE gels containing urea were used (Summer et al., 2009). Electrophoresis and handling were similar to SDS-PAGE gels. 17.5\% Acrylamide/0.23\% bisacrylamide was used as stock to prepare UREA-SDS-PAGE. The stacking gel contained 3.6 M urea and the resolving gel 5.4 M. Urea PAGE running buffer was used for electrophoretic run, which was performed at $50 \mathrm{~mA}$ per gel.

\subsubsection{BN-PAGE}

Native protein complexes were separated by BN-PAGE analysis (Schägger and von Jagow, 1991; Wittig et al., 2006).

Prior to gel loading, mitochondria were re-isolated and solubilized with buffer containing $1 \%$ digitonin, at a concentration of $1 \mathrm{mg} / \mathrm{ml}$. After incubation of $30 \mathrm{~min}$ on ice, samples were clarified by centrifugation at 20000 rpm for $15 \mathrm{~min}$ at $4{ }^{\circ} \mathrm{C}$. Then, supernatant was mixed with the appropriate BN loading buffer. For analysis of protein of the respiratory chain complexes, 15 $\mu \mathrm{g}-50 \mu \mathrm{g}$ of solubilized mitochondria were loaded per lane. Gradient gels were poured using the Hoefer gel system. 4-13\% Gradient gels were used in this study with $4 \%$ acrylamide for stacking gel. BN cathode and anode buffers were used for gel electrophoresis. Electrophoresis run was performed at 15 $\mathrm{mA}, 600 \mathrm{~V}$ per gel at $4{ }^{\circ} \mathrm{C}$. After 1 hour, the cathode buffer containing $0.02 \%$ Coomassie Brilliant Blue G-250 (blue cathode buffer) was exchange with cathode buffer without Coomassie to increase blotting efficiency and the gel was let run for further 3-4 h. As a standard of molecular weight, the HMW calibration kit (GE Healthcare) was used. 


\subsubsection{Western blot}

After separation by electrophoretic run, proteins were transferred on PVDF membranes (Millipore) by semi-dry blotting (Gallagher et al., 2004). PVDF membranes were activated by incubation in methanol. Subsequently, gels, PVDF membranes and Whatman papers (Heinemann Labortechnik) were equilibrated in blotting buffer. After their assembly in the blotting chamber, proteins were transferred from the gel to the PVDF membrane at $25 \mathrm{~V}, 250$ $\mathrm{mA}$ for $2 \mathrm{~h}$.

\subsubsection{Coomassie staining}

Proteins on PVDF membranes or polyacrylamide gels were stained with Coomassie staining solution for $2 \mathrm{~min}$ or $2 \mathrm{~h}$ respectively. Coomassie destaining solution was used to remove background staining, $1 \mathrm{~h}$ for gels and 5 min for membranes. After labeling of the marker of molecular weight, PVDF membranes were cut to detect proteins of various sizes and subsequently reactivated in methanol for further immunostaining procedures.

\subsubsection{Immunostaining}

Activated PVDF membranes were briefly rinsed in TBST buffer and blocked in TBST buffer containing 5\% of milk powder (blocking solution) for $1 \mathrm{~h}$ or overnight at $4{ }^{\circ} \mathrm{C}$ (Gallagher et al., 2004). Following blocking, membranes were incubated in primary antibody solution (blocking solution or TBST buffer) for $1 \mathrm{~h}$ at room temperature or overnight at $4{ }^{\circ} \mathrm{C}$. Afterwards, the blots were washed three times for $10 \mathrm{~min}$ in TBST buffer at room temperature and incubated in secondary antibody coupled to HRP (1 : 5000 in blocking solution) for $1 \mathrm{~h}$. After three additional washes in TBST buffer, the antibodyprotein complexes were detected upon incubation of the membranes with ECL Western Blotting detection reagent (GE-Healthcare) and signals were visualized on medical X-ray films (Foma). 


\subsubsection{Determination of protein concentration}

Bradford analysis was performed to determine protein concentrations (Bradford, 1976) using Roti ${ }^{\circledR}$-Quant reagent (Roth). As a standard, bovine IgG (Biorad) was used to establish a calibration curve. For the measurement samples were diluted 1:10. Eppendorf ${ }^{\circledR}$ BioPhotometer was used to measure the absorbance of protein solutions at $595 \mathrm{~nm}$.

\subsubsection{Steady state analysis of protein levels}

To analyze steady state levels of mitochondrial proteins, isolated yeast mitochondria were pelleted at $20000 \mathrm{rpm}$ for $10 \mathrm{~min}$ at $4{ }^{\circ} \mathrm{C}$. Pellets were resuspended in 1x SDS loading dye at $1 \mathrm{mg} / \mathrm{ml}$. Different sample dilutions were prepared to load equal volumes per gel lane onto SDS-PAGE. Analysis by immunostaining followed (2.2.6.6)

\subsubsection{IgG chromatography}

Isolation of protein complexes via Protein A-tag was performed using IgG chromatography method (Rehling et al., 2003).

To prepare an IgG affinity matrix, human IgGs (Sigma-Aldrich) were coupled to cyanogen bromide activated Sepharose 4B (GE Healthcare) as described in the manufacturer's instructions. Prior binding of the solubilized sample onto the IgG sepharose, it was washed twice with acetate buffer, twice with $2 x$ solubilization buffer and equilibrated with $1 x$ solubilzation buffer containing $1 \%$ digitonin. The washing steps were done in Mobicol "classic" spin columns (MoBiTec) with 10 times more of the IgG sepharose volume at $100 \mathrm{~g}$ for $30 \mathrm{sec}$ at $4{ }^{\circ} \mathrm{C}$.

For complex isolation, mitochondria from wild type and Protein A-tag strains were solubilized in solubilization buffer containing $1 \%$ digitonin for $30 \mathrm{~min}$ on ice. Supernatant was clarified from unsolubilized material by centrifugation at maximum speed for $15 \mathrm{~min}$ at $4{ }^{\circ} \mathrm{C}$. Afterwards a fraction of 
the clarified mitochondrial extract was taken, termed total, and the rest was incubated with the IgG sepharose for $2 \mathrm{~h}$ at $4{ }^{\circ} \mathrm{C}$ with mild agitation. Upon incubation time, the unbound fraction was removed. Then the resin was washed 10 times with washing buffer. To cleave Protein A- off the sepharose, AcTEV protease (Invitrogen, $10 \mathrm{U} / \mu \mathrm{l}$ ) in washing buffer was added onto the resin and incubated overnight with mild agitation at $4{ }^{\circ} \mathrm{C}$.

TEV protease carrying a polyhistidine tag was removed from the sample by addition of Ni-NTA (Quiagen) pre-equilibrated with wash buffer. After 40 min incubation at $4{ }^{\circ} \mathrm{C}$, the cleaved native complexes were eluted by centrifugation at $4{ }^{\circ} \mathrm{C}$ for $1 \mathrm{~min}$ at $100 \mathrm{xg}$ mixed with the appropriate loading dye and analyzed by SDS-PAGE or BN-PAGE.

Alternatively, for SDS-PAGE analysis beads were incubated with $0.1 \mathrm{M}$ Glycine $\mathrm{pH} 2.8$ for $7 \mathrm{~min}$ with agitation at room temperature. Acidic $\mathrm{pH}$ was neutralized by titration with $0.1 \mathrm{M}$ Tris $\mathrm{pH} 11.5$.

\subsubsection{In organello labeling}

In organello labeling of mitochondrial translation products was performed as described by Westermann et al., 2001. Per labeling reaction, mitochondria (10 $\mathrm{mg} / \mathrm{ml}$ ) were mixed with freshly prepared translational buffer containing 2.5 $\mathrm{mg} / \mathrm{ml}$ of creatine kinase. After sample equilibration with mild agitation at $30{ }^{\circ} \mathrm{C}$ for $2 \mathrm{~min}$, labeling reaction was started by addition of $20 \mu \mathrm{M}$ of $\left[{ }^{35} \mathrm{~S}\right]-\mathrm{L}$ methionine. Labeling was stopped after $20 \mathrm{~min}$ by addition of $15 \mathrm{mM}$ nonlabeled methionine, reactions were further incubated for $5 \mathrm{~min}$ at $30^{\circ} \mathrm{C}$ before the reaction was cooled down on ice. Before IgG chromatography or SDSPAGE analysis, mitochondria were re-isolated and washed twice in SEM buffer. After gel electrophoresis, SDS-PAGE gels were dried in a vacuum gel dryer at $65{ }^{\circ} \mathrm{C}$ for $2 \mathrm{~h}$. Radioactively labeled proteins were detected by digital autoradiography. Dried gels were exposed to Storage Phosphor Screens (GE Healthcare) and signals were recorded using a scanner (Storm820; GE Healthcare). 


\subsubsection{Stable isotope labeling of amino acids in cell culture (SILAC)}

For SILAC analysis, double deletion strains deficient in lysine and arginine synthesis were used (Ong and Mann, 2006). Since YPH499 is already auxotrophic for lysine, to generate the strains for SILAC labeling the ARG4 gene was deleted in the wild-type and Cox $20^{\text {ProtA }}$ strains (table 6). Yeast cells were grown on minimal SILAC medium (table 4) containing heavy amino acids, L-arginine (U-13C6, 99\%; U-15N4, 99\%) and L-lysine (U-13C6, 99\%; U15N2, 99\%; Cambridge Isotope Laboratories), as well as light amino acids. Two independent experiments were performed. For the forward experiment, the Cox $20^{\text {ProtA }}$ was grown on heavy amino acids media and the wild-type was grown on media containing light amino acids and vice versa for the reverse experiment. Cells were grown in SILAC medium supplemented with 2\% galactose at $30^{\circ} \mathrm{C}$ as described in section 2.2.1.1.

Differentially labeled mitochondria (wild-type and $\operatorname{Cox} 20^{\text {ProtA }}$ ) were isolated, mixed in a ratio 1:1 and solubilized together prior to Cox $20^{\text {ProtA }}$ complexes isolation.

\subsubsection{Mass spectrometry of SILAC labeled protein complexes}

Isolated SILAC labeled Cox20 complexes (Cox20 ProtA heavy/wild-type light; Cox $20^{\text {ProtA }}$ light/ wild-type heavy) were analyzed by SDS- and BN-PAGE.

Directly following the gel run, the gel lanes were cut into individual slices and proteins were in gel digested with trypsin (Wiese et al., 2007).

For the BN-PAGE analysis of isolated SILAC labeled Cox20 complexes, eluates were separated on 4-13\% gradient BN-PAGE. Afterwards, the gel lane was cut into 13 slices of equal size and the normalized heavy-over-light and light-over-heavy ratios (relative intensity) of proteins isolated via Cox20 were plotted against the gel slices.

Tryptic peptides were analyzed by LC-MS coupled to an Ultimate 3000 RSLCnano/LTQ-Orbitrap XL mass spectrometer (Thermo Fisher Scientific, Bremen, Germany). 


\subsubsection{Mass spectrometry data analysis}

MaxQuant software was used for data processing (Cox et al., 2011).

Mass spectrometry data analysis and visualization was performed in the Functional Proteomics group of Prof. Bettina Warscheid at the BIOSS Centre for Biological Signalling Studies (Institute for Biology II, University of Freiburg), mainly by Dr. Silke Oeljeklaus. 


\section{RESULTS}

\subsection{Functional analysis of Cox20}

The Cox20 protein is involved in Cox2 biogenesis whereby it acts as a Cox2specific chaperone. In fact, experimental data suggests that Cox20 is known to remain associated with Cox2 throughout the steps prior to the assembly of Cox2 into the cytochrome $c$ oxidase (Hell et al., 2000). However, the precise function of Cox20 for Cox2 maturation, as well as other proteins that may be involved in this association, is not known. Therefore, to further elucidate the molecular role of Cox20 and to identify novel players in the early steps of Cox2 assembly, a C-terminally Protein A-tag was genomically integrated, which enables native isolation of Cox20, together with any associated proteins.

Cox20 overlaps with the putative open reading frame YDR230W.

Thus, C-terminal tag of Cox20 disrupts this open reading frame. To ensure that the presumed protein Ydr230Wp is not responsible for the respiratory growth phenotype of the cox $20 \Delta$ strain, COX20 and YDR230W were cloned and transfected in both the double delta and the cox20 $\Delta$ strain (FIG 3.1).
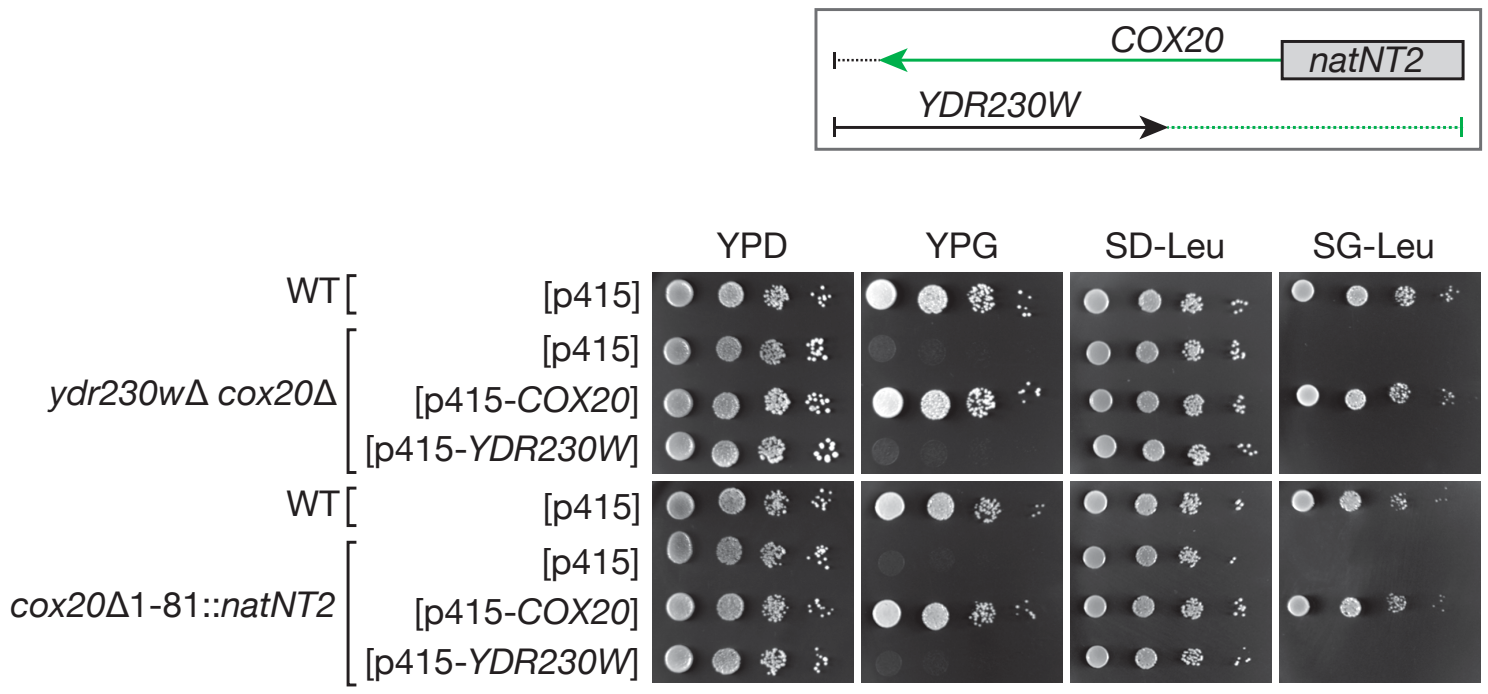

FIG 3.1 Complementation test.

COX20 (green) and YDRW230 (black) were cloned in the plasmid (p415) and transfected in the indicated strains. Yeast cells were spotted in 10 fold dilutions on fermentable (YPD, SD-Leu) or non-fermentable (YPG, SG-Leu) media and incubated at $30^{\circ} \mathrm{C}$. Included is the schematic representation of the genetic locus containing the two open reading frames (Box). The insertion cassette natNT2 was used for the specific deletion of COX20. 
Ydr230Wp did not recover the respiratory growth of any of the tested strains. Although it is not certain whether YDR230W actually encodes a protein, disruption of the gene is not linked to loss of respiration.

\subsubsection{Growth and respiratory ability of the Cox $20^{\text {ProtA }}$ strain}

Afterwards, to test the functionality of the Cox20 fusion protein, the growth of the Cox $20^{\text {ProtA }}$ strain was compared to wild-type and cox $20 \Delta$ strains on fermentable (YPD) and non-fermentable (YPG) medium at different temperatures (FIG 3.2). The cox20s strain did not grow on non-fermentable medium, verifying that the Cox20 protein is essential for respiration (Elliott et al., 2012). A strain expressing tagged Cox20 shows wild-type-like growth behavior at all tested conditions, indicating a functional protein.

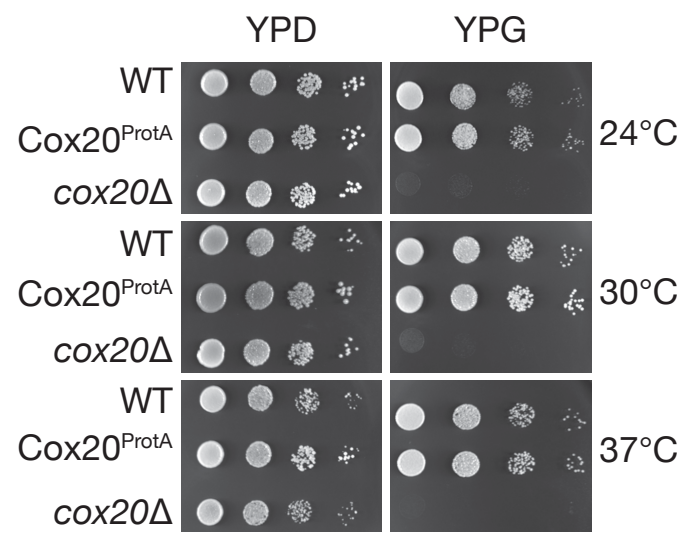

FIG 3.2 Growth analysis of C-terminally tagged Cox20.

Yeast cells were spotted in 10 fold dilutions on fermentable (YPD) and non fermentable (YPG) carbon sources and incubated at different temperatures $\left(24^{\circ} \mathrm{C}\right.$, $30^{\circ} \mathrm{C}$ and $\left.37^{\circ} \mathrm{C}\right)$. 


\subsubsection{Analysis of mitochondrial translation products}

Since Cox20 has previously been shown to be essential for Cox2 N-terminal processing, it was assessed whether the C-terminal tag on Cox20 hampers Cox2 N-tail processing (Hell et al., 2000). Therefore, the synthesis of mitochondria-encoded proteins was analyzed in wild-type, cox20 $\Delta$ and Cox $20^{\text {ProtA }}$ strains. The imp $1 \Delta$ strain, in which the proteolytic maturation of the pre-Cox2 leader peptide is absent, was used as a control for impaired Cox2 processing (Jan et al., 2000).

Cox $20^{\text {ProtA }}$ and wild-type strains exhibited similar labeling efficiencies of mitochondrial translation products and comparable Cox2 processing (FIG 3.3

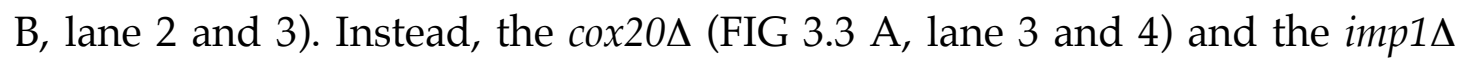
(FIG $3.3 \mathrm{~B}$, lane 1) strains led to the accumulation of a slower migrating precursor form of Cox2.

A

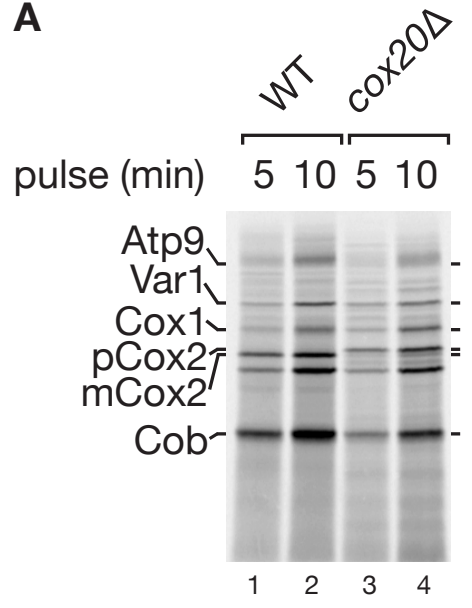

B
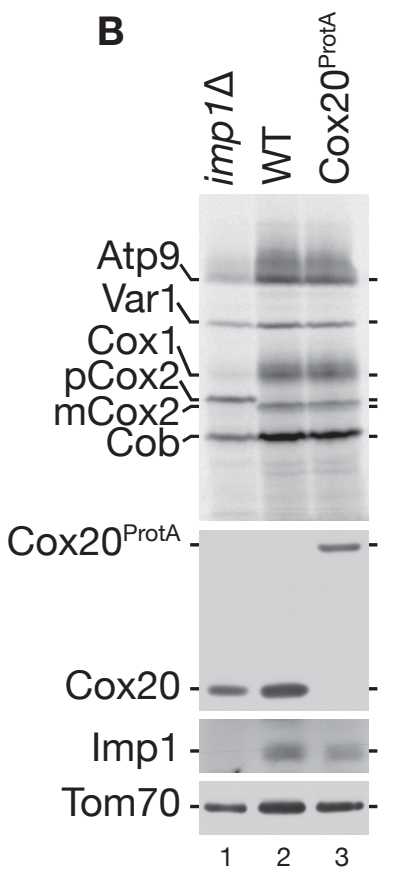

FIG 3.3 Labeling of mitochondria-encoded proteins in the Cox $20^{\text {ProtA }}$ strain.

In organello translation of isolated mitochondria from the indicated strains was performed for 5 and $10 \mathrm{~min}(\mathrm{~A})$ and $20 \mathrm{~min}(\mathrm{~B})$ at $30^{\circ} \mathrm{C}$. Samples were analyzed by SDS-PAGE and digital autoradiography, or Western-blotting. pCox2, pre-Cox2; mCox2, mature Cox2. 


\subsubsection{Protein steady state analysis of the Cox $20^{\text {ProtA }}$ and $\operatorname{cox} 20 \Delta$ strains}

To further investigate if Cox20 tagging affects mitochondrial protein levels or mitochondrial protein complexes, mitochondria from wild-type, Cox $20^{\text {ProtA }}$ and cox20 $\Delta$ cells were isolated. Western blot analyses were performed using antibodies against a variety of mitochondrial proteins (FIG 3.4). Levels of most of these tested proteins, such as the outer mitochondrial membrane protein Tom70, matrix protein Aco1, inner mitochondrial membrane protein Tim23, complex IV assembly factor Coa3, complex V component Atp5, were similar in all the strains.

Despite the absence of Cox20 leading to a lack of Cox2, as well as Cox1, and a slightly reduced protein level of Cox6 and Cox4, the Cox $20^{\text {ProtA }}$ strain displayed wild-type steady state levels of all tested proteins in mitochondria (FIG 3.4 A and B).
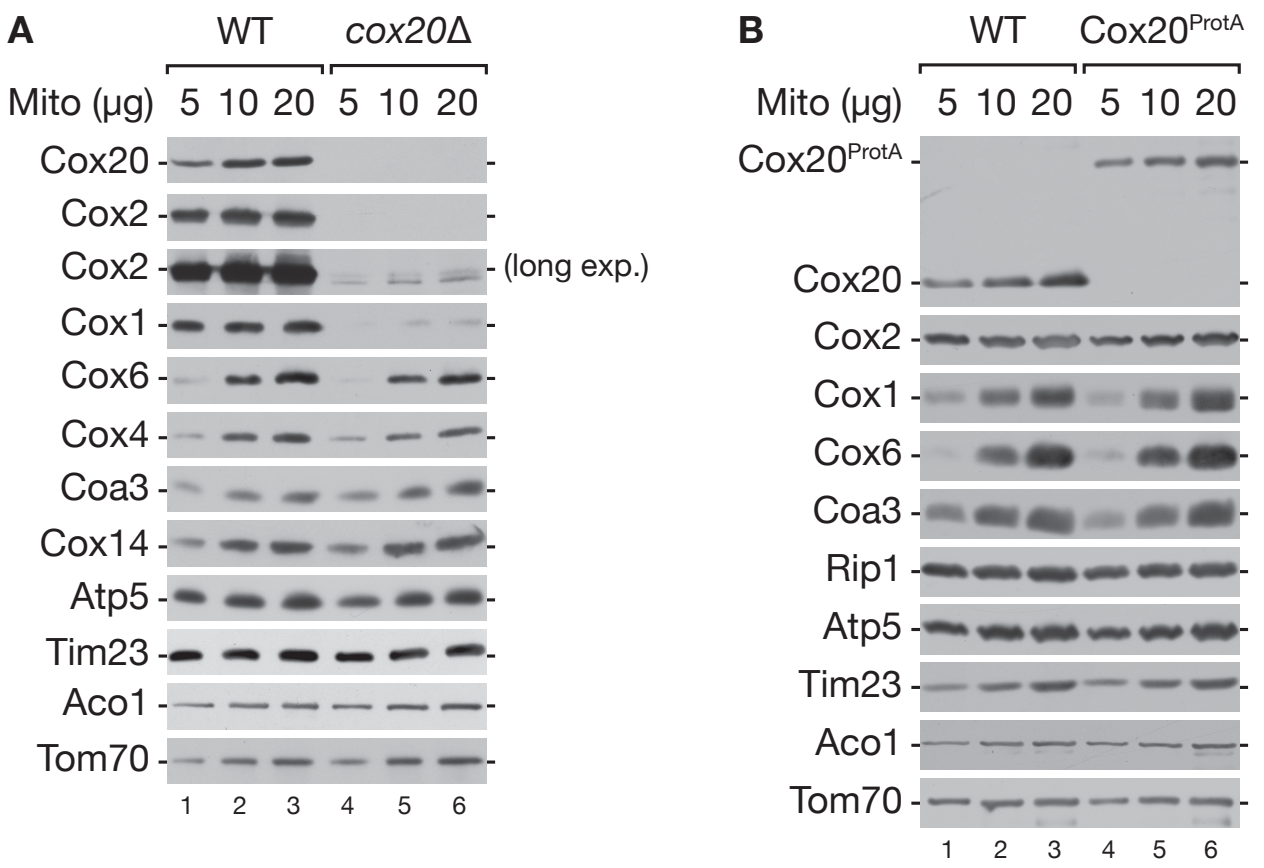

FIG 3.4 Analysis of protein steady state levels.

The indicated amounts of protein from WT, cox $20 \Delta$ (A) and Cox $20^{\text {ProtA }}$ (B) strains were separated by SDS-PAGE and analyzed by Western-blotting. 
The formation of mitochondrial respiratory chain complexes was analyzed using BN-PAGE (FIG 3.5 A and B). Mature cytochrome $c$ oxidase was not detected in the cox20 $\Delta$ strain (FIG $3.5 \mathrm{~A}$ ). As a consequence of the lack of mature cytochrome $c$ oxidase, the cytochrome $b c_{1}$ complex was not able to assemble into supercomplexes $\left(\mathrm{III}_{2} / \mathrm{IV}\right)$ and only its dimer form was detected using the Rip1 antibody. In addition, the Cox1 assembly factors Coa3 and Cox14 accumulate in the COA complex, which is an assembly intermediate involved in Cox1 biogenesis. In contrast to Coa3, Cox14 was also detected in a previously described complex termed $\mathrm{III}_{2} / \mathrm{IV}^{*}$ (Mick et al., 2007).

Instead, no significant difference was observed in the amount of complexes III and IV for Cox $20^{\text {ProtA }}$ mitochondria compared to wild-type. Furthermore, the amount of $\mathrm{F}_{1} \mathrm{~F}_{\mathrm{o}}$-ATPsynthase, detected using Atp5 antibody, was not affected in all three strains (FIG $3.5 \mathrm{~B}$ ).

In accordance with the growth analysis and the in organello labeling assay, the steady state analysis of tagged Cox20 revealed wild-type-like mitochondrial protein complexes. Hence, it can be concluded that $\operatorname{Cox} 20^{\text {ProtA }}$ is a functional protein. 

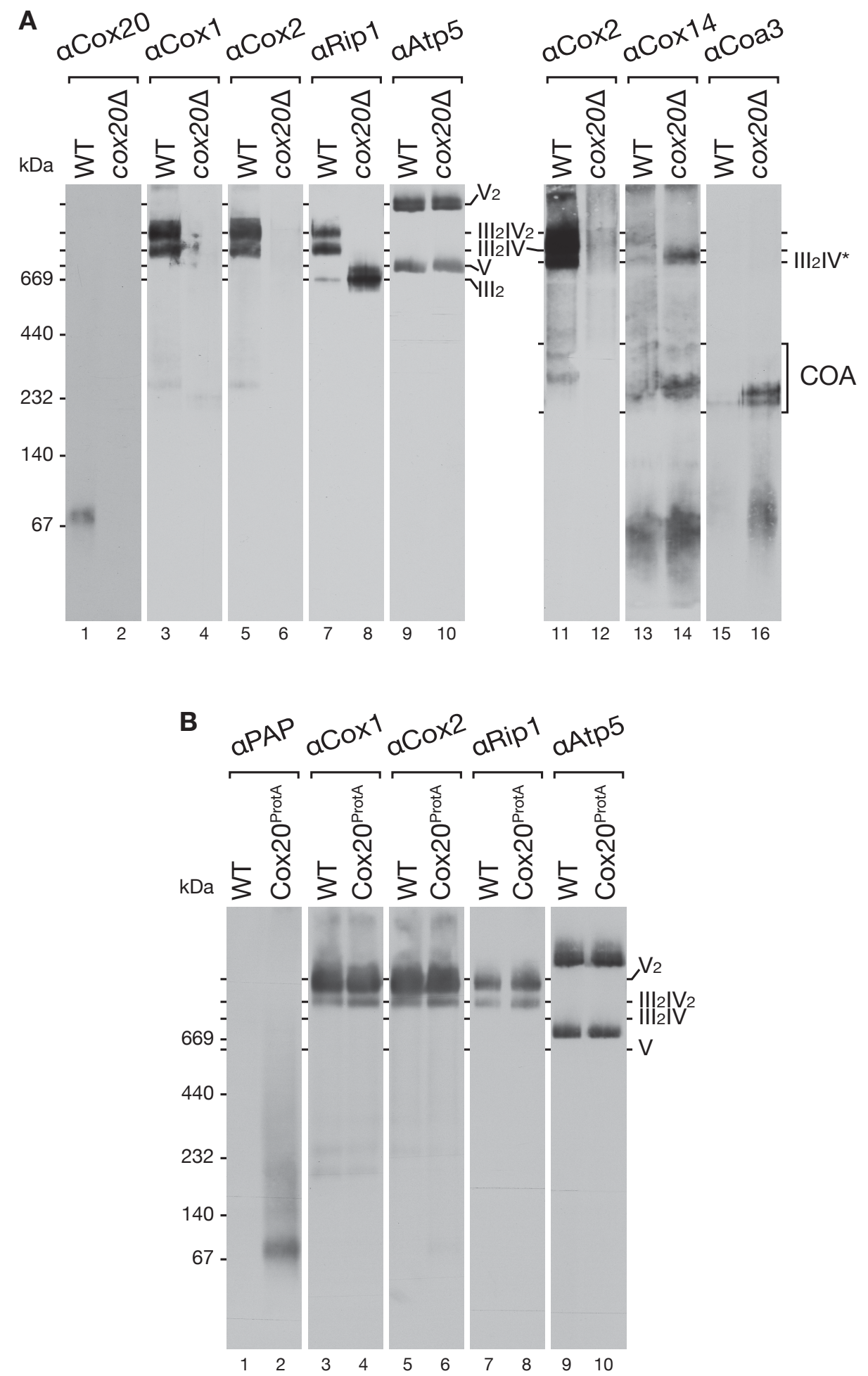

FIG 3.5 OXPHOS complex analysis.

Solubilized mitochondria from WT, cox20 $(\mathrm{A})$ and Cox $20^{\text {ProtA }}$ (B) strains were analyzed by BN-PAGE and Western-blotting for components of the $\mathrm{F}_{1} \mathrm{~F}_{\mathrm{o}}$ ATPsynthase (Atp5), the cytochrome $b c_{1}$ complex (Rip1), the cytochrome $c$ oxidase (Cox1 and Cox2) and for Protein A (PAP). 


\subsection{Biochemical analysis of Cox20-containing complexes}

\subsubsection{Endogenous Cox20 forms multiple complexes}

Since low molecular weight Cox20-containing complexes were detected by BN-PAGE (FIG 3.5 A lane 1 and 3.5 B lane 2), a comprehensive analysis of endogenous Cox20 assemblies was performed. While COA complexes (Mick et al., 2010), have been extensively characterized, it was assessed whether these intermediates co-migrate with Cox20 complexes.

Therefore, mitochondrial protein complexes from wild-type cells were solubilized in the mild detergent digitonin and separated by two-dimensional electrophoresis; BN-PAGE in the first dimension, followed by SDS-PAGE in the second dimension, and assessed by Western-blotting (FIG 3.6). Cox20 forms a trail of complexes with two prominent complexes in the low molecular range at $100 \mathrm{kDa}\left(\mathrm{Cox} 20^{100 \mathrm{kDa}}\right)$ and $65 \mathrm{kDa}\left(\mathrm{Cox} 20^{65 \mathrm{kDa}}\right)$ respectively, which are distinct from the COA complexes. These assembly intermediates are detectable as three main complexes, co-migrating with the core subunits, Cox1 and Cox2.

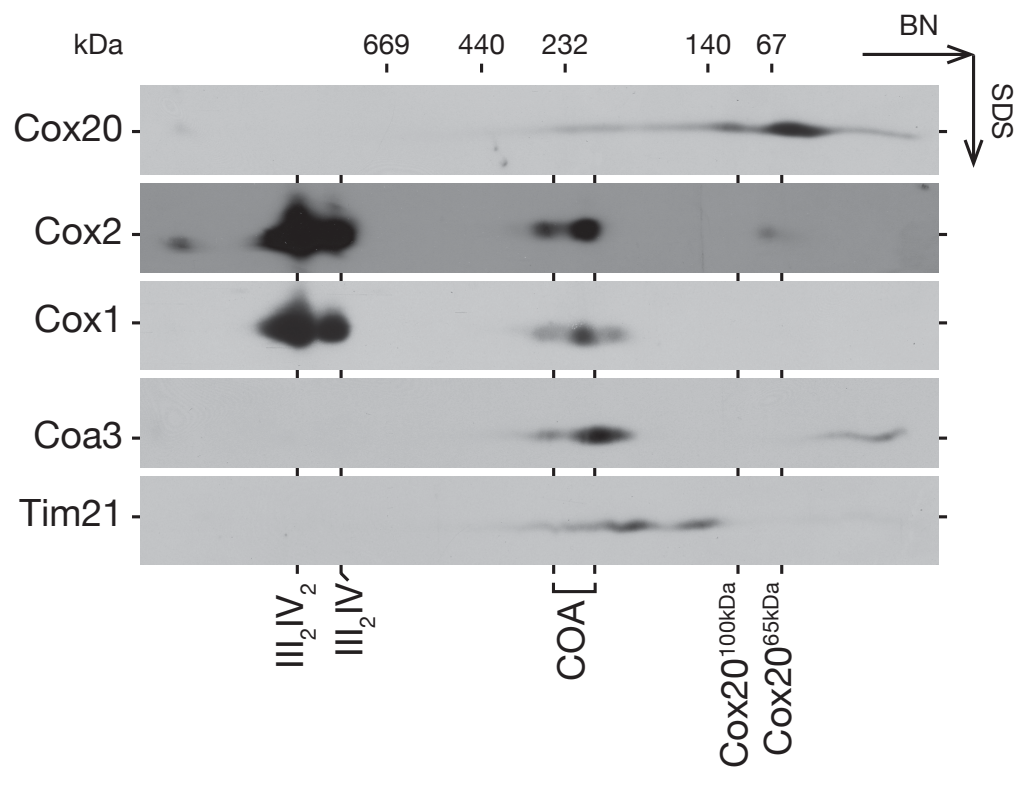

FIG 3.6 Second dimension analysis of Cox20 complexes.

Solubilized mitochondria were analyzed by BN-PAGE 4-13\% in the first dimension, followed by SDS-PAGE in the second dimension with subsequent Western-blotting using antibodies against Cox20, Tim21, Coa3 and components of complex IV (Cox1 and Cox2). 
To assess the composition of these protein complexes, the complexes were isolated in their native state from solubilized mitochondria using the Cox $20^{\text {ProtA }}$.

Afterwards, isolated proteins were cleaved natively from the column via TEV (Tobacco Etch Virus) protease treatment and analyzed by SDS-PAGE or BNPAGE, followed by Western-blotting. Wild-type mitochondria were used as a control.

This small-scale isolation of Cox $20^{\text {ProtA }}$ allowed efficient co-isolation of Cox2. After cleavage, due to the 7His linker between the TEV site and the protein, Cox20 migrates slightly higher than the endogenous form (FIG 3.7 A).

None of the tested structural subunits of the cytochrome $c$ oxidase, like Cox1, Cox4 and Cox6 were co-isolated with Cox20, supporting the hypothesis that Cox20 acts in the early steps of assembly of Cox2 (Hell et al., 2000). Moreover, nonspecific binding was not detected, as can be seen by the absence of interaction with control proteins like Tom70 and Tim17. Based on this successful approach, IgG chromatography on a large scale was performed and protein complexes were separated by BN-PAGE (FIG 3.7 B). Western blot analyses revealed purification of the Cox $20^{100 k \mathrm{ka}}$ and Cox $20^{65 \mathrm{kDa}}$ complexes, along with a trail of complexes as was shown before in the second dimension analysis (FIG 3.6). Both Cox $20^{100 \mathrm{kDa}}$ and Cox $20^{65 \mathrm{kDa}}$ isolated complexes appear to contain Cox2 (FIG 3.7 B), supporting the previously suggested Cox2chaperone function of Cox20 (Hell et al., 2000). 


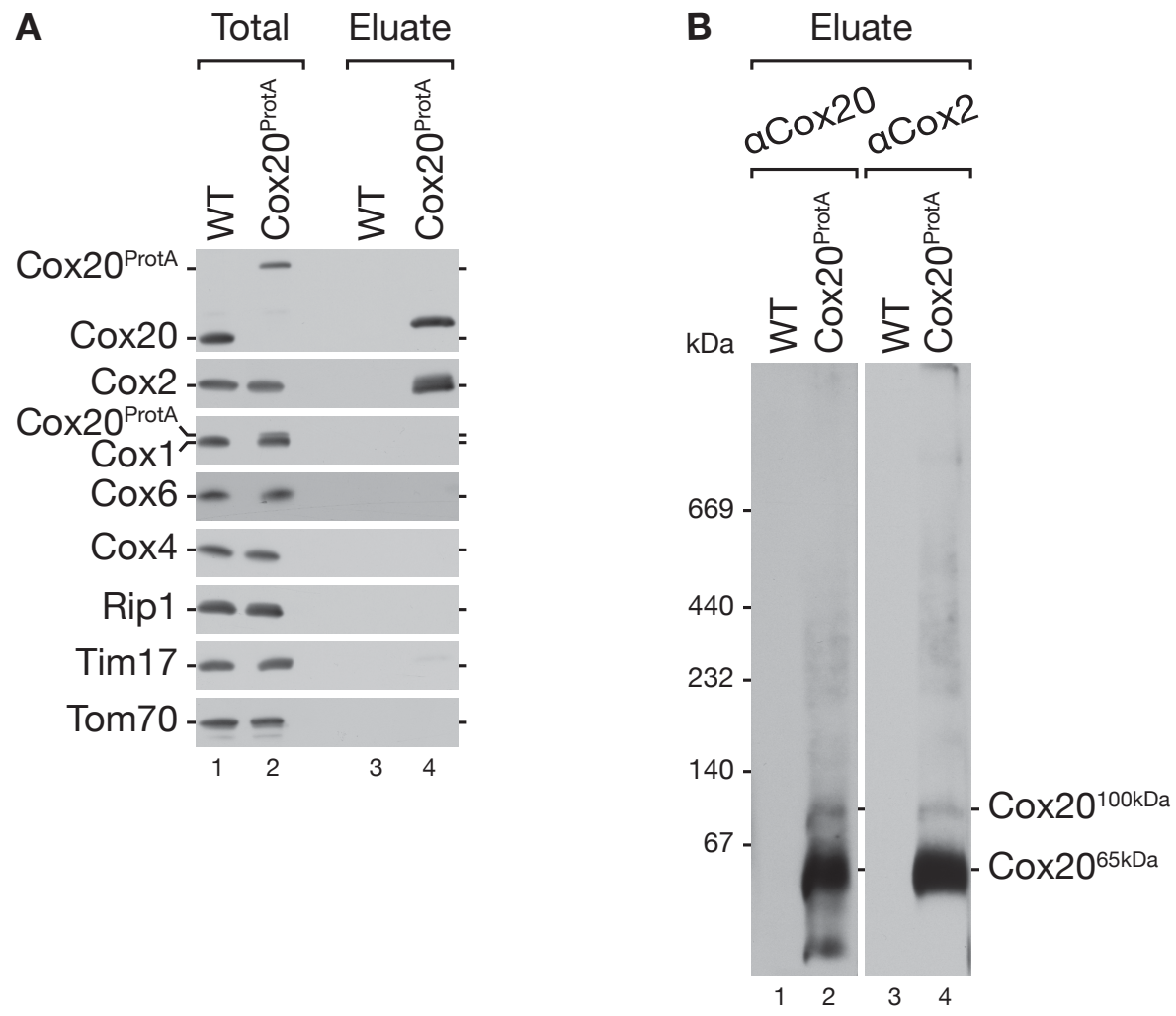

FIG 3.7 Isolation of Cox20 complexes.

Purified proteins from Cox $20^{\text {ProtA }}$ and wild-type were analyzed by SDS-PAGE (A) or BN-PAGE 4-13\% (B) and Western-blotting. Total 1\%, Eluate $100 \%$. 


\subsubsection{Cox20 interactome analysis by quantitative mass spectrometry}

The identification of several Cox20 complexes indicates the presence of additional physical interaction partners that have not been characterized. Therefore, to define the Cox20 interaction network, Cox20-containing complexes were isolated after metabolic labeling in culture (stable isotope labeling of amino acids in cell culture [SILAC]; (Ong et al., 2002) for characterization by quantitative mass spectrometry (FIG 3.8).
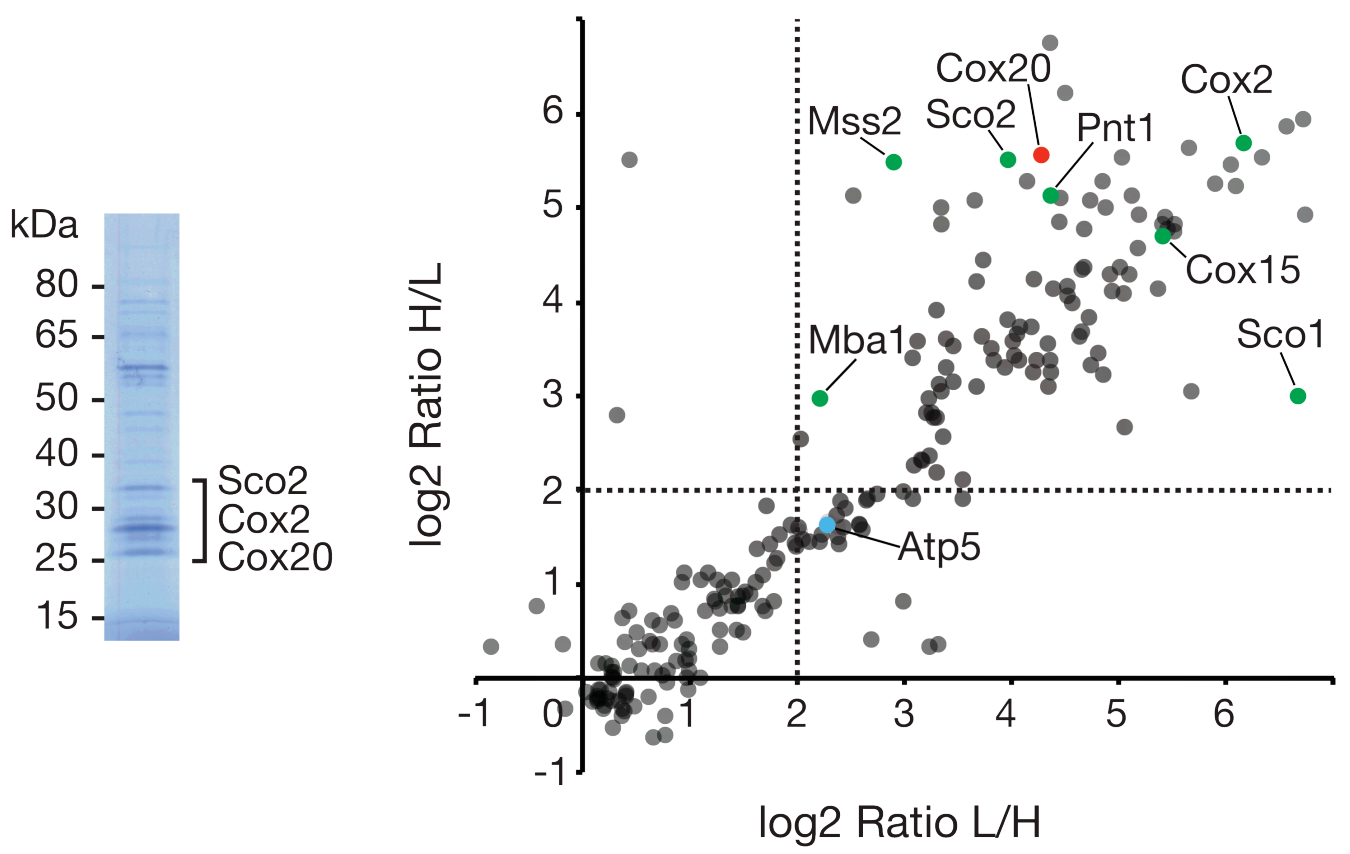

FIG 3.8 Quantitative mass spectrometric analysis of Cox $20^{\text {ProtA }}$ purified complexes after SILAC labeling.

Equal amounts of differentially labeled mitochondria (WT and Cox $20^{\text {Prota }}$ ) were pooled, solubilized and isolated via IgG chromatography, followed by TEV cleavage. Eluates were separated by SDS-PAGE and analyzed by LC-MS. Enriched proteins with a $\log 2$ ratio above 2 in the Cox $20^{\text {ProtA }}$ purification compared to control purification are indicated as potential interacting partners. Proteins displayed in green were confirmed by Western blot. As a negative control, Atp5 is displayed in blue. Cox20 is displayed in red. Other proteins are shown in grey. Mass spectrometry data analysis and visualization was performed in the Functional Proteomics group of Prof. Bettina Warscheid at the BIOSS Centre for Biological Signalling Studies (Institute for Biology II, University of Freiburg), mainly by Dr. Silke Oeljeklaus. 
Proteins that were enriched in the $\operatorname{Cox} 20^{\text {ProtA }}$ purification with a $\log 2$ ratio (Light/Heavy and Heavy/Light) above 2 were considered as candidates. Among the specific Cox20 interaction partners were proteins involved in Cox2 assembly, like Mss2, Pnt1, Sco2, Sco1 and the heme $a$ synthase Cox15.

Western blot analyses confirmed interactions with all previously mentioned proteins.

However, components of the mature cytochrome $c$ oxidase (Cox4, Cox5a, Cox6 and Cox13), as well as Cox1 assembly factors (Coa1, Shy1 and Mss51) and abundant proteins from complex III (Qcr8, Cyt1 and Rip1) were detected by mass spectrometry but could not be confirmed by Western-blotting (FIG 3.9 A and FIG $3.11 \mathrm{~A}$ ).

The identification of components of the Cox2 C-terminal translocation complex, like Mss2 and Pnt1, as well as Cox2, was anticipated and reflected a successful purification approach. In fact, the translocase Cox18 is known to interact with Mss2, Pnt1 and with Cox20 in a Cox2 dependent manner (Elliott et al., 2012). Nevertheless, Cox18 was not identified by mass spectrometry. Furthermore, Western blot analysis of Cox18 couldn't be performed because of the lack of a functional antibody, but $\operatorname{Cox} 18^{\text {ProtA }}$ isolation confirmed the interaction with Cox20 and Cox2 (FIG 3.9 B).

Interestingly, the mitochondrial ribosome binding protein Mba1, involved in co-translational membrane insertion (Preuss et al., 2001), was also detected as part of the Cox20 interactome and confirmed by Western-blotting.

Associations between components of the insertion machinery and Cox2 assembly factors have not been reported so far. However, the association between Cox18 and Mba1 was also tested but Mba1 was not detected in the eluate (FIG 3.9 B). These results support the hypothesis that Cox20 is a constituent of multiple complexes, one containing Cox18 which is distinct from the one containing Mba1. 


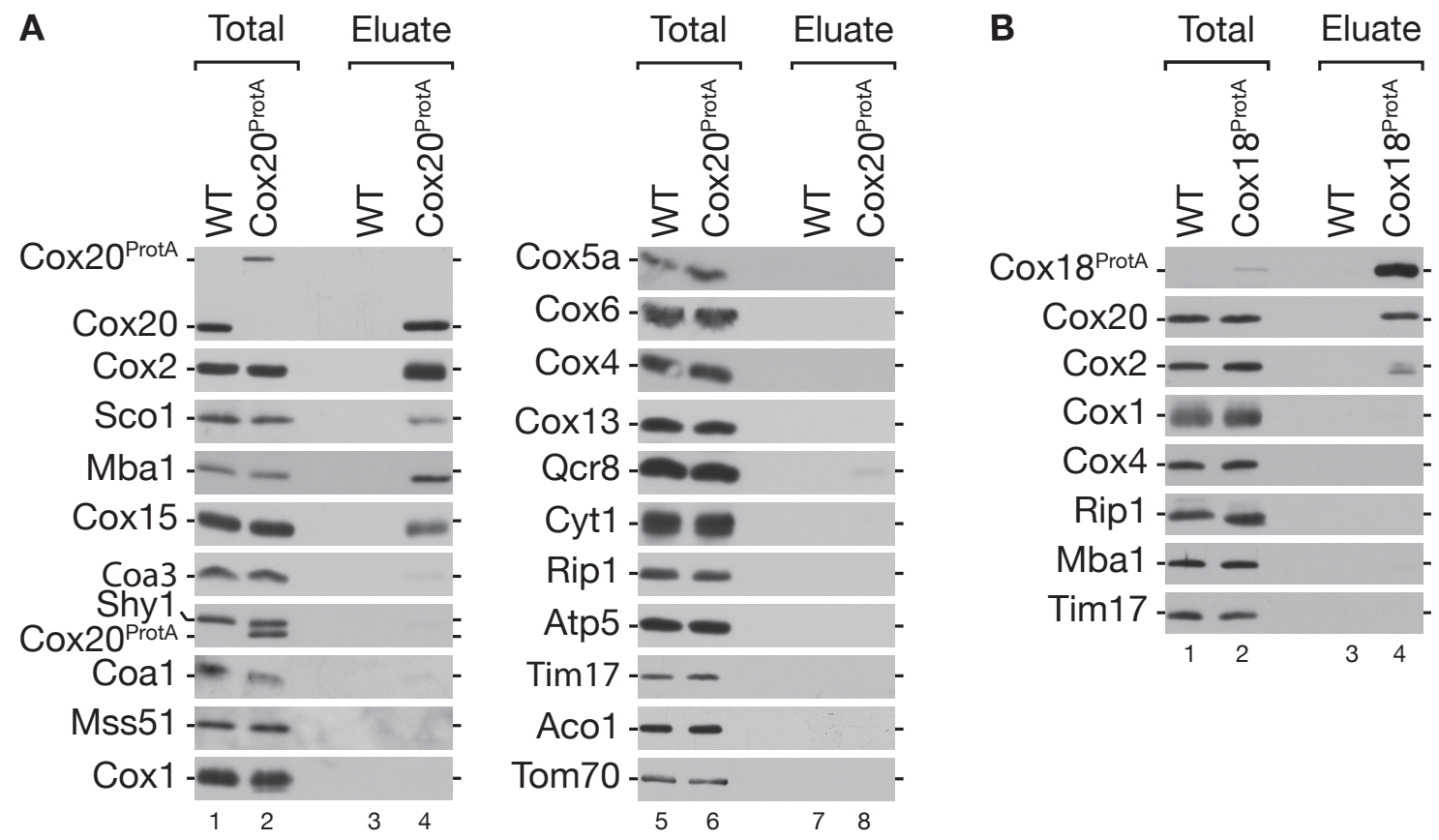

FIG 3.9 Confirmation of putative Cox20 and Cox18 interaction partners.

Solubilized mitochondria from wild-type, $\operatorname{Cox} 20^{\text {ProtA }}(\mathrm{A})$ and $\operatorname{Cox} 18^{\text {ProtA }}$ (B) were subjected to IgG chromatography. Samples were analyzed by SDS-PAGE and Western-blotting. Total, 1\%; Eluate 100\%. 


\subsubsection{BN-PAGE analysis of isolated SILAC labeled Cox20 complexes}

To evaluate the protein composition of the Cox20 assemblies, mass spectrometric analysis was performed on purified SILAC labeled Cox20 complexes after separation by BN-PAGE. Gel lanes containing the eluate were cut into 13 slices and subjected to in-gel trypsin digestion (FIG 3.10). The normalized abundance profiles for several proteins of interest that co-isolated with Cox 20 were calculated across the 13 gel slices.

The similarity of the Cox20 peptide profile with that of Cox2 indicates that all the isolated Cox20 complexes contain Cox2, sustaining the proposed Cox20chaperone function. This finding supports this experimental strategy to identify new associated proteins required for the early steps of Cox2 assembly via Cox20 isolation.

The Cox20 (bait) profile exhibited the highest peptide abundances in two main peaks (slice 6 and 11, FIG 3.10). The first peak, in the low molecular range, corresponds to the Cox $20^{65 \mathrm{kDa}}$ and Cox $20^{100 \mathrm{kDa}}$ complexes (gel slices 11 and 10 respectively, FIG 3.10). These two assemblies overlap in a single peak. Interestingly, Mba1 shows the highest intensity at the size of the Cox $20^{100 \mathrm{kDa}}$ complex. The second, larger peak (gel slice 6, FIG 3.10), at approximately 230 $\mathrm{kDa}$, contains components involved in the maturation of the C-terminus of Cox2, like Sco2, required for copper insertion, and Cox18, Pnt1 and Mss2, all of which have a role in Cox $2 \mathrm{C}$-terminal translocation. 
A
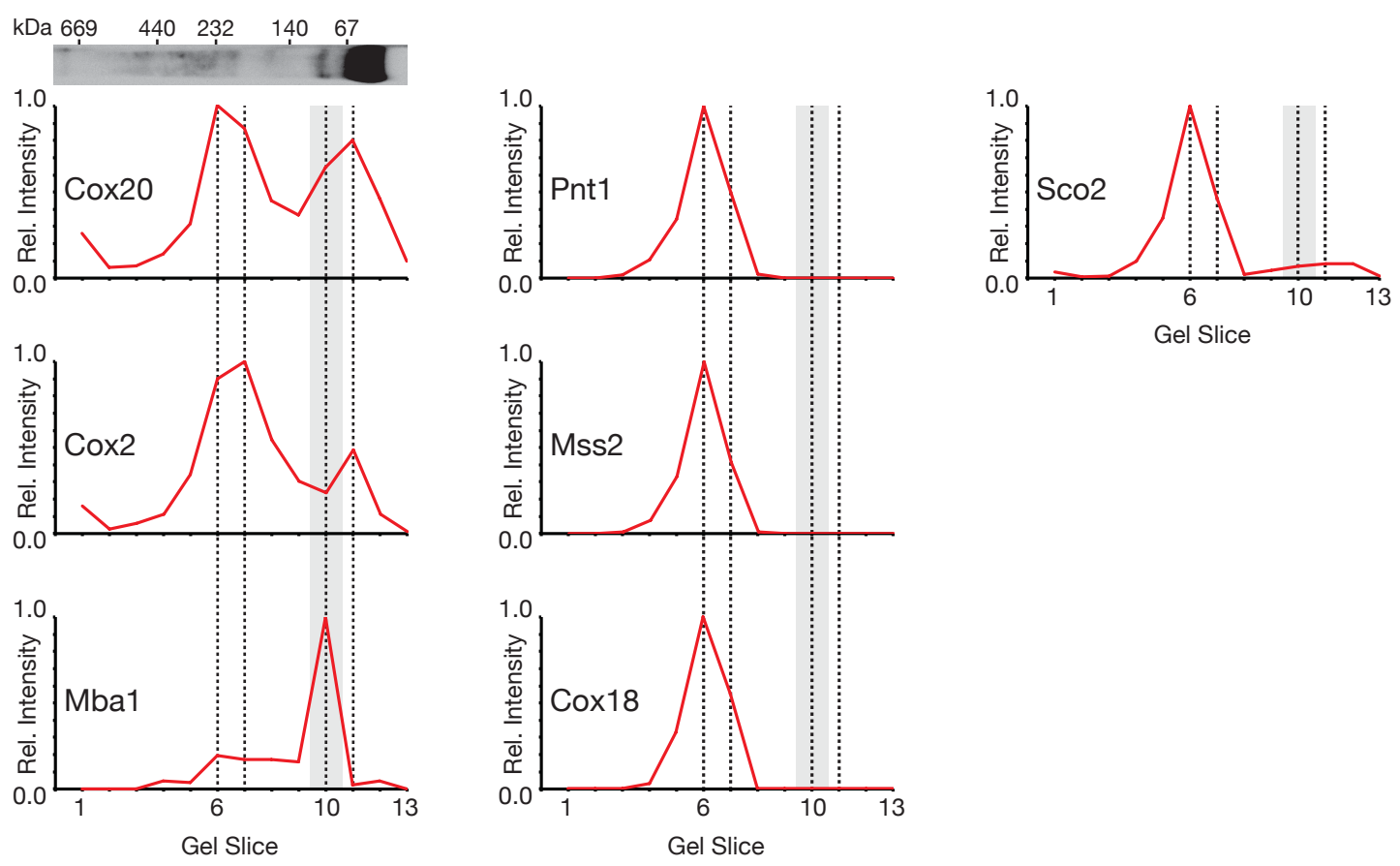

B
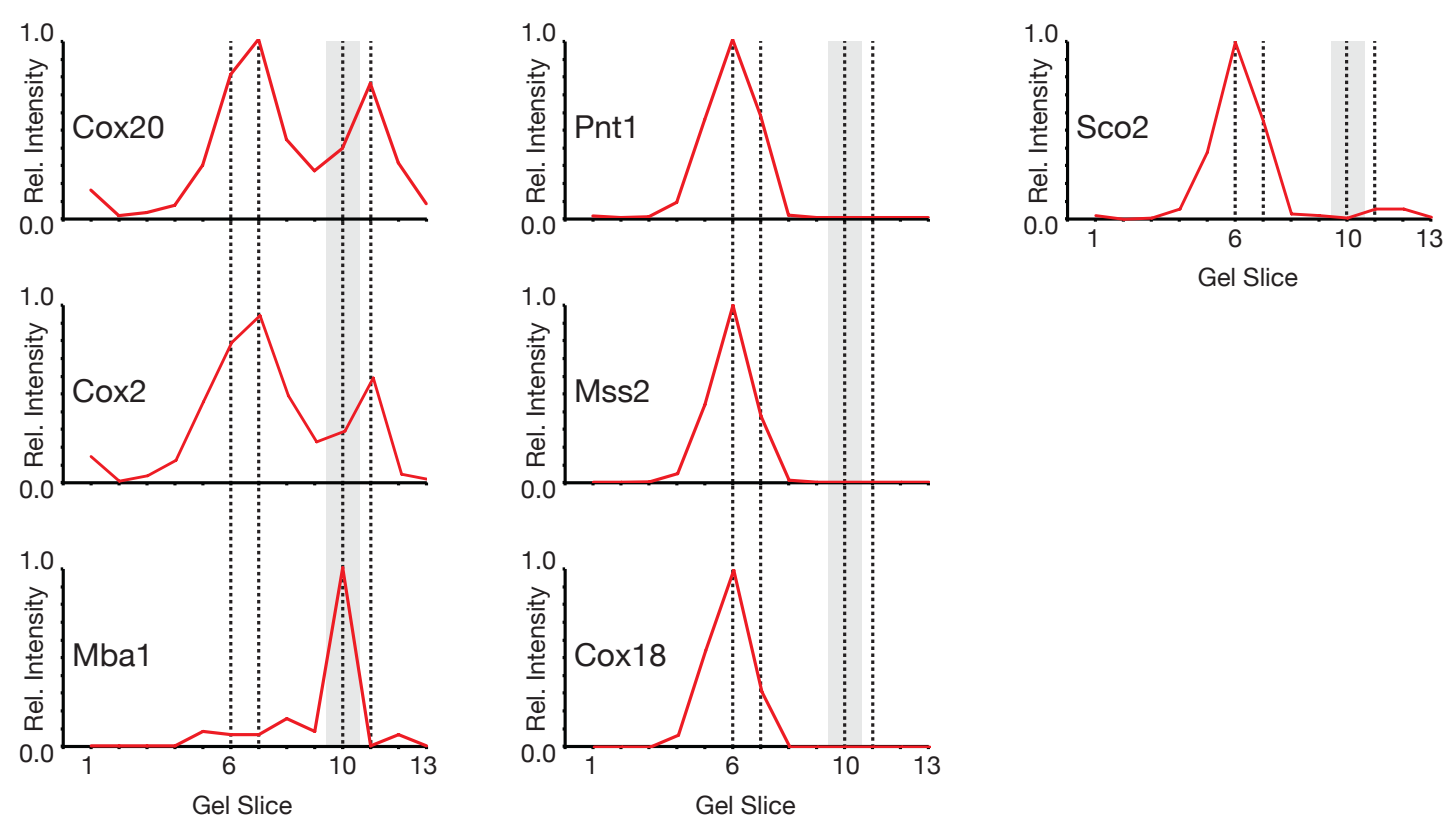

FIG 3.10 SILAC analysis of Cox20 protein complexes separated by BN-PAGE.

Eluates from FIG 3.8 were analyzed by BN-PAGE. Gel lanes were cut into 13 slices (1, top; 13 bottom) followed by LC-MS analysis. Peptide profiles of normalized proteins (relative intensity) co-isolated with Cox20 were plotted against the 13 gel slices. Gray box indicates the Cox $20^{100 k D a}$ complex. Dashed lines indicate gel fractions with the highest intensity peaks. The experiment was repeated with reverse labeling. Forward experiment: Cox $20^{\text {ProtA }}$ heavy labeled mitochondria were combined with light labeled wild-type mitochondria (A). Reverse experiment is shown in panel B.

Data analysis was performed as described in FIG 3.8. 
Consistently, Western blot analysis (FIG 3.11 A and B) confirmed the association of Cox20 and Cox18 with Mss2, Pnt1 and of Cox20 with Sco2. This supports the hypothesis that Cox20 forms multiple complexes with the translocation machinery (Cox18, Mss2 and Pnt1) and with the copperchaperones (Sco1 and Sco2). However, on BN-PAGE, mass spectrometry analysis did not detect a significant enrichment of Sco1 peptides, although the co-isolation of Sco1 with Cox20 was confirmed by Western blot analysis. The exposure of proteins to BN-PAGE may cause further dissociation of proteins from complexes, which can result in a loss of particularly labile proteins, This may be the case for Sco1.

To further sustain the association between Cox20 and Mba1, a C-terminal protein A-tag-encoding cassette was integrated into the chromosomal MBA1 locus for purification of Mba1-containing complexes. Mba1 was efficiently isolated from mitochondria. The Cox20 protein and a small amount of Cox2 were also recovered in the eluate of the Mba1 purification (FIG 3.11 A).

A comparison of the Cox20 and Mba1 isolations reveals different interaction networks along the Cox2 assembly line. Indeed, Mba1 displays association with components of the Cox2 C-terminal translocation machinery (Pnt1 and Mss2). This lack of interaction of Mba1 with Sco1 and Sco2 suggests a possible role for Mba1 before the $\mathrm{Cu}_{\mathrm{A}}$ site of Cox2 is formed. These results are in contrast to the interaction network of Cox20 where it associates with the copper chaperones, Sco1 and Sco2. 

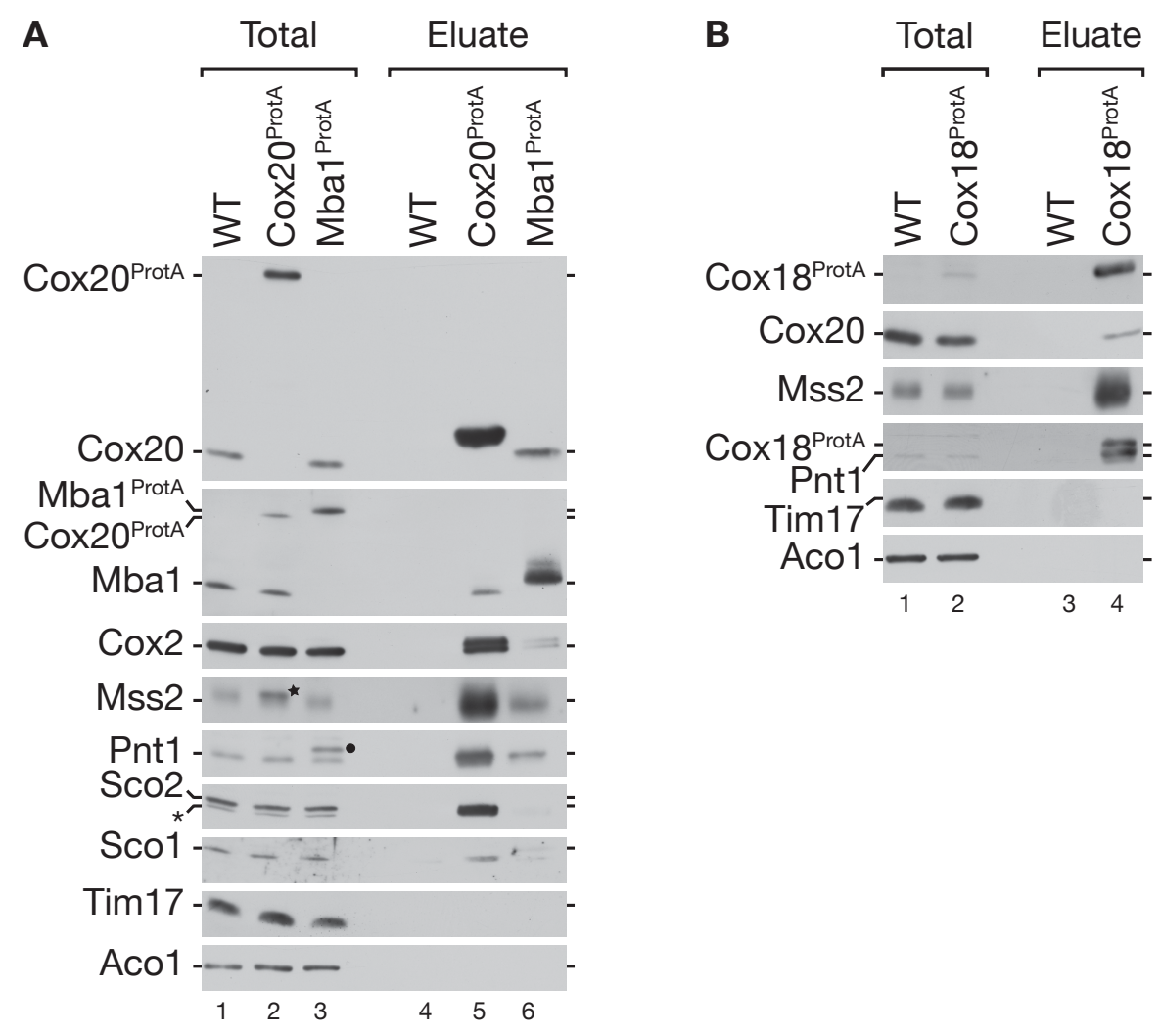

FIG 3.11 Isolation of protein complexes from the Cox $20^{\text {ProtA }}$, Mba1 $1^{\text {ProtA }}$ and Cox18 ${ }^{\text {ProtA }}$ strains. Protein complexes were purified via IgG chromatography from digitonin lysed mitochondria. The black dot indicates the Mba1 ${ }^{\text {ProtA }}$ signal and the black star indicates the Cox $20^{\text {ProtA }}$ signal. Total 1\%, Eluate $100 \%$.

To further investigate which of the low molecular range Cox20 complexes contain Mba1, BN-PAGE analysis of eluates from Mba1 ${ }^{\text {ProtA }}$ and Cox $20^{\text {ProtA }}$ isolations was carried out (FIG 3.12). Using an antibody against Cox20, it was possible to detect a prominent complex (lane 3, FIG 3.12), which runs at the same size as the complex containing Mba1 in the Cox20 isolation (lane 5, FIG 3.12). This complex corresponds to that previously seen on a 2D-PAGE analysis as the Cox $20^{100 k D a}$ complex (FIG 3.6). Cox2 was mainly detected in the Cox $20^{65 \mathrm{kDa}}$ complex and a shadow of Cox2 was visible in the range of the Cox $20^{100 k D a}$ complex via Cox20 isolation (lane 8, FIG 3.12). These results indicate a potential cooperation of Mba1 with Cox20 during Cox2 early maturation. 


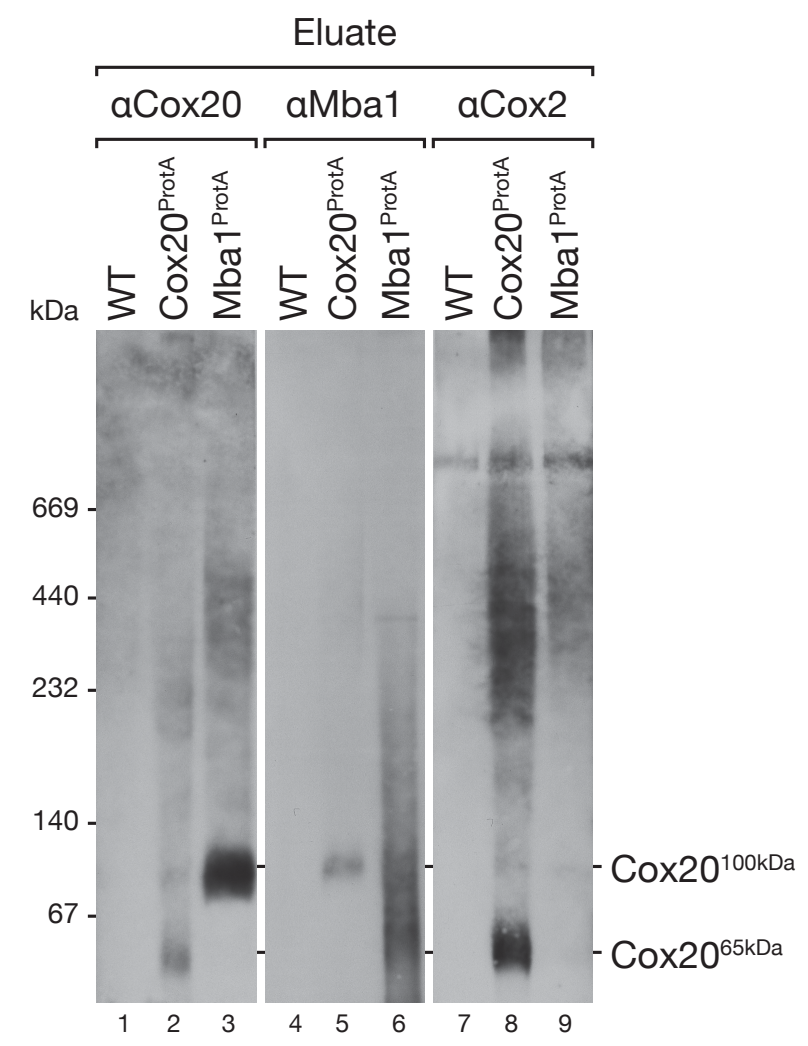

FIG 3.12 The Cox20 ${ }^{100 \mathrm{kDa}}$ complex contains Mba1.

Mitochondria were solubilized in buffer containing $1 \%$ digitonin and complexes were isolated via IgG chromatography. Afterwards, eluates were separated by BNPAGE and probed for Cox20, Mba1 and Cox2 containing complexes. Total 1\%, Eluate $100 \%$.

\subsection{The role of Mba1 in Cox2 synthesis and assembly}

\subsubsection{Cox20 interacts with mitochondrial ribosomes and Mba1}

The identification of Mba1 in the mass spectrometry analysis provides an interesting lead into a possible connection of Cox2 assembly to its translation. In the yeast $S$. cerevisiae, Mba1, has been implicated in the proper insertion of newly translated Cox2 into the mitochondrial inner membrane (Preuss et al., 2001; Ott et al., 2006). In addition, crosslinking experiments found Mba1 bound to mitochondrial ribosomes. Moreover, recent structural studies suggest that Mba1 is located next to the ribosomal exit tunnel (Pfeffer et al., 2015). 
Despite the finding that Cox20 associates with Mba1, no ribosomal proteins were significantly enriched in the SILAC labeled Cox20 purification. This was probably due to the presence of EDTA in the solubilization buffer, which disrupts ribosome structure by $\mathrm{Mg}^{2+}$ ion chelation. $\mathrm{Mg}^{2+}$ ions are required to stabilize RNA tertiary structures (Klein et al., 2004). To test this hypothesis, Cox $20^{\text {ProtA }}$ and $\mathrm{Mba}^{\text {ProtA }}$ isolations were performed in solubilization buffer with and without EDTA. Eluates were then probed against ribosomal proteins of the large and small subunits, Mrp14 and Mrp51 respectively. Consistent with the mass spectrometry data, none of the tested ribosomal subunits could be detected in the Cox20 eluate in the presence of EDTA (lane 8 FIG 3.13). In contrast, in the absence of EDTA, Cox20 and Mba1 co-isolate both Mrpl4 and Mrp51 (lane 11 and 12, FIG 3.13). It can therefore be concluded that Cox20 associates with the mitochondrial ribosome.

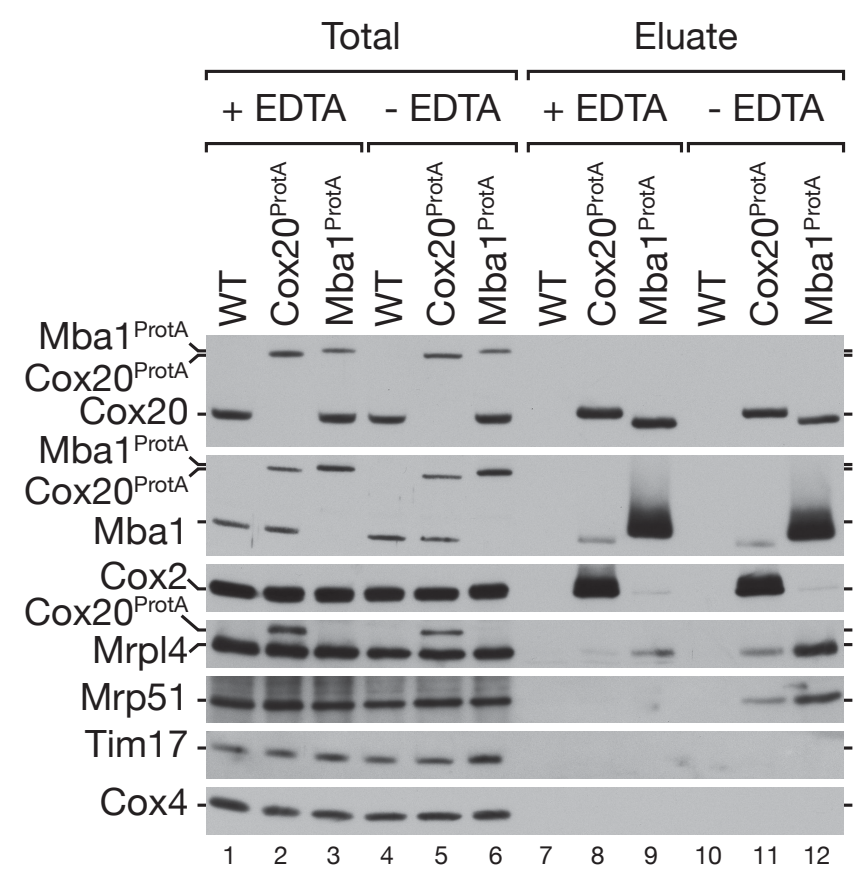

FIG 3.13 Cox20 association with the mitochondrial ribosome.

Affinity purification from digitonin solubilized wild-type, Cox $20^{\text {ProtA }}$ and Mba1 $1^{\text {ProtA }}$ mitochondria in the presence (+) or absence (-) of EDTA. Total 1\%, Eluate $100 \%$. 


\subsubsection{Mba1 binds newly synthesized Cox 2 in the absence of Cox20}

The identification of Cox20 and Mba1 in the same complex might indicate a cooperative function for both proteins in Cox 2 maturation. Hence, to address the role of Mba1 in the Cox20-Cox2 interaction, mitochondrial translation products were radioactively labeled and isolated via $\operatorname{Cox} 20^{\text {ProtA }}$ in the mba1s background (FIG 3.14). Cox20 co-isolates mature Cox2 in the wild-type background, but is also capable of binding unprocessed Cox2 (pCox2), as can been seen when comparing with the imp $1 \Delta$ strain (lane 6 and 7, FIG 3.14). Without Imp1, Cox 2 processing is prevented and pre-Cox2 accumulates, enabling its detection. In the absence of Mba1, no interaction of Cox20 with pre-Cox2 was detected (lane 8, FIG 3.14) although the amount of mature Cox2 and pre-Cox 2 are similar in the total sample (lane 4, FIG 3.14). This indicates that Mba1 is required for the association of Cox20 with pre-Cox2.

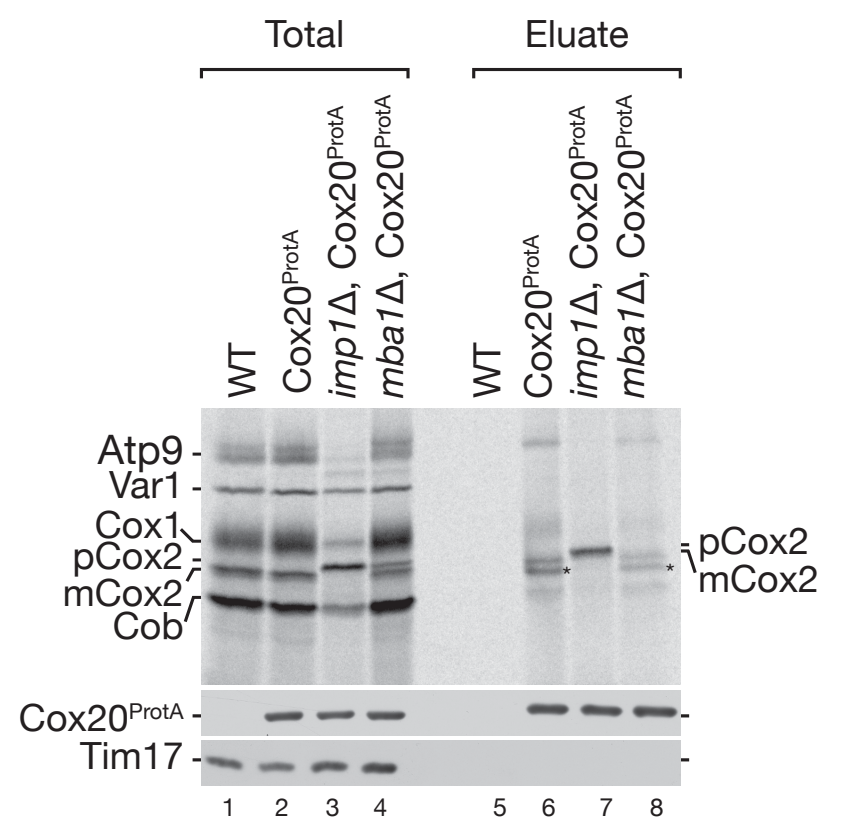

FIG 3.14 Mba1 is needed for the association of Cox20 with pre-Cox2.

IgG chromatography after in organello labeling of mitochondrial translation products. Samples were analyzed by SDS-PAGE and digital autoradiography or Western blot. Asterisk displays a Cox2 isoform. Total 10\%, Eluate 100\%. Precursor form of Cox2 is indicated as pCox 2 and the mature form of Cox2 is indicated as mCox2. 
To further investigate if Mba1 is necessary for the interaction of pre-Cox2 with other Cox2 assembly factors downstream of Cox20, an experiment with a similar setting as that previously described was conducted with the Cox $18^{\text {ProtA }}$ strain (FIG 3.15). In this case, the cox $20 \Delta$ strain, instead of $i m p 1 \Delta$, was used as a control for visualizing pre-Cox2. As expected, Cox $18^{\text {ProtA }}$ interacts with processed and unprocessed Cox2 in WT and cox20د respectively (FIG 3.15 lane 6 and 8). In accordance, Mba1 is needed for the interaction of pre-Cox2 with the Cox2 assembly factors Cox20, and the latter assembly factor Cox18.

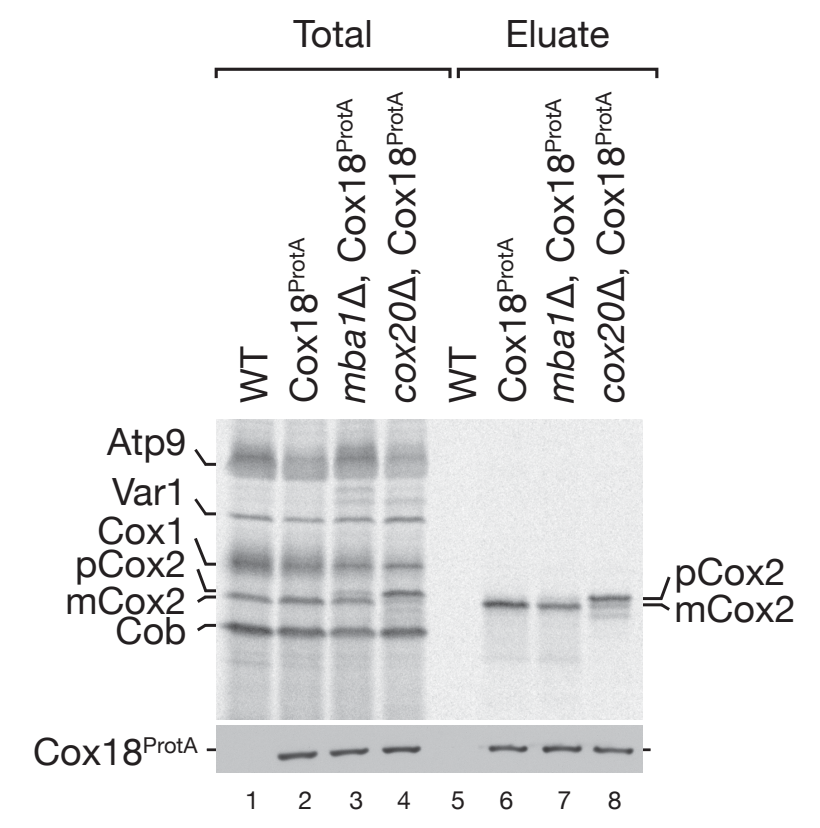

FIG 3.15 The Cox18-pre-Cox2 interaction requires Mba1.

IgG chromatography from solubilized mitochondria after in organello labeling of mitochondrial translation products. Samples from the indicated strains were analyzed by SDS-PAGE followed by digital autoradiography or Western-blotting. Total 10\%, Eluate $100 \%$. 
To address, if there is a reciprocal effect of Cox20 on the Mba1-Cox2 interaction, radiolabeled mitochondrial translational products were isolated via $\mathrm{Mba}^{\text {ProtA }}$ and Cox20 ${ }^{\text {ProtA }}$ in the respective mutants (FIG 3.16). Mba1 coisolated newly synthesized Cox2, both in the mature and precursor forms. However, this interaction was only detected in the absence of Cox20 (lanes 8 and 10, FIG 3.16). Although, it has been shown that Mba1 interacts with the ribosome, it was not possible to co-isolate any mitochondrial translational products with Mba1 in a wild-type background (lanes 8, FIG 3.16), possibly indicating a transient association of Mba1 with Cox2 in the presence of Cox20.

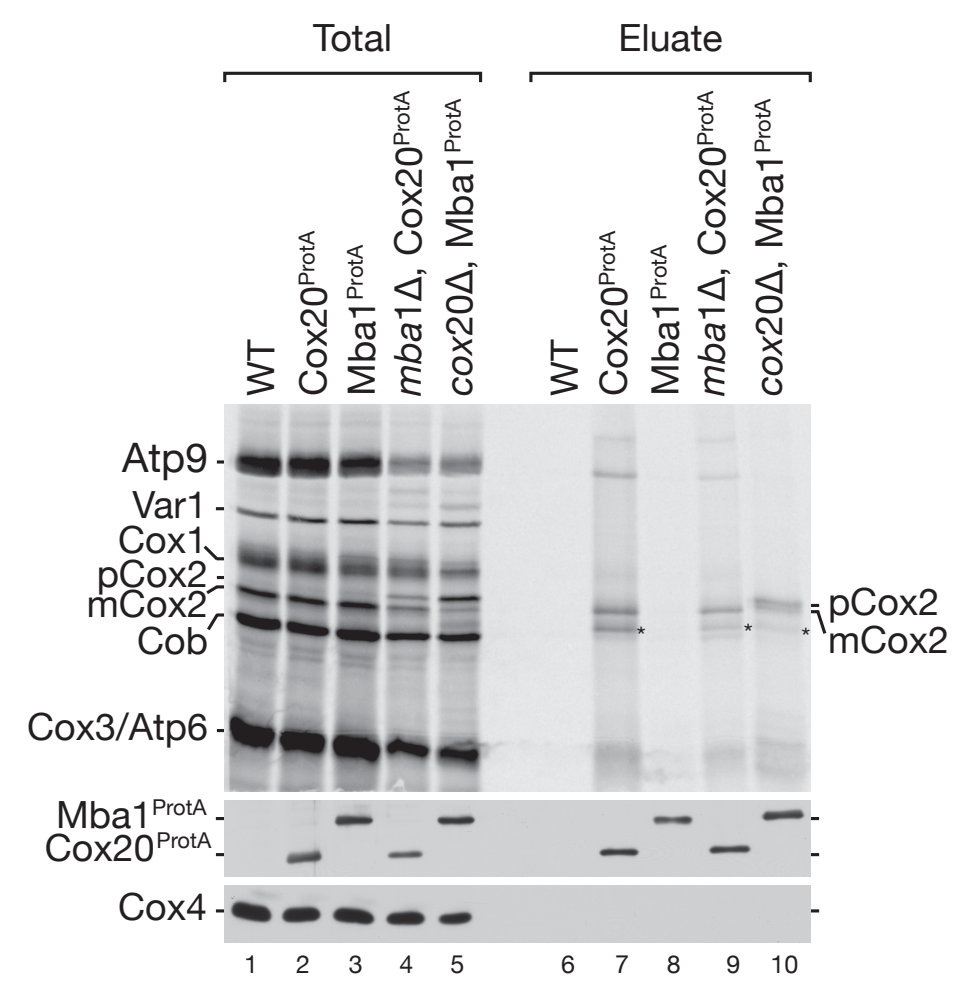

FIG 3.16 Mba1 associates with Cox2 in the absence of Cox20.

Affinity purification from digitonin solubilized mitochondria of the indicated strains after labeling of mitochondrial translation products. Samples were separated by SDSPAGE and analyzed by Western-blotting or digital autoradiography. Asterisk displays a Cox 2 isoform. Total 10\%, Eluate $100 \%$. 


\subsubsection{Mba1 and Cox20 interact during the early stages of Cox2 assembly}

To support the idea that the ribosome interaction with Cox20 occurs at an early stage following Cox 2 translation and is specific to Cox20, the association of the ribosomal proteins Mrp14 and Mrp51 with Cox18 was investigated. Cox18 is a protein that is suggested to act downstream of Cox20 in the assembly line. Because of the lack of an antibody against Cox18, the Cox18 protein cannot be detected when natively eluted using the TEV protease. During TEV cleavage, the TEV protease cleaves at a site between the Protein A tag and the C-terminus of Cox18. Therefore eluted Cox18 complexes no longer contain the Protein A tag, rendering the bait undetectable. To detect the Cox $18^{\text {ProtA }}$ bait, elution was carried out using 0.1M Glycin (Gly). In order to maintain comparable elution methods with $\mathrm{Mba}^{\text {ProtA }}$ isolation, elution was also performed using TEV protease. Cox $18^{\text {ProtA }}$ bound to IgG was split in two different columns and eluted with $0.1 \mathrm{M}$ Glycin (Gly) or natively via TEV cleavage (TEV). As expected, Cox20 was detected in all the elution fractions, but ribosomal proteins were detected only in the eluate from Mba1 purification (FIG 3.17). This sustains data from a previous publication by Preuss et al., indicating the lack of a C-terminal ribosome binding site on Cox18 (Preuss et al., 2005) and it can therefore be concluded that ribosome association is specific to the Cox20-Mba1 complex. 


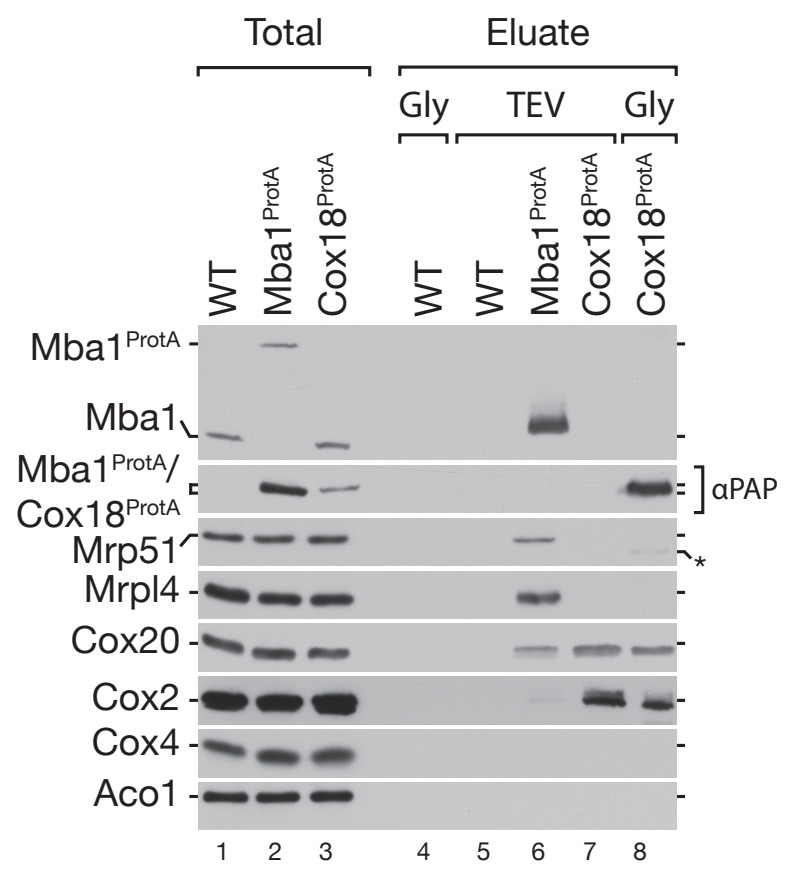

FIG 3.17 Comparison of $\mathrm{Mba1}^{\text {ProtA }}$ and $\operatorname{Cox}^{\text {ProtA }}$ isolation for ribosome association. Affinity isolation from the indicated strains. Bound proteins were eluted by acid $\mathrm{pH}$ using glycine (Gly) or by TEV cleavage (TEV). $\alpha$ PAP indicates anti-ProtA antibody and a cross-reaction is indicated with an asterisk. Total 1\%, Eluate, $100 \%$. 


\subsection{Characterization of the Cox20-Mba1 complex}

\subsubsection{Cox20 and Mba1 association is mitochondrial translation dependent}

Since Cox20 and Mba1 associate with the ribosome and newly synthesized Cox2, it is conceivable to investigate if the formation of this complex is linked to the presence of mitochondria-encoded proteins. Therefore, experiments in $r h o^{0}$ strains lacking mitochondrial DNA were carried out. In these samples, the association of Cox20 with Mba1 was not observed and vice versa (FIG 3.18).

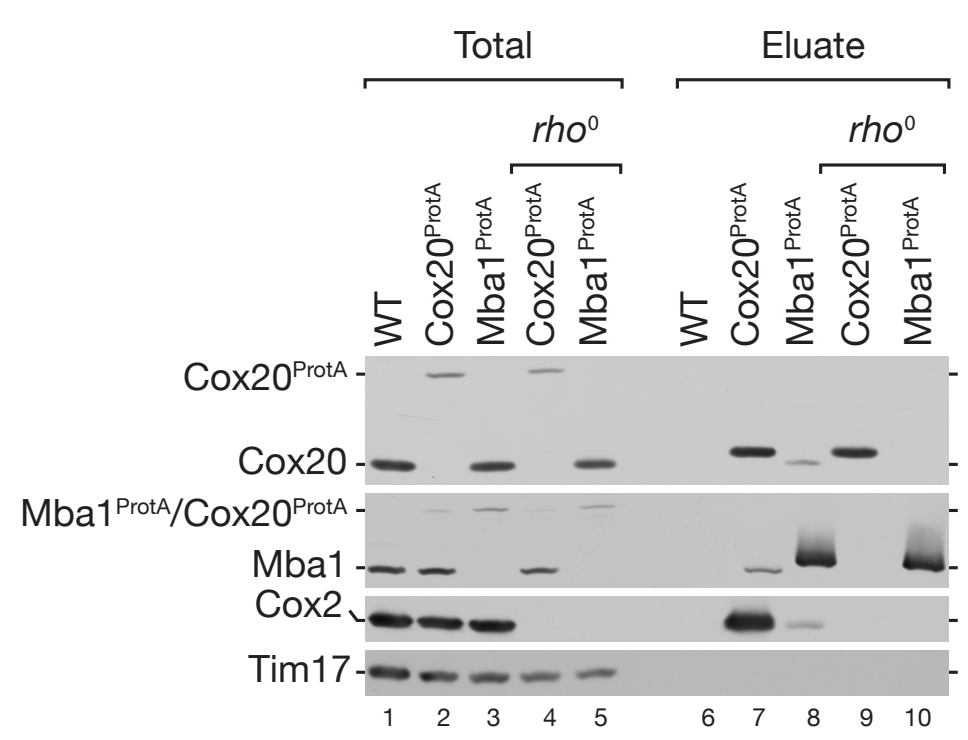

FIG 3.18 Interaction of Cox20 with Mba1 is mitochondrial DNA-dependent.

IgG chromatography was performed from solubilized mitochondria, purified from wild-type, tagged (Cox $20^{\text {ProtA }}$ and Mba1 ${ }^{\text {ProtA }}$ ) and rho strains. Total $1 \%$, Eluate, $100 \%$.

To see if the lack of interaction between Cox20 and Mba1 is linked to mitochondrial translation, solubilized mitochondria from cells treated with the mitochondrial translation inhibitor, chloramphenicol, were subjected to IgG chromatography (FIG 3.19). Compared to the untreated control, the coisolation of Cox20 with Mba1, and vice versa, was not detected following chloramphenicol treatment (lane 9 and 10, FIG 3.19). Moreover, the ribosome association was also affected. In the case of Mba1, ribosome association was reduced and with Cox20 it was absent. 
Thus, the reciprocal interaction of Cox20 with Mba1, as well as its association with the ribosome, appears to be stimulated by the active synthesis of polypeptide chains.

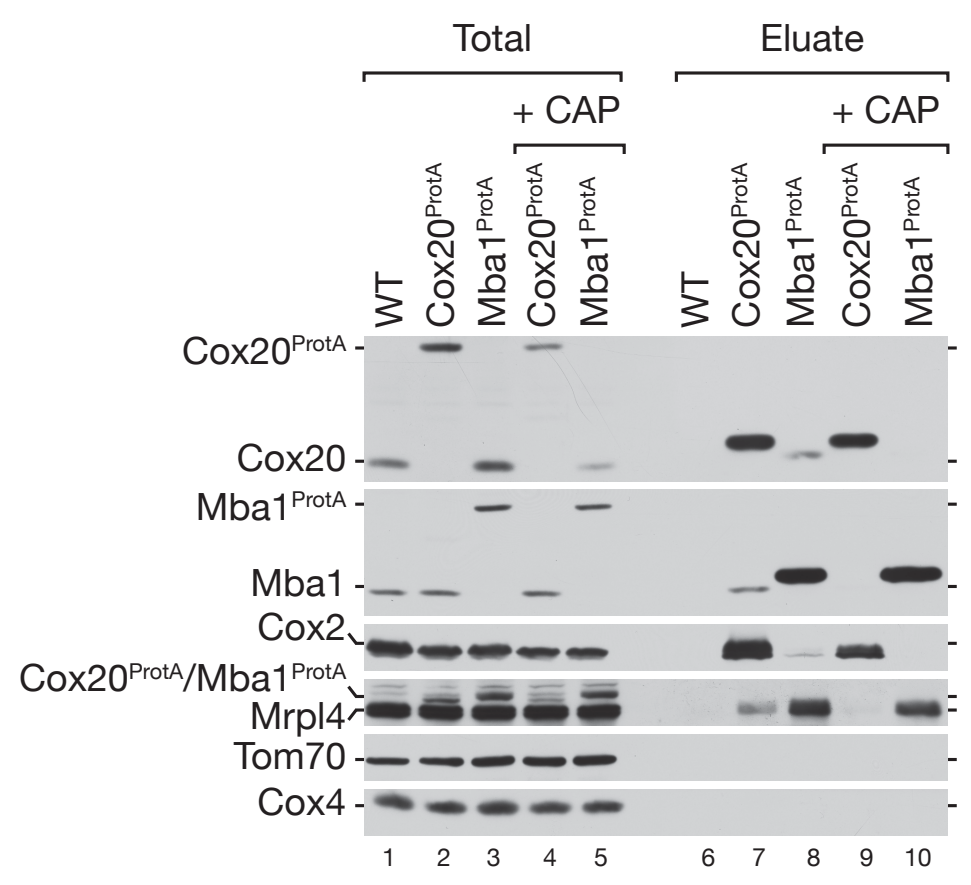

FIG 3.19 Affinity purification from the indicated strains treated with Chloramphenicol. Solubilized mitochondria from Chloramphenicol (CAP) treated cells (3 hours treatment) were subjected to IgG chromatography and analyzed by SDS-PAGE and Western-blotting. Total, 1\%; Eluate, $100 \%$. 


\subsubsection{Formation of the Cox20-Mba1 complex is Cox2 dependent}

Considering that the block in mitochondrial translation prevents the association of Cox20 with Mba1, it was further investigated whether this interaction specifically requires the translation of Cox2. Therefore, Cox $20^{\text {ProtA }}$ and $\mathrm{Mba}^{\text {ProtA }}$ were isolated from mitochondria of the pet111 $\Delta$ strain, which does not express Cox2 (FIG 3.20). Pet111 is a translational activator of Cox2, and acts on the 5 -Leader of COX2 mRNA to promote the translation of downstream coding sequences (Green-Willms et al., 2000).

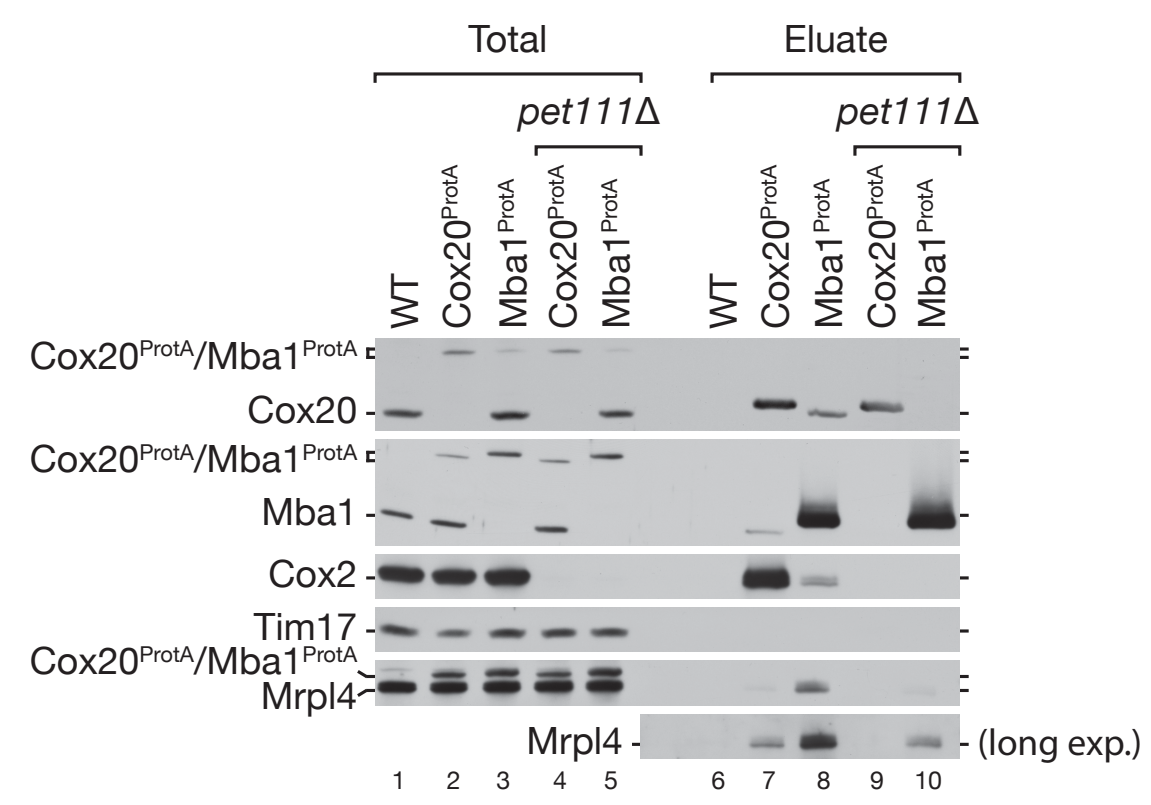

FIG 3.20 Cox2 is required for Cox20-Mba1 interaction.

Western blot analysis of digitonin solubilized protein complexes purified by $\operatorname{IgG}$ chromatography from mitochondria expressing $\mathrm{Cox} 2 \mathrm{O}^{\text {ProtA }}$ and $\mathrm{Mba1}^{\text {ProtA }}$, respectively in both wild-type and pet111 $\Delta$ backgrounds. Total, 1\%; Eluate, $100 \%$.

In the pet111 mutant, Cox20 does not interact with Mba1 and vice versa (lane 9 and 10, FIG 3.20). In addition, in the pet111 $\Delta$ strain the interaction between the ribosome and Cox20 is absent and in the case of Mba1, it is reduced. These results are in line with the previous ones (FIG 3.19) and possibly indicate that ribosomes actively translating Cox2 are necessary for the association of Cox20 with Mba1. Previous results demonstrated that the interaction between Cox20 and mature Cox2 is independent of Mba1 (lane 9, FIG 3.16). These finding are supported by the absence of interaction between Cox20 and Mba1, although Cox2 is still associated to Cox20 (lane 9, FIG 3.19). 


\subsubsection{Cox20 associates with the ribosome in an Mba1 independent manner}

Considering the absence of interaction of Cox20 with both the ribosome and Mba1 in the pet111 strain, it is plausible that Cox20 associates with ribosomes via Mba1. In order to test this, Cox $20^{\text {ProtA }}$ isolated from an mba1 $\Delta$ background was probed for ribosomal proteins. As shown in FIG. 3.21, compared to $\operatorname{Cox} 20^{\text {ProtA }}$ in a wild-type background, $\operatorname{Cox} 20^{\text {ProtA }}$ was equally associated to ribosomes in the absence of Mba1 (lane 7 and 9, FIG 3.21). In contrast, Mba1 ${ }^{\text {ProtA }}$ co-isolated less ribosome in the absence of Cox20, compared with the wild-type background, although more Cox2 was found to accumulate (lane 8 and 10, FIG 3.21). In summary, Cox20 binds mitochondrial ribosomes independently of Mba1. Moreover, a decrease in the amount of ribosomes co-isolated with Mba1 in the cox 20د strain could indicate that Cox2 assembly defects stall Mba1 with unassembled Cox2, reducing its interaction with the ribosome.

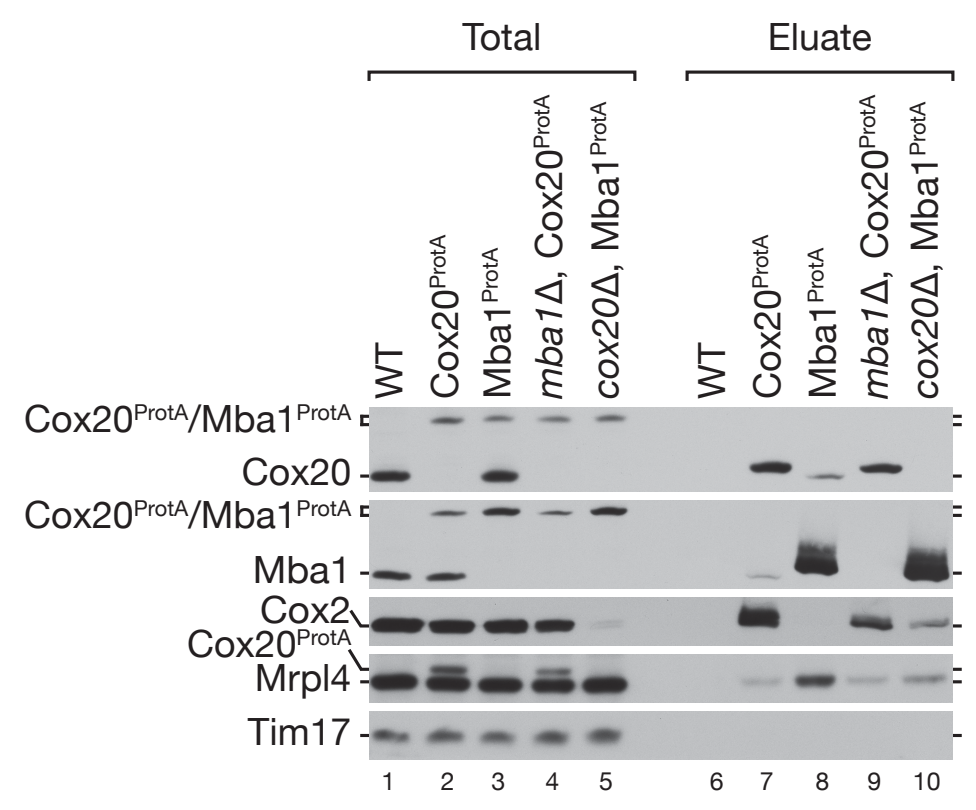

FIG 3.21 Protein complex purification via IgG chromatography.

Affinity purification from solubilized mitochondria of the indicated strains was analyzed by SDS-PAGE, followed by Western-blotting. Total 1\%, Eluate, $100 \%$. 


\subsubsection{Cox2 assembly defects results in a reduction of the Mba1- ribosome interaction}

To test, if association of Mba1 with premature Cox2 was caused by a block in Cox2 assembly due to the absence of Cox20, or by general defects in Cox2 biogenesis, Mba1 ${ }^{\text {ProtA }}$ isolation was performed in the cox18 $\Delta$ background. In this strain, translocation of the C-terminus of Cox2 is impaired and the interaction with the ribosome has been excluded (FIG 3.22 A). In this case, the presence of components of the small mitochondrial ribosomal subunit, like Mrp51, was additionally tested. Compared to Mba1 ${ }^{\text {ProtA }}$ in the wild-type

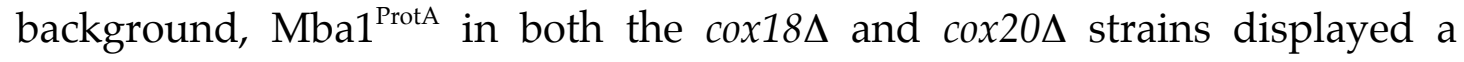
decreased association with the ribosome. This finding supports the initial hypothesis suggesting that the reduced interaction of Mba1 with ribosomal proteins is not Cox20 specific, but rather occurs due to a defect in Cox2 maturation. Another argument in favor of this hypothesis is that Mba1 accumulates in distinct Cox2 complexes depending at which stage the Cox2 assembly line is blocked. For example, the accumulation of Mba1 with Cox20 in the cox18 $\Delta$ strain (lane 8, FIG 3.22 A) and the accumulation of Mba1 with Pnt1 and Mss2, components of the C-terminal translocation complex of Cox2, in the cox20 $\Delta$ strain (lane 7, FIG 3.22 A; lane 9, FIG 3.22 B).

Other mutants of the Cox2-assembly line were also tested for similar effects (FIG 3.22 B). The pnt1 and mss2 null mutants revealed a comparable phenotype to the cox18 strain. Indeed, both display an accumulation of Cox2 with Mba1. In contrast to the cox20 mutant, co-isolation of Mss2 or Pnt1 proteins with Mba1 could not be observed. This leads to the hypothesis that the expression or stability of these two proteins is linked.

Reverse experiments using the Cox $20^{\text {ProtA }}$ strain confirmed the previously observed accumulation of Mba1 with Cox20 in mutant strains of the Cterminal translocation complex (FIG 3.23).

Collectively, these analyses show that Mba1 shuttles between the insertion machinery and Cox 2 assembly intermediates in a process that promotes Cox 2 maturation. 

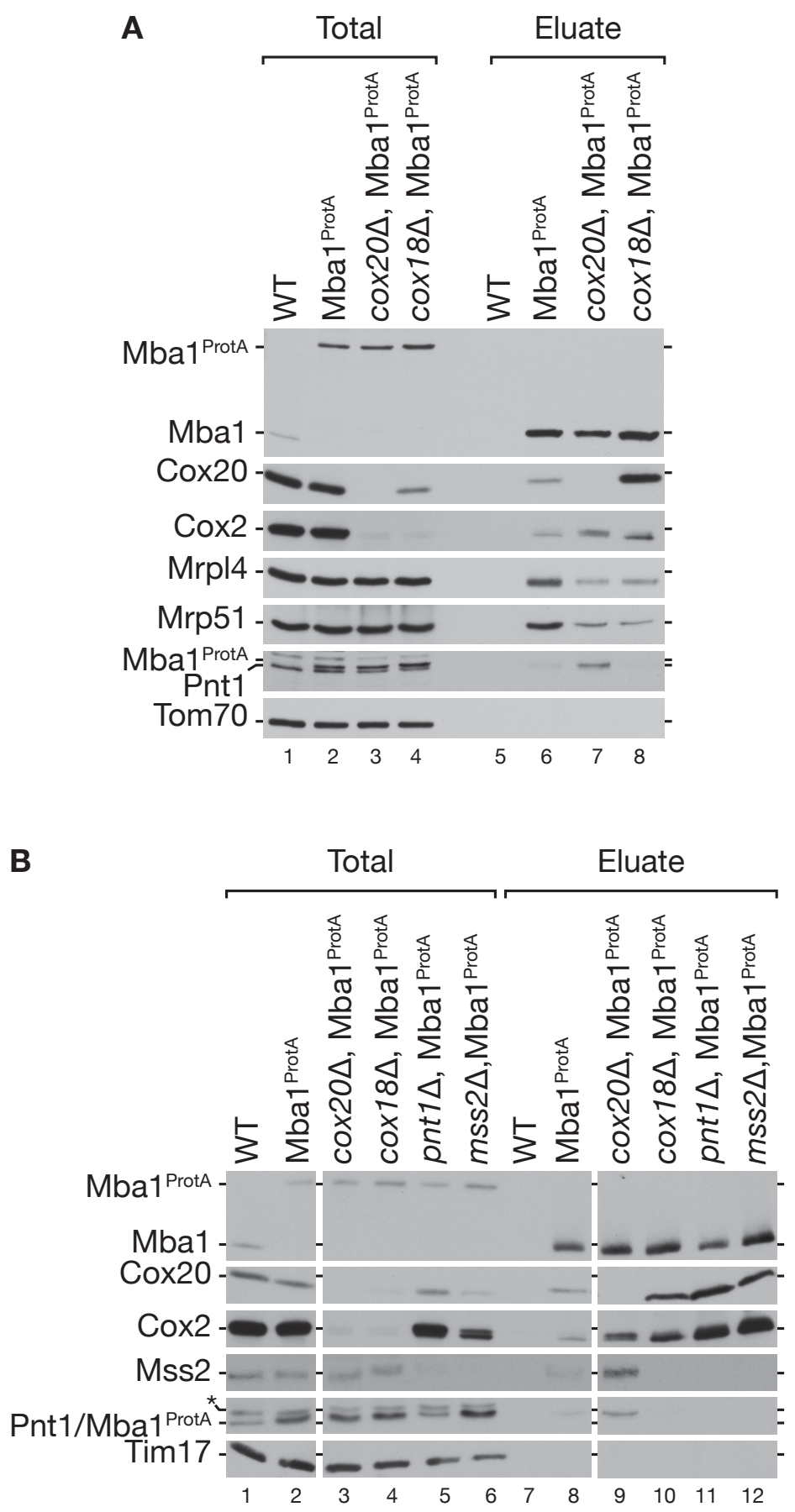

FIG 3.22 Isolation of $\mathrm{Mba1}^{\text {ProtA }}$ in wild-type and mutants background via IgG chromatography. Mitochodria from the indicated strains were solubilized in buffer containing $1 \%$ digitonin and protein complexes were isolated via IgG chromatography. Eluates were separated by SDS-PAGE and analyzed by Westernblotting. Results for the pnt1 $\Delta$ and mss2 $\Delta$ strains are indicated in panel B. Total samples correspond to $1 \%$ of the elution. Asterisk indicates cross-reaction of the antibody. 


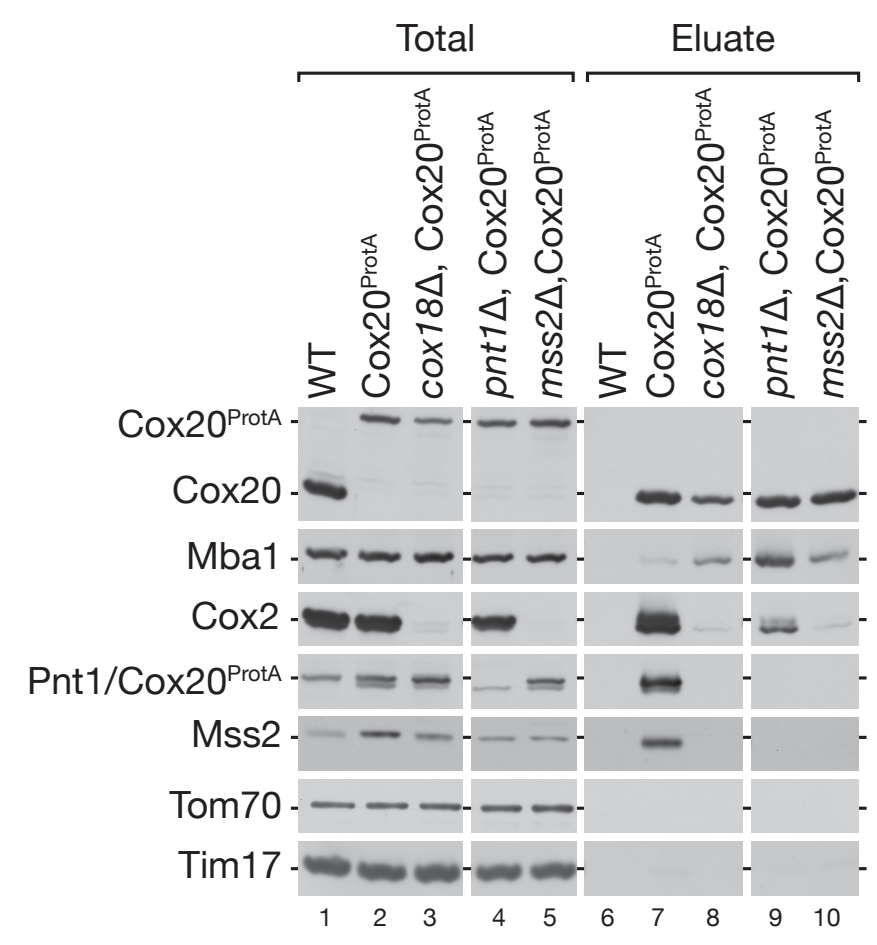

FIG 3.23 Cox $20^{\text {ProtA }}$ isolations in mutants of the Cox 2 assembly line.

Protein complexes were isolated via affinity purification from solubilized mitochondria of the indicated strains. Eluates were separated on SDS-PAGE and analyzed by Western-blotting. Total 1\%, Eluate, $100 \%$. 


\section{DISCUSSION}

\subsection{Identification of novel Cox20 complexes}

A plethora of assembly factors are involved in the biogenesis of the cytochrome $c$ oxidase. Defects in this process cause enzymatic deficiency and lead to severe human disorders. Cox2 is one of the core subunits of complex IV and is strictly required for the process of electron transfer.

Formerly, it has been demonstrated that the assembly factor Cox20 is required for Cox2 biogenesis (Elliott et al., 2012; Hell et al., 2000).

The purpose of this study was to gain new insights into Cox20 function during Cox 2 maturation. Previous reports focused on single interaction studies without providing full information on the Cox20 interaction network. In this work, a quantitative proteomic approach was taken in order to detect novel Cox20 interaction partners in an unbiased manner.

Cox20 has been postulated as "the chaperone of Cox2" (Elliott et al., 2012). Indeed, studies on cox4 and imp1 null mutants, which stall Cox2 in the early steps of cytochrome $c$ oxidase assembly, have revealed that the majority of Cox2 is bound to Cox20 (Hell et al., 2000). In addition, further evidence shows that Cox20 binds to the newly synthesized Cox2 (Keil et al., 2012). The finding of this thesis that all detected Cox20 complexes contain Cox2 is in accordance with previously published data and supports the proposed Cox2 chaperone function of Cox20.

BN-PAGE analysis of Cox20-containing complexes revealed three main assemblies, the Cox $20^{65 \mathrm{kDa}}$ complex, the Cox $20^{100 \mathrm{kDa}}$ complex and a trail of complexes, which run at approximately $230 \mathrm{kDa}$. Although all of these assemblies contain Cox2, the complexes at $230 \mathrm{kDa}$ and the Cox $20^{100 \mathrm{kDa}}$ complex additionally comprise of proteins with distinct functions, like those involved in Cox2-C-terminal maturation and co-translational insertion respectively (Hell et al., 2001; Preuss et al., 2001; Souza, 2000).

Early Cox2 assembly factors, such as Cox18, Mss2, Pnt1 and Sco2 were found in the complexes at $230 \mathrm{kDa}$. Co-isolation of the translocase Cox18 with Mss2 and Pnt1 confirms this previously suggested physical interaction and hints at the involvement of these three proteins in the translocation of the Cox2 Cterminal domain as a unique translocation complex (Broadley et al., 2001; He and Fox, 1999; Saracco and Fox, 2002). 
Indeed, the expression and stability of these three proteins are strictly connected.

Deletion of COX18 leads to a lack of association between Mba1 and / or Cox20 and Mss2 and Pnt1, suggesting a potential role for Cox18 in acting as a bridge between these interactions. In addition, null mutations in the PNT1 gene cause instability or lack of expression of Mss2. On the other hand, in the mss2 $2 \Delta$ strain, Cox18 and Pnt1 do not associate, again indicating a strict regulation in the assembly and stability of the C-terminal translocation complex (Saracco and Fox, 2002).

Although Cox20 has previously been found to associate with the Cox2 Cterminal translocase Cox18 (Elliott et al., 2012), this is the first report of Cox20 association with Mss2, Pnt1 and Sco2, indicating involvement of Cox20 in several steps of Cox 2 maturation, from Cox2 translocation until copper insertion (Cobine et al., 2004; Lode et al., 2002; Nittis, 2001; Rigby et al., 2008). Cytochrome $c$ oxidase assembles in a sequential manner whereby the mitochondria-encoded subunits Cox1 and Cox2 are integrated via separate assembly lines (Mick et al., 2011). It is currently unknown whether they share assembly factors. In the proteomic analysis carried out in this work, there was no interaction observed between Cox20 and Cox 1 assembly factors, or any of the structural subunits of the cytochrome $c$ oxidase. Thus, it is likely that Cox20 acts specifically within the Cox2 assembly line. However, an association of Cox20 with the Cox1 assembly factor, Cox15 (Bareth et al., 2013) was detected after isolation on SDS-PAGE. Nevertheless, complexes simultaneously containing Cox20 and Cox15 could not be identified, indicating either an unspecific association or a labile interaction that results in dissociation of the complex during BN-PAGE analysis.

Cox1 assembly factors have been found to interact with a transitional form of supercomplexes, which comprises of some complex IV subunits and some complex III subunits, prior to complete formation of supercomplexes (Mick et al., 2007; Vukotic et al., 2012). In contrast, no association of Cox20 with components of complex III was identified, dismissing the possibility of Cox20 involvement in supercomplex formation.

Previous complex analysis of cox2 $2^{-}$mutant mitochondria, which lack Cox2, have displayed an association of the Cox1 assembly factors, Cox14 and Shy1, with a higher molecular weight complex, termed III $_{2} / \mathrm{IV}^{*}$ (Mick et al., 2007). 
This assembly intermediate contains all the necessary subunits to support association with complex III. A Cox20 null mutant shows a similar phenotype, leading to the accumulation of Cox14 in the $\mathrm{III}_{2} / \mathrm{IV}^{*}$ complex. These findings extend the existing view on the function of these proteins in complex IV maturation, shedding new light on the necessary assembly factors that are needed to associate with complex IV prior to Cox2 incorporation (Soto et al., 2012). Although Cox20 was not found with components of complex III, the cox20 deletion strain could be used as a tool to investigate the complex IV assembly line from the early step of Cox2 biogenesis until supercomplex formation. 


\subsection{The involvement of Mba1 in the early steps of Cox2 assembly}

The assembly of the cytochrome $c$ oxidase is known to be functionally coupled to the regulation of Cox1 expression (Barrientos et al., 2004; PerezMartinez et al., 2003; 2009). However, it has remained unclear whether a feedback mechanism connecting the early steps of Cox2 maturation and assembly with its translational regulation exist. Several findings point to the fact that Cox2 C-terminal translocation, an early step in the Cox2 assembly process, occurs post-translationally (Preuss et al., 2005). For example no interaction was observed between the Cox18 translocase and ribosomal components, or with the ribosome associated protein Mba1.

Mba1 has previously been implicated in the co-translational insertion of mitochondrial translation products (Bauerschmitt et al., 2010; Ott et al., 2006). In addition to the general role of Mba1 in the biogenesis of complex III and IV, it has been shown to be specifically required for the stability of newly synthesized Cox2 (Preuss et al., 2001). However, the mechanism by which Mba1 promotes Cox2 assembly and maturation has remained enigmatic and unitl now, Mba1 interaction with subcomplexes that regulate maturation of Cox2 have not been reported.

An unexpected finding of this thesis was the identification of the mitochondrial ribosome binding protein, Mba1 (Pfeffer et al., 2015), as a component of the Cox $20^{100 \mathrm{kDa}}$ complex. It is possible to speculate, based on the size of the components found in the Cox $20^{100 k D a}$ complex, that the ratio between Cox20, Cox2 and Mba1 is 1:1:1. A comparison of the Cox20 and Mba1 isolations revealed different interacting networks. In fact, Mba1 does not interact with the copper chaperones, Sco1 and Sco2. This possibly indicates the existence of different Cox20 pools, one involved in Cox2 cotranslational insertion and one that is required for copper-integration (Cobine et al., 2004; Szyrach et al., 2003). Moreover, Mba1 associates with Mss2 and Pnt1 even in the absence of Cox18. This means that the association of Mba1 with the translocation complex (Saracco and Fox, 2002) is not mediated via the Cox18 translocase, but rather through Mss2 and Pnt1. However, experiments indicating direct interaction between these two proteins and Mba1 are still missing, pull down experiments might clarify this aspect. 
In addition to the physical interaction between Mba1 and Cox20 identified in this thesis, co-isolation experiments, revealing an association of Cox20 with the mitochondrial ribosome, indicate that the Cox20-Mba1-ribosome association is upstream of Cox18 mediated translocation (Souza, 2000).

The finding of a specific Mba1-Cox20 complex suggests a cooperative function of both proteins with regard to Cox2 assembly. Isolation of Mba1 in the cox20 null mutant, which shows accumulation of Cox2 with Mba1, could indicate that Mba1 is required for handing over pre-Cox2 to Cox20. According to the proposed shuttling hypothesis, one might reason that Mba1 interacts with newly translated Cox 2 and therefore, downstream assembly is stalled in the absence of Mba1. In contrast, an Mba1-dependent association of mature Cox 2 with Cox20 could not be displayed, observations that can be possibly attributed to the weak Mba1 phenotype (Preuss et al., 2001; Ott et al., 2006), which shows only a partial Cox2 assembly defect; suggesting the involvement of alternative pathways in Cox2 insertion or shuttling (Hell et al., 2001; Keil et al., 2012). However, Mba1 in wild-type background could not be found in association with newly synthesized Cox2, possibly indicating a transient interaction (Ott et al., 2006), which is only stabilized if downstream assembly is impaired by COX20 or COX18 deletion.

Pulse-chase and cross-linking experiments, combined with the co-isolation of Mba1 with newly synthesized mitochondrial products, further supports the transient association of this protein with Cox2 in the early steps of its biogenesis (Preuss et al., 2001). 


\subsection{Interaction between the ribosome and the Cox2 insertion machinery is highly dynamic}

Mitochondrial ribosomes are membrane tethered by the coordinated action of Oxa1 and Mba1 (Ott and Herrmann, 2010). However, these two proteins are not strictly required for ribosomal membrane association, since association can occur independently via the ribosomal RNA 96-ES1, constituent of the large subunit (Amunts et al., 2014; Pfeffer et al., 2015). Thus, Mba1 could perform additional functions resulting in its dynamic association with the ribosome. In support of this, Mba1 is stalled by Cox2 assembly defects, resulting in its reduced ribosomal binding. It can therefore be speculated that there are two existing pools of Mba1. This sequestration mechanism is similar to feedback loops of translational activators such as Mss51 (Mick et al., 2010; Zambrano et al., 2007). However, Mba1 is not a translational regulator, but rather acts in the shuttling of Cox2 from the ribosome to the translocation machinery. Moreover, a dynamic interaction of Mba1 with the ribosome is further supported by its decreased association with the ribosome in the absence of Cox2. In the pet111 null mutant (Green-Willms et al., 2001; Mulero and Fox, 1993), Mba1 binding to the ribosome is reduced, but not abolished, suggesting the preferential binding of Mba1 to ribosomes actively translating Cox2. Interestingly, this shuttling function of Mba1 might not be conserved in human.

MRPL45 is the proposed homolog of Mba1 in human. This is based on sequence homology as well as structural modeling that places MRPL45 in spatial proximity to the ribosome contact site of Mba1 (Ott et al., 2006; Pfeffer et al., 2015). MRPL45 is a structural ribosomal subunit, thus it is unlikely to be dynamically associated to the ribosome (Amunts et al., 2014). Therefore, another factor might be involved in this process, possibly the Cox20 human homolog (COX20).

The unexpected finding of the Cox20-ribosome association has, for the first time, linked the Cox2-chaperone with translation of Cox2. The initial hypothesis suggested that this interaction could be mediated via Mba1, but further tests disproved this idea. Ribosome association is unlikely to be direct since Cox20 lacks a clear ribosomal binding domain. Therefore, a third factor could mediate this interaction. Oxa1 is an obvious candidate due to its 
ribosome binding domain and its role in Cox2 in insertion (Jia et al., 2003; Szyrach et al., 2003). But no Cox20-Oxa1 interaction could be detected. This could be due to a technical issue, such as antibody detection limit or the presence of a yet unknown tethering factor.

Finally, the Mba1 and Cox20 interaction appears to be dynamic in its nature. Association between these two proteins strictly requires Cox 2 , meaning that they do not constitutively form a complex, similar to Cox20 and Cox18, which interact in a Cox2-dependent manner (Elliott et al., 2012). It appears that Cox2 bridges the dynamic interaction between them.

Interestingly, in the absence of Cox20, Cox2 assembly is stalled at the Cterminal translocation step (Fiumera et al., 2007, 2009; He et al., 1997). Moreover, Mba1 accumulates with the translocation machinery, possibly tethered by an additional factor. A further interesting question is whether Mba1 can directly shuttle Cox2 to the translocation machinery (Herrmann et al., 2003; Saracco and Fox, 2002). One possibility to test this is by monitoring Cox2 maturation in a cox20 mba1 double deletion mutant. If this is the case, the role of Cox20 might be to accelerate dissociation of newly inserted Cox2 from Mba1.

Therefore, while not directly involved in Cox2 translocation, Cox20 would be required for the efficient cycling of Mba1 at the insertion machinery (Dalbey et al., 2014; Funes et al., 2009; Preuss et al., 2005).

Mba1 than can substitute the chaperone-like function of Cox20 in its absence. One hypothesis could see Mba1 in stabilizing the C-terminus of Cox2.

Collectively, these analyses reveal a dynamic distribution of Mba1 between Cox2 assembly intermediates and the insertion machinery.

Taken together, these results suggest a novel role for Mba1 in Cox2 maturation. Mba1 co-operates with Cox20 during Cox2 biogenesis and is involved in handing over Cox 2 from the insertion apparatus to Cox20 in a process that promotes maturation of Cox2 (FIG 4.1).

The Cox20-Mba1 complex reflects the first step of Cox2 assembly, which possibly occurs in close proximity to the insertion machinery. Therefore, these data propose a new shuttling mechanism of newly translated Cox 2 from the ribosome and the insertion apparatus to downstream assembly intermediates. 


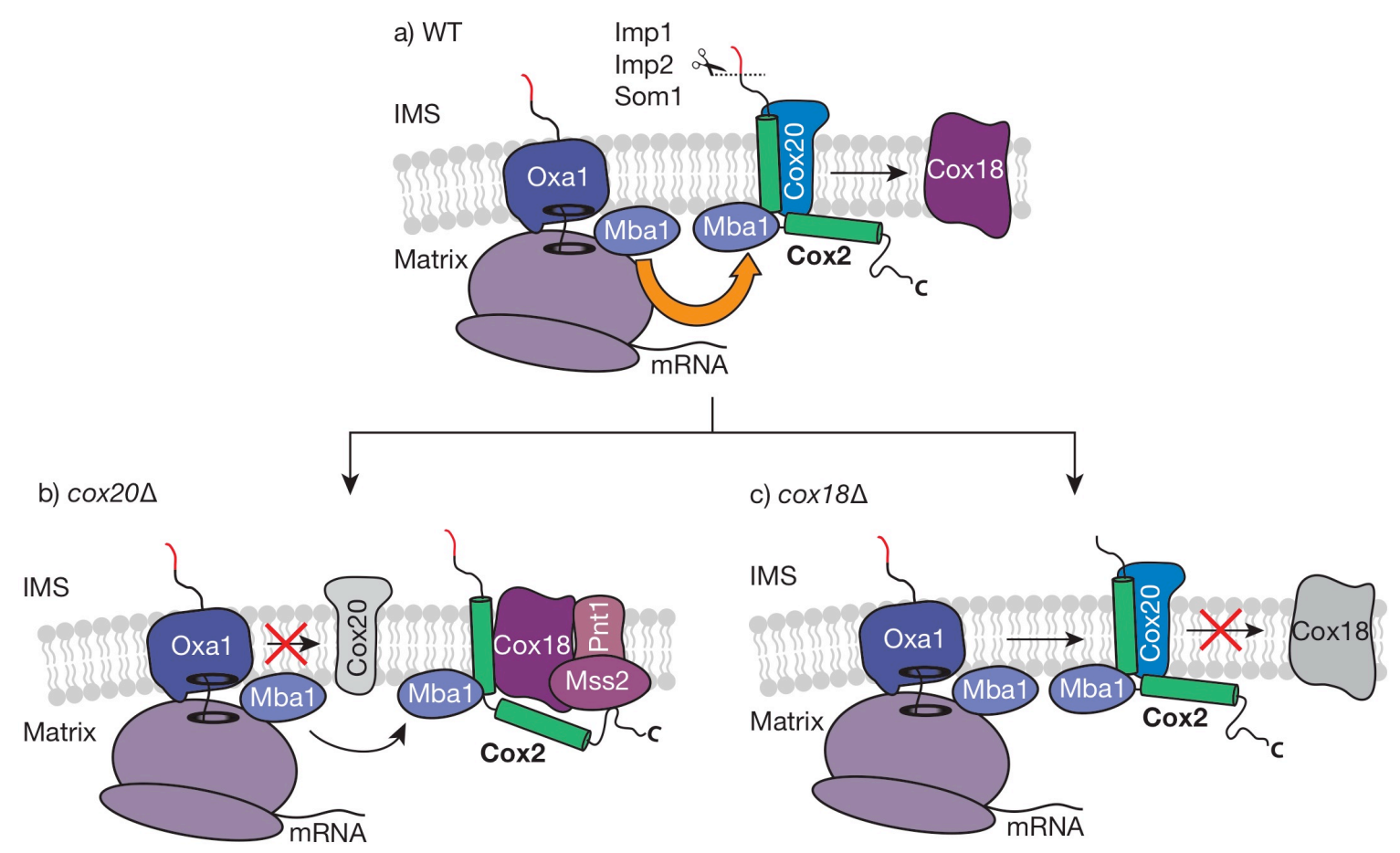

FIG 4.1 Mba1 forms a complex with Cox20 and associates with Cox2 assembly intermediates. Mba1 is found in a complex with Cox20 (a). In the absence of Cox20 (b), Mba1 is sequestered with pre-Cox2 and components of the C-terminal translocation machinery, like Pnt1. When the Cox2 assembly line is blocked at the step of the Cox18 translocase (c), Mba1 accumulates with Cox20 and processes Cox2. See text for further details. 


\subsection{Potential role of Cox20 in copper insertion}

In addition to its insertion and maturation, Cox2 requires the formation of the copper-center within its C-terminal domain before it assembles into the final enzyme (Cobine et al., 2004).

In yeast, Cox2 copper insertion is believed to be a post-translational event, since mutations of the cysteines coordinating the copper still allow Cox2 Cterminal translocation (Fiumera et al., 2007). However, no further proof has been provided for this hypothesis and further studies are required to directly place the copper insertion step into the Cox2 assembly line.

In contrast, copper insertion in Cox1 is proposed to occur co-translationally, with the help of the assembly factor Cox11 (Carr et al., 2005; Khalimonchuk et al., 2005).

One important finding of this thesis was a novel interaction of Cox20 with the copper chaperone Sco2. Interestingly, association of Cox20 with the copper chaperone, Sco1, was also detected after isolation on SDS-PAGE but Cox20 complexes containing Sco1 could not be identified, indicating either unspecific association or a labile interaction that leads to the dissociation of the complex during BN-PAGE analysis.

How Cox20 cooperates with Sco2 to promote copper insertion is currently unknown. In mammals, COX20 has been found in complex with the copper chaperones SCO1 and SCO2, together with newly synthesized COX2 (Bourens et al., 2014). A recent study by Pacheu-Grau et al., has described the cooperation between the novel COX2 assembly factor, COA6, and SCO2 for COX2 maturation during complex IV assembly (Pacheu-Grau et al., 2015). It has been proposed that COA6 is a new constituent of the copper relay system and promotes SCO2 function during copper insertion.

COA6 is also conserved in yeast. In addition to the common interaction with the Sco protein family, it would be interesting to know whether Coa6 associates with Cox20 in human and in yeast.

Thus, focused studies on the Cox20-Sco2 interaction might provide new information on the role of Cox20 in copper insertion. 


\section{SUMMARY AND CONCLUSIONS}

Within mitochondria, the biogenesis of the respiratory chain complexes is a highly coordinated process. Single subunits need to be transported across the inner mitochondrial membrane and integrated together with other components, in the right topology, to form mature complexes. This work has addressed the biogenesis of the mitochondrial enzyme cytochrome $c$ oxidase and specifically the assembly process of the Cox2 subunit.

The results presented in this thesis dissect the early steps that immediately follow Cox2 translation. This work focused on elucidating the Cox20 interaction network and has revealed novel Cox20-containing protein complexes involved in Cox2 translation, membrane insertion and metallation. The Cox20 protein is a ubiquitous assembly factor for Cox2, required for the early steps of Cox2 biogenesis. Cox20 association with the mitochondrial ribosome was shown for the first time, providing a new link to Cox2 translation.

The finding of a specific Mba1-Cox20 complex suggests a cooperative function for both proteins with regard to Cox2 translation and maturation, implicating Mba1 in Cox2 assembly. The Mba1-Cox20 interaction strictly requires Cox 2 and appears to be dynamic in nature.

The presented data propose a novel shuttling mechanism for newly translated Cox2; from the ribosome and the insertion machinery, to downstream assembly intermediates.

Although Cox20 has previously been implicated in Cox2 C-terminal translocation, Cox20 association with Pnt1 and Mss2 had never been shown.

The findings presented in this work reveal Cox20 in complex with Pnt1 and Mss2.

In addition, a novel interaction of Cox20 with Sco2 was identified, suggesting a possible role for Cox20 in copper insertion. A Cox20-Sco2 interaction has already been characterized in human. However, molecular details of this interaction are not completely understood. Future focused studies with the yeast model might provide new information on the role of human COX20 in copper insertion. 


\section{BIBLIOGRAPHY}

Allen, L. A., Zhao, X. J., Caughey, W., and Poyton, R. O. (1995). Isoforms of yeast cytochrome $c$ oxidase subunit $\mathrm{V}$ affect the binuclear reaction center and alter the kinetics of interaction with the isoforms of yeast cytochrome $c$. Journal of Biological Chemistry 270, 110-118.

Amunts, A., Brown, A., Bai, X.-C., Llácer, J. L., Hussain, T., Emsley, P., Long, F., Murshudov, G., Scheres, S. H. W., and Ramakrishnan, V. (2014). Structure of the yeast mitochondrial large ribosomal subunit. Science 343, 1485-1489.

Banci, L., Bertini, I., Cavallaro, G., and Ciofi-Baffoni, S. (2011). Seeking the determinants of the elusive functions of Sco proteins. Febs Journal 278, 22442262.

Bareth, B., Dennerlein, S., Mick, D. U., Nikolov, M., Urlaub, H., and Rehling, P. (2013). The Heme a Synthase Cox15 Associates with Cytochrome $c$ Oxidase Assembly Intermediates during Cox1 Maturation. Molecular and Cellular Biology 33, 4128-4137.

Barrientos, A., Zambrano, A., and Tzagoloff, A. (2004). Mss51p and Cox14p jointly regulate mitochondrial Cox1p expression in Saccharomyces cerevisiae. EMBO Journal 23, 3472-3482.

Barros, M. H., Johnson, A., and Tzagoloff, A. (2004). COX23, a homologue of COX17, is required for cytochrome oxidase assembly. Journal of Biological Chemistry 279, 31943-31947.

Bauerschmitt, H., Mick, D. U., Deckers, M., Vollmer, C., Funes, S., Kehrein, K., Ott, M., Rehling, P., and Herrmann, J. M. (2010). Ribosome-binding proteins Mdm38 and Mba1 display overlapping functions for regulation of mitochondrial translation. Molecular Biology of Cell 21, 1937-1944. 
Becker, T., Böttinger, L. and Pfanner, N. (2012). Mitochondrial protein import: from transport pathways to an integrated network. Trends in biochemical sciences, 37, 85-91.

Bohnert, M., Rehling, P., Guiard, B., Herrmann, J. M., van der Laan, M. (2010). Cooperation of stop-transfer and conservative sorting mechanisms in mitochondrial protein transport. Current biology, 20, 1227-1232.

Bonnefoy, N., Bsat, N., and Fox, T. D. (2001). Mitochondrial translation of Saccharomyces cerevisiae COX2 mRNA is controlled by the nucleotide sequence specifying the Pre-Cox2p leader peptide. Molecular and Cellular Biology 21, 2359-2372.

Bonnefoy, N., Fiumera, H. L., Dujardin, G., and Fox, T. D. (2009). Roles of Oxa1-related inner-membrane translocases in assembly of respiratory chain complexes. Biochimica et Biophysica Acta. 1793, 60-70.

Bonnefoy, N., Kermorgant, M., Groudinsky, O., Minet, M., Slonimski, P. P., and Dujardin, G. (1994). Cloning of a human gene involved in cytochrome oxidase assembly by functional complementation of an oxa1 mutation in Saccharomyces cerevisiae. Proc. Natl. Acad. Sci. U.S.A. 91, 11978-11982.

Bourens, M., Boulet, A., Leary, S. C., and Barrientos, A. (2014). Human COX20 cooperates with $\mathrm{SCO} 1$ and $\mathrm{SCO} 2$ to mature COX2 and promote the assembly of cytochrome $c$ oxidase. Human Molecular Genetic 23, 2901-2913.

Bradford, M. M. (1976). A rapid and sensitive method for the quantitation of microgram quantities of protein utilizing the principle of protein-dye binding. Analytical Biochemistry 72, 248-254.

Broadley, S. A., Demlow, C. M., and Fox, T. D. (2001). Peripheral mitochondrial inner membrane protein, Mss2p, required for export of the mitochondrially coded Cox 2 C tail in Saccharomyces cerevisiae. Molecular and Cellular Biology 21, 7663-7672. 
Campello, S., and Scorrano, L. (2010). Mitochondrial shape changes: orchestrating cell pathophysiology. EMBO Reports 11, 678-684.

Carr, H. S., Maxfield, A. B., Horng, Y.-C., and Winge, D. R. (2005). Functional analysis of the domains in Cox11. Journal of Biological Chemistry 280, 2266422669.

Castresana, J., Lubben, M., Saraste, M. and Higgins, D. G. (1994). Evolution of cytochrome oxidase, an enzyme older than atmospheric oxygen. EMBO Journal 13, 2516-2525.

Chakavarti, B. and Chakavarti, D. (2008). Electrophoretic separation of proteins. Journal of Visualized Experiments.

Church, C., Goehring, B., Forsha, D., Wazny, P., and Poyton, R. O. (2005). A role for Pet100p in the assembly of yeast cytochrome $c$ oxidase: interaction with a subassembly that accumulates in a pet100 mutant. Journal of Biological Chemistry 280, 1854-1863.

Clapham, D. E. (2007). Calcium signaling. Cell 131, 1047-1058.

Cox, J., Neuhauser, N., Michalski, A., Scheltema, R.A., Olsen, J.V., and Mann, M. (2011). Andromeda: a peptide search engine integrated into the MaxQuant environment. Journal of Proteome Research 10, 1794-1805.

Cobine, P. A., Ojeda, L. D., Rigby, K. M., and Winge, D. R. (2004). Yeast contain a non-proteinaceous pool of copper in the mitochondrial matrix. Journal of Biological Chemistry 279, 14447-14455.

Curran, B. P. and Bugeja, V. (2006). Basic investigations in Saccharomyces cerevisiae. Methods in Molecular Biology 313, 1-13.

Dalbey, R. E., Kuhn, A., Zhu, L., and Kiefer, D. (2014). The membrane insertase YidC. Biochimica et Biophysica Acta 1843, 1489-1496. 
Daley, D. O., Adams, K. L., Clifton, R., Qualmann, S., Millar, A. H., Palmer, J. D., Pratje, E., and Whelan, J. (2002). Gene transfer from mitochondrion to nucleus: novel mechanisms for gene activation from Cox2. Plant Journal 30, 11-21.

Dimauro, S. and Schon, E. A., (2008). Mitochondrial disorders in the nervous system. Annual review of neuroscience, 31, 91-123.

Dudek, J., Rehling, P. and van der Laan, M. (2013). Mitochondrial protein import: common principles and physiological networks. Biochimica et Biophysica Acta 1833, 274-285.

Elliott, L. E., Saracco, S. A., and Fox, T. D. (2012). Multiple roles of the Cox20 chaperone in assembly of Saccharomyces cerevisiae cytochrome $c$ oxidase. Genetics 190, 559-567.

Endo, T. and Yamano, K. (2010). Transport of proteins across or into the mitochondrial outer membrane. Biochimica et Biophysica Acta 1803, 706-14.

Fiumera, H. L., Broadley, S. A., and Fox, T. D. (2007). Translocation of mitochondrially synthesized Cox2 domains from the matrix to the intermembrane space. Molecular and Cellular Biology 27, 4664-4673.

Fiumera, H. L., Dunham, M. J., Saracco, S. A., Butler, C. A., Kelly, J. A., and Fox, T. D. (2009). Translocation and assembly of mitochondrially coded Saccharomyces cerevisiae cytochrome $c$ oxidase subunit Cox2 by Oxa1 and Yme1 in the absence of Cox18. Genetics 182, 519-528.

Frazier, A. E., Taylor, R. D., Mick, D. U., Warscheid, B., Stoepel, N., Meyer, H. E., Ryan, M. T., Guiard, B., and Rehling, P. (2006). Mdm38 interacts with ribosomes and is a component of the mitochondrial protein export machinery. Journal of Cell Biology. 172, 553-564. 
Funes, S., Nargang, F. E., Neupert, W., and Herrmann, J. M. (2004). The Oxa2 protein of Neurospora crassa plays a critical role in the biogenesis of cytochrome oxidase and defines a ubiquitous subbranch of the Oxa1/YidC/Alb3 protein family. Molecular Biology of Cell 15, 1853-1861.

Funes, S., Hasona, A., Bauerschmitt, H., Grubbauer, C., Kauff, F., Collins, R., Crowley, P. J., Palmer, S. R., Brady, L. J., and Herrmann, J. M. (2009). Independent gene duplications of the YidC/Oxa/Alb3 family enabled a specialized cotranslational function. Proc. Natl. Acad. Sci. U.S.A. 106, 66566661.

Galati, D., Srinivasan, S., Raza, H., Prabu, S. K., Hardy, M., Chandran, K., Lopez, M., Kalyanaraman, B., and Avadhani, N. G. (2009). Role of nuclearencoded subunit $\mathrm{Vb}$ in the assembly and stability of cytochrome $c$ oxidase complex: implications in mitochondrial dysfunction and ROS production. Biochemistry Journal 420, 439-449.

Gallagher, S., Winston, S. E., Fuller, S. A. and Hurrell, J. G. (2004). Immunoblotting and immunodetection. Current Protocols in Molecular Biology, Chapter 10, Unit 10.8.

Gennis, R. B. (1998). How does cytochrome oxidase pump protons? Proc. Natl. Acad. Sci. U.S.A. 95, 12747-12749.

Gietz, R. D. and Schiestl, R. H. (2007). Quick and easy yeast transformation using the LiAc/SS carrier DNA/PEG method. Nature Protocols 2, 35-37.

Glerum, D. M., Shtanko, A., and Tzagoloff, A. (1996). SCO1 and SCO2 act as high copy suppressors of a mitochondrial copper recruitment defect in Saccharomyces cerevisiae. Journal of Biological Chemistry. 271, 20531-20535.

Graack, H. R., and Wittmann-Liebold, B. (1998). Mitochondrial ribosomal proteins (MRPs) of yeast. Biochemistry Journal 329, 433-448. 
Graef, M., Seewald, G., and Langer, T. (2007). Substrate recognition by AAA+ ATPases: distinct substrate binding modes in ATP-dependent protease Yme1 of the mitochondrial intermembrane space. Molecular and Cellular Biology $27,2476-2485$.

Green-Willms, N. S., Butler, C. A., Dunstan, H. M., and Fox, T. D. (2001). Pet111p, an inner membrane-bound translational activator that limits expression of the Saccharomyces cerevisiae mitochondrial gene COX2. Journal of Biological Chemistry 276, 6392-6397.

Gruschke, S., Grone, K., Heublein, M., Holz, S., Israel, L., Imhof, A., Herrmann, J. M., Ott, M. (2010). Proteins at the polypeptide tunnel exit of the yeast mitochondrial ribosome. Journal of Biological Chemistry 285, 1902219028.

Hanahan, D. (1983). Studies on transformation of Escherichia coli with plasmids. Journal of Molecular Biology 166, 557-580.

He, S., and Fox, T. D. (1997). Membrane translocation of mitochondrially coded Cox $2 \mathrm{p}$ : distinct requirements for export of $\mathrm{N}$ and $\mathrm{C}$ termini and dependence on the conserved protein Oxa1p. Molecular Biology of Cell 8, 1449-1460.

He, S., and Fox, T. D. (1999). Mutations affecting a yeast mitochondrial inner membrane protein, Pnt1p, block export of a mitochondrially synthesized fusion protein from the matrix. Molecular and Cellular Biology 19,6598-6607.

Heijne, G. (1986). The distribution of positively charged residues in bacterial inner membrane proteins correlates with the trans-membrane topology. EMBO Journal 5, 3021-3027.

Hell, K., Herrmann, J. M., Pratje, E., Neupert, W., and Stuart, R. A. (1998). Oxa1p, an essential component of the N-tail protein export machinery in mitochondria. Proc. Natl. Acad. Sci. U.S.A. 95, 2250-2255. 
Hell, K., Neupert, W., and Stuart, R. A. (2001). Oxa1p acts as a general membrane insertion machinery for proteins encoded by mitochondrial DNA. EMBO Journal 20, 1281-1288.

Hell, K., Tzagoloff, A., Neupert, W., and Stuart, R. A. (2000). Identification of Cox20p, a novel protein involved in the maturation and assembly of cytochrome oxidase subunit 2. Journal of Biological Chemistry 275, 4571-4578.

Herrmann, J. M. (2012). Oxa1-ribosome complexes coordinate the assembly of cytochrome $c$ oxidase in mitochondria. Journal of Biological Chemistry 287, 34484-34493.

Herrmann, J. M., Koll, H., Cook, R. A., Neupert, W., and Stuart, R. A. (1995). Topogenesis of oxidase subunit II. Mechanisms of protein export from the mitochondrial matrix. Journal of Biological Chemistry 270, 27079-27086.

Herrmann, J., and Neupert, W. (2003). Protein insertion into the inner membrane of mitochondria. International Union of Biochemistry and Molecular Biology: Life 55, 219-225.

Herrmann, J. M., Neupert, W., and Stuart, R. A. (1997). Insertion into the mitochondrial inner membrane of a polytopic protein, the nuclear-encoded Oxa1p. EMBO Journal 16, 2217-2226.

Horan, S., Bourges, I., Taanman, J.-W., and Meunier, B. (2005). Analysis of COX2 mutants reveals cytochrome oxidase subassemblies in yeast. Biochemistry Journal 390, 703-708.

Horng, Y.-C., Cobine, P. A., Maxfield, A. B., Carr, H. S., and Winge, D. R. (2004). Specific copper transfer from the Cox17 metallochaperone to both Sco1 and Cox11 in the assembly of yeast cytochrome $c$ oxidase. Journal of Biological Chemistry 279, 35334-35340. 
Hosler, J. P. (2004). The influence of subunit III of cytochrome $c$ oxidase on the D pathway, the proton exit pathway and mechanism-based inactivation in subunit I. Biochimica et Biophysica Acta 1655, 332-339.

Jan P. S., Esser, K., Pratje, E. and Michaelis, G. (2000). Som1, a third component of the yeast mitochondrial inner membrane peptidase complex that contains Imp1 and Imp2. Molecular Genetics and Genomics 263, 483-491.

Jia, L., M. Dienhart, M. Schramp, M. McCauley, K. Hell and R. A. Stuart (2003). Yeast Oxa1 interacts with mitochondrial ribosomes: the importance of the C-terminal region of Oxa1. EMBO Journal 22, 6438-6447.

Jia, L., Kaur, J. and R. A. Stuart (2009). Mapping of the Saccharomyces cerevisiae Oxa1-mitochondrial ribosome interface and identification of MrpL40, a ribosomal protein in close proximity to Oxa1 and critical for oxidative phosphorylation complex assembly. Eukaryotic Cell 8, 1792-1802.

Khalimonchuk, O., Ostermann, K., and Rödel, G. (2005). Evidence for the association of yeast mitochondrial ribosomes with Cox11p, a protein required for the $\mathrm{CuB}$ site formation of cytochrome $c$ oxidase. Current Genetics 42, 223233.

Kaur, J., and Stuart, R.A. (2011). Truncation of the Mrp20 protein reveals new ribosome-assembly subcomplex in mitochondria. EMBO Reports 12, 950-955.

Keil, M., Bareth, B., Woellhaf, M. W., Peleh, V., Prestele, M., Rehling, P., and Herrmann, J. M. (2012). Oxa1-ribosome complexes coordinate the assembly of cytochrome $c$ oxidase in mitochondria. Journal of Biological Chemistry 287, 34484-34493.

Klein, D. J., Moore, P. B., and Steitz, T. A. (2004). The contribution of metal ions to the structural stability of the large ribosomal subunit. Rna 10, 13661379. 
Kruger, V., Deckers, M., Hildenbeutel, M., van der Laan, M., Hellmers, M., Dreker, C., Preuss, M., Herrmann, J. M., Rehling, P., Wagner, R. and Meinecke, M. (2012). The Mitochondrial Oxidase Assembly Protein1 (Oxa1) Insertase forms a membrane pore in lipid bilayers. Journal of Biological Chemistry 287, 33314-33326.

Laemmli, U. K. (1970). Cleavage of structural proteins during the assembly of the head of bacteriophage T4. Nature 227, 680-685.

Leary, S. C., Antonicka, H., Sasarman, F., Weraarpachai, W., Cobine, P. A., Pan, M., Brown, G. K., Brown, R., Majewski, J., Ha, K. C. H., Rahman, S. and Shoubridge, E. A. (2013). Novel mutations in SCO1 as a cause of fatal infantile encephalopathy and lactic acidosis. Human Mutation 34, 1366-1370.

Leary, S. C., Cobine, P. A., Kaufman, B. A., Guercin, G.-H., Mattman, A., Palaty, J., Lockitch, G., Winge, D. R., Rustin, P., Horvath, R., and Shoubridge, E. A. (2007). The human cytochrome c oxidase assembly factors SCO1 and $\mathrm{SCO} 2$ have regulatory roles in the maintenance of cellular copper homeostasis. Cell Metabolism 5, 9-20.

Leary, S.C., Kaufman, B.A., Pellecchia, G., Guercin, G.-H., Mattman, A., Jaksch, M., and Shoubridge, E.A. (2004). Human SCO1 and SCO2 have independent, cooperative functions in copper delivery to cytochrome $c$ oxidase. Human Molecular Genetics 13, 1839-1848.

Leary, S. C., Sasarman, F., Nishimura, T., and Shoubridge, E. A. (2009). Human $\mathrm{SCO} 2$ is required for the synthesis of $\mathrm{CO}$ II and as a thiol-disulphide oxidoreductase for SCO1. Human Molecular Genetics 18, 2230-2240.

Liesa, M., Palacín, M., and Zorzano, A. (2009). Mitochondrial dynamics in mammalian health and disease. Physiological Reviews 89, 799-845. 
Lill, R., Hoffmann, B., Molik, S., Pierik, A.J., Rietzschel, N., Stehling, O., Uzarska, M. A., Webert, H., Wilbrecht, C., and Mühlenhoff, U. (2012). The role of mitochondria in cellular iron-sulfur protein biogenesis and iron metabolism. Biochimica et Biophysica Acta 1823, 1491-1508.

Lithgow, T., and Schneider, A. (2010). Evolution of macromolecular import pathways in mitochondria, hydrogenosomes and mitosomes. Philosophical Transactions of the Royal Society of London B: Biological Sciences 365, 799817.

Lode, A., Paret, C., and Rödel, G. (2002). Molecular characterization of Saccharomyces cerevisiae Sco2p reveals a high degree of redundancy with Sco1p. Yeast 19, 909-922.

Luciano, P. and Geli, V. (1996). The mitochondrial processing peptidase: function and specificity. Experientia 52, 1077-1082.

Ludewig, G., and Staben, C. (1994). Characterization of the PNT1 pentamidine resistance gene of Saccharomyces cerevisiae. Antimicrobial Agents and Chemotherapy 38, 2850-2856.

Luo, W., Fang, H., and Green, N. (2006). Substrate specificity of inner membrane peptidase in yeast mitochondria. Molecular Genetics and Genomics 275, 431-436.

Massa, V., Fernandez-Vizarra, E., Alshahwan, S., Bakhsh, E., Goffrini, P., Ferrero, I., Mereghetti, P., D'Adamo, P., Gasparini, P., and Zeviani, M. (2008). Severe infantile encephalomyopathy caused by a mutation in COX6B1, a nucleus-encoded subunit of cytochrome $c$ oxidase. American Journal of Human Genetics 82, 1281-1289.

Meisinger, C., Pfanner, N. and Truscott, K. N. (2006). Isolation of yeast mitochondria. Methods in Molecular Biology 313, 33-39. 
Mick, D. U., Fox, T. D., and Rehling, P. (2011). Inventory control: cytochrome $c$ oxidase assembly regulates mitochondrial translation. Nature Reviews Molecular Cell Biology 12, 14-20.

Mick, D. U., Vukotic, M., Piechura, H., Meyer, H. E., Warscheid, B., Deckers, M., and Rehling, P. (2010). Coa3 and Cox14 are essential for negative feedback regulation of COX1 translation in mitochondria. Journal of Cell Biology 191, 141-154.

Mick, D. U., Wagner, K., van der Laan, M., Frazier, A. E., Perschil, I., Pawlas, M., Meyer, H. E., Warscheid, B., and Rehling, P. (2007). Shy1 couples Cox1 translational regulation to cytochrome $c$ oxidase assembly. EMBO Journal 26, 4347-4358.

Mitchell, P., and Moyle, J., (1968). Proton translocation coupled to ATP hydrolysis in rat liver mitochondria. European journal of biochemistry/FEBS 4, 530-539.

Mulero, J. J., and Fox, T. D. (1993). PET111 acts in the 5'-leader of the Saccharomyces cerevisiae mitochondrial COX2 mRNA to promote its translation. Genetics 133, 509-516.

Nittis, T. (2001). Yeast Sco1, a protein essential for cytochrome $c$ oxidase function is a $\mathrm{Cu}(\mathrm{I})$-binding protein. Journal of Biological Chemistry 276, $42520-42526$.

Nobrega, M. P., Bandeira, S. C. B., Beers, J., and Tzagoloff, A. (2002). Characterization of COX19, a widely distributed gene required for expression of mitochondrial cytochrome oxidase. Journal of Biological Chemistry 277, 40206-40211.

Nunnari, J., Fox, T. D., and Walter P. (1993). A mitochondrial protease with two catalytic subunits of nonoverlapping specificities. Science 262, 1997-2004. 
Oberst, A., Bender, C., and Green, D. R. (2008). Living with death: the evolution of the mitochondrial pathway of apoptosis in animals. Cell Death and Differentiation 15, 1139-1146.

Ong, S.-E., Blagoev, B., Kratchmarova, I., Kristensen, D. B., Steen, H., Pandey, A., and Mann, M. (2002). Stable isotope labeling by amino acids in cell culture, SILAC, as a simple and accurate approach to expression proteomics. Molecular and Cellular Proteomics 1, 376-386.

Ong, S. E., and Mann, M. (2006) A practical recipe for stable isotope labeling by amino acids in cell culture (SILAC). Nature Protocols 1, 2650-2660.

Ott, M., and Herrmann, J. M. (2010). Co-translational membrane insertion of mitochondrially encoded proteins. Biochimica et Biophysica Acta. 1803, 767775.

Ott, M., Prestele, M., Bauerschmitt, H., Funes, S., Bonnefoy, N., and Herrmann, J. M. (2006). Mba1, a membrane-associated ribosome receptor in mitochondria. EMBO Journal 25, 1603-1610.

Pacheu-Grau, D., Bareth, B., Dudek, J., Juris, L., Vögtle, F. N., Wissel, M., Leary, S. C., Dennerlein, S., Rehling, P., and Deckers, M. (2015). Cooperation between COA6 and SCO2 in COX2 maturation during cytochrome c oxidase assembly links two mitochondrial cardiomyopathies. Cell Metabolism 21, 823833.

Papadopoulou, L. C., Sue, C. M., Davidson, M. M., Tanji, K., Nishino, I., Sadlock, J. E., Krishna, S., Walker, W., Selby, J., Glerum, D. M., Coster R. V., Lyon, G., Scalais, E., Lebel, R., Kaplan, P., Shanske, S., De Vivo, D. C., Bonilla, E., Hirano, M., DiMauro, S., and Schon, E. A. (1999). Fatal infantile cardioencephalomyopathy with COX deficiency and mutations in SCO2, a COX assembly gene. Nature Genetics 23, 333-337. 
Perez-Martinez, X., Broadley, S. A., and Fox, T. D. (2003). Mss51p promotes mitochondrial Cox1p synthesis and interacts with newly synthesized Cox1p. EMBO Journal 22, 5951-5961.

Perez-Martinez, X., Butler, C. A., Shingu-Vazquez, M., and Fox, T. D. (2009). Dual functions of Mss51 couple synthesis of Cox1 to assembly of cytochrome $c$ oxidase in Saccharomyces cerevisiae mitochondria. Molecular Biology of Cell 20, 4371-4380.

Petek, E., Windpassinger, C., and Vincent, J. B. (2001). Disruption of a novel gene (IMMP2L) by a breakpoint in $7 \mathrm{q} 31$ associated with Tourette syndrome. American Journal of Human Genetics 68, 848-858.

Petruzzella, V., Tiranti, V., Fernandez, P., Ianna, P., Carrozzo, R., and Zeviani, M. (1998). Identification and characterization of human cDNAs specific to BCS1, PET112, SCO1, COX15, and COX11, five genes involved in the formation and function of the mitochondrial respiratory chain. Genomics 54, 494-504.

Pfeffer, S., Woellhaf, M. W., Herrmann, J. M., and Förster, F. (2015). Organization of the mitochondrial translation machinery studied in situ by cryoelectron tomography. Nature Communications 6, 6019.

Piao, L., Li, Y., Kim, S. J., Byun, H. S., Huang, S. M., Hwang, S.-K., Yang, K.-J., Park, K. A., Won, M., Hong, J., Hur, G. M., Seok, J. H., Shong, M., Cho, M. H., Brazil, D. P., Hemmings, B. A., and Park, J. (2009). Association of LETM1 and MRPL36 contributes to the regulation of mitochondrial ATP production and necrotic cell death. Cancer Research 69, 3397-3404.

Preuss, M., Leonhard, K., Hell, K., Stuart, R. A., Neupert, W., and Herrmann, J. M. (2001). Mba1, a novel component of the mitochondrial protein export machinery of the yeast Saccharomyces cerevisiae. Journal of Cell Biology 153, 1085-1096. 
Preuss, M., Ott, M., Funes, S., Luirink, J., and Herrmann, J.M. (2005). Evolution of mitochondrial oxa proteins from bacterial YidC. Inherited and acquired functions of a conserved protein insertion machinery. Journal of Biological Chemistry 280, 13004-13011.

Ravaud, S., Stjepanovic, G., Wild, K., and Sinning, I. (2008) The crystal structure of the periplasmic domain of the Escherichia coli membrane protein insertase YidC contains a substrate binding cleft. Journal of Biological Chemistry 283, 9350-9358.

Rehling, P., Model, K., Brandner, K., Kovermann, P., Sickmann, A., Meyer, H. E., Kuhlbrandt, W., Wagner, R., Truscott, K. N. and Pfanner, N. (2003). Protein insertion into the mitochondrial inner membrane by a twin-pore translocase. Science 299, 1747-1751.

Rep, M., and Grivell, L. A. (1996). MBA1 encodes a mitochondrial membraneassociated protein required for biogenesis of the respiratory chain. FEBS Letters 388, 185-188.

Rigby, K., Cobine, P. A., Khalimonchuk, O., and Winge, D. R. (2008). Mapping the Functional Interaction of Sco1 and Cox2 in Cytochrome Oxidase Biogenesis. Journal of Biological Chemistry 283, 15015-15022.

Sacconi, S., Trevisson, E., Pistollato, F., Baldoin, M. C., Rezzonico, R., Bourget, I., Desnuelle, C., Tenconi, R., Basso, G., DiMauro, and S., Salviati, L. (2005). hCOX18 and hCOX19: two human genes involved in cytochrome $c$ oxidase assembly. Biochemical and Biophysical Research Communications 337, 832839.

Sambrook, J. and Russel, D. W. (2001). Molecular Cloning: A laboratory manual. 3rd edition. New York: Cold Spring Harbor Laboratory Press. 
Sanchirico, M. E., Fox, T. D., and Mason, T. L. (1998). Accumulation of mitochondrially synthesized Saccharomyces cerevisiae Cox $2 p$ and Cox3p depends on targeting information in untranslated portions of their mRNAs. EMBO Journal 17, 5796-5804.

Saracco, S. A., and Fox, T. D. (2002). Cox18p is required for export of the mitochondrially encoded Saccharomyces cerevisiae Cox $2 \mathrm{p}$ C-tail and interacts with Pnt1p and Mss2p in the inner membrane. Molecular Biology of the Cell 13, 1122-1131.

Schägger, H., and Pfeiffer, K. (2000). Supercomplexes in the respiratory chains of yeast and mammalian mitochondria. EMBO Journal 19, 1777-1783.

Schagger, H. and von Jagow, G. (1991). Blue native electrophoresis for isolation of membrane protein complexes in enzymatically active form. Analytical Biochemistry 199, 223-231.

Soto, I. C., Fontanesi, F., Liu, J., and Barrientos, A. (2012). Biogenesis and assembly of eukaryotic cytochrome $c$ oxidase catalytic core. Biochimica et Biophysica Acta 1817, 883-897.

Souza, R.L. (2000). Cloning and characterization of COX18, a Saccharomyces cerevisiae PET gene required for the assembly of cytochrome oxidase. Journal of Biological Chemistry 275, 14898-14902.

Stiburek, L., Vesela, K., Hansikova, H., Pecina, P., Tesarova, M., Cerna, L., Houstek, J., and Zeman, J. (2005). Tissue-specific cytochrome c oxidase assembly defects due to mutations in SCO2 and SURF1. Biochemistry Journal $392,625-632$.

Summer, H., Gramer, R. and Droge, P. (2009). Denaturing urea polyacrylamide gel electrophoresis (Urea PAGE). Journal of visualized experiments. 
Szklarczyk, R., Wanschers, B. F. J., Nijtmans, L. G., Rodenburg, R. J., Zschocke, J., Dikow, N., van den Brand, M. A. M., Hendriks-Franssen, M. G. M., Gilissen, C., Veltman, J. A., Nooteboom, M., Koopman, W. J., Willems, P. H., Smeitink, J. A., Huynen, M. A., and van den Heuvel, L. P. (2013). A mutation in the FAM36A gene, the human ortholog of COX20, impairs cytochrome $c$ oxidase assembly and is associated with ataxia and muscle hypotonia. Human Molecular Genetics 22, 656-667.

Szyrach, G., Ott, M., Bonnefoy, N., Neupert, W., and Herrmann, J. M. (2003). Ribosome binding to the Oxa1 complex facilitates co-translational protein insertion in mitochondria. EMBO Journal 22, 6448-6457.

Tiranti, V., Corona, P., Greco, M., Taanman, J. W., Carrara, F., Lamantea, E., Nijtmans, L., Uziel, G., and Zeviani, M. (2000). A novel frameshift mutation of the mtDNA COIII gene leads to impaired assembly of cytochrome $c$ oxidase in a patient affected by Leigh-like syndrome. Human Molecular Genetics 9, 2733-2742.

Tsukihara, T., Aoyama, H., Yamashita, E., Tomizaki, T., Yamaguchi, H., Shinzawa-Itoh, K., Nakashima, R., Yaono, R., and Yoshikawa, S. (1995). Structures of metal sites of oxidized bovine heart cytochrome $c$ oxidase at 2.8 A. Science 269, 1069-1074.

Tsukihara, T., Aoyama, H., Yamashita, E., Tomizaki, T., Yamaguchi, H., Shinzawa-Itoh, K., Nakashima, R., Yaono, R., and Yoshikawa, S. (1996). The whole structure of the 13-subunit oxidized cytochrome $c$ oxidase at $2.8 \mathrm{~A}$. Science 272, 1136-1144.

Valnot, I., Osmond, S., Gigarel, N., Mehaye, B., Amiel, J., Cormier-Daire, V., Munnich, A., Bonnefont, J. P., Rustin, P., and Rötig, A. (2000). Mutations of the SCO1 gene in mitochondrial cytochrome $c$ oxidase deficiency with neonatal-onset hepatic failure and encephalopathy. American Journal of Human Genetics 67, 1104-1109. 
Van der Laan, M., Hutu, D. P. and Rehling, P. (2010). On the mechanism of preprotein import by the mitochondrial presequence translocase. Biochimica et Biophysica acta 1803, 732-739.

Van Der Laan, M., Rissler, M. and Rehling, P. (2006). Mitochondrial preprotein translocases as dynamic molecular machines. FEMS Yeast research 6, 849-861.

Vogtle, F. N., Wortelkamp, S., Zahedi, R. P., Becker, D., Leidhold, C., Gevaert, K., Kellermann, J., Voos, W., Sickmann, A., Pfanner, N. and Meisinger, C. (2009). Global analysis of the mitochondrial N-proteome identifies a processing peptidase critical for protein stability. Cell 139, 428-39.

Voss, C., Lahiri, S., Young, B. P., Loewen, C. J., and Prinz, W. A. (2012). ERshaping proteins facilitate lipid exchange between the ER and mitochondria in S. cerevisiae. Journal of Cell Science 125, 4791-4799.

Vukotic, M., Oeljeklaus, S., Wiese, S., Vögtle, F. N., Meisinger, C., Meyer, H. E., Zieseniss, A., Katschinski, D. M., Jans, D. C., Jakobs, S., Warscheid, B., Rehling, P., and Deckers, M. (2012). Rcf1 mediates cytochrome oxidase assembly and respirasome formation, revealing heterogeneity of the enzyme complex. Cell Metabolism 15, 336-347.

Westermann, B., Herrmann, J. M., and Neupert, W. (2001). Analysis of mitochondrial translation products in vivo and in organello in yeast. Methods in Cell Biology 65, 429-438.

Wiese, S., Gronemeyer, T., Ofman, R., Kunze, M., Grou, C.P., Almeida, J.A., Eisenacher, M., Stephan, C., Hayen, H., Schollenberger, L., Korosec, T., Waterham, H. R., Schliebs, W., Erdmann, R., Berger, J., Meyer H. E., Just, W., Azevedo, J. E., Wanders, R. J. A., and Warscheid, B. (2007). Proteomics characterization of mouse kidney peroxisomes by tandem mass spectrometry and protein correlation profiling. Molecular and Cellular Proteomics 6, 20452057. 
Williams, E. H., Bsat, N., Bonnefoy, N., Butler, C. A., and Fox, T. D. (2005).

Alteration of a novel dispensable mitochondrial ribosomal small-subunit protein, Rsm28p, allows translation of defective COX2 mRNAs. Eukaryotic Cell 4, 337-345.

Williams, J. C., Sue, C., Banting, G. S., Yang, H., Glerum, D. M., Hendrickson, W. A., and Schon, E. A. (2005). Crystal structure of human SCO1: implications for redox signaling by a mitochondrial cytochrome $c$ oxidase "assembly" protein. Journal of Biological Chemistry 280, 15202-15211.

Williams, S. L., Valnot, I., Rustin, P., and Taanman, J. W. (2004). Cytochrome $c$ oxidase subassemblies in fibroblast cultures from patients Carrying Mutations in COX10, SCO1, or SURF1. Journal of Biological Chemistry 279, 7462-7469.

Wittig, I., Braun, H. P. and Schagger, H. (2006). Blue native PAGE. Nature Protocols 1, 418-28.

Yaffe, M. P. and Schatz, G. (1984). Two nuclear mutations that block mitochondrial protein import in yeast. Proc. Natl. Acad. Sci. U. S. A. 81, 48194823.

Zambrano, A., Fontanesi, F., Solans, A., de Oliveira, R. L., Fox, T. D., Tzagoloff, A., and Barrientos, A. (2007). Aberrant translation of cytochrome $c$ oxidase subunit 1 mRNA species in the absence of Mss51p in the yeast Saccharomyces cerevisiae. Molecular Biology of Cell 18, 523-535.

Zick, M., Rabl, R., and Reichert, A. S. (2009). Cristae formation-linking ultrastructure and function of mitochondria. Biochimica et Biophysica Acta 1793, 5-19. 


\section{ACKNOWLEDGEMENTS}

First and foremost, I would like to thank Prof. Dr. Peter Rehling for the PhD opportunity in his lab and for giving me the chance to work on this interesting project. I would like to express my gratitude for his full support, patience and guidance throughout these past four years.

I would like to thank my thesis committee members, Prof. Dr. Ralph Kehlenbach and Prof. Dr. Mikael Simons for their suggestions, criticism, inspiration and helpful discussions during our meetings.

I am especially grateful to Dr. Sven Dennerlein for his supervision, all his help and for sharing his knowledge and experience. Dr. David U. Mick for following me in the first period of my doctoral studies.

I also have to thank Prof. Dr. Bettina Warscheid and Dr. Silke Oeljeklaus for the mass spectrometry analysis of my samples.

I would like to thank also my current and former lab members, Abhishek, Martina, Arpita, Jan, Ricarda, Alexander, Christin, Cong, Markus, Moritz, Katharina, Mirjam and Tobias for creating a stimulating environment.

Thank to my colleagues Maria, Sylvie, Nataliia, Ridhima that made these four years truly unforgettable. Thank to Bettina Bareth, Christian Schulz and Oleksandr Lytovchenko for their patience and for answering all my questions. I would like to thank Sylvie Callegari for language proofreading and critical revision of this work. Maria Levchenko and David Pacheu Grau for valuable suggestions. Frank Richter for reading the Material and method part.

I would like to thank the Molecular Medicine study program, especially Erik Meskauskas and Werner Albig for their commitment to higher education. Petra Engelmann for administrative support.

A special thank to all my friends from Bologna for being a part of my happy memories.

I am grateful to my family who has always supported me and helped me grow and become the person I am today. I thank Matteo for his love, care, and support and for making me laugh at the unfunny things. 